\title{
The Production, Value, and Reduction Responsibility of Carbon Emissions through Electricity Consumption of Manufacturing Industries in South Korea and Thailand
}

\author{
Medhawin Kitikun \\ West Virginia University
}

Follow this and additional works at: https://researchrepository.wvu.edu/etd

\author{
Recommended Citation \\ Kitikun, Medhawin, "The Production, Value, and Reduction Responsibility of Carbon Emissions through \\ Electricity Consumption of Manufacturing Industries in South Korea and Thailand" (2013). Graduate \\ Theses, Dissertations, and Problem Reports. 4976. \\ https://researchrepository.wvu.edu/etd/4976
}

This Dissertation is protected by copyright and/or related rights. It has been brought to you by the The Research Repository @ WVU with permission from the rights-holder(s). You are free to use this Dissertation in any way that is permitted by the copyright and related rights legislation that applies to your use. For other uses you must obtain permission from the rights-holder(s) directly, unless additional rights are indicated by a Creative Commons license in the record and/ or on the work itself. This Dissertation has been accepted for inclusion in WVU Graduate Theses, Dissertations, and Problem Reports collection by an authorized administrator of The Research Repository @ WVU.

For more information, please contact researchrepository@mail.wvu.edu. 
The Production, Value, and Reduction Responsibility of Carbon Emissions through Electricity Consumption of Manufacturing Industries in South Korea and Thailand

\section{Medhawin Kitikun}

Dissertation submitted to the College of Business and Economics

West Virginia University in fulfillment of the requirements for the degree of

Doctor of Philosophy

in

Economics

Stratford Douglas, Ph.D., Chair

Arabinda Basistha, Ph.D.

Feng Yao, Ph.D.

Qipeng Zheng, Ph.D.

Thirimachos Bourlai, Ph.D.

Department of Economics

Morgantown, West Virginia

2012

Keywords: Environmental Value; Manufacturing Industries; Emission Reduction; Electricity Consumption; Carbon Emissions Copyright 2012 Medhawin Kitikun 


\section{ABSTRACT \\ The Production, Value, and Reduction Responsibility of Carbon Emissions through Electricity Consumption of Manufacturing Industries in South Korea and Thailand}

\section{Medhawin Kitikun}

This dissertation provides a new method of measuring efforts by manufacturing industries to reduce their emissions by curtailing electricity consumption. Employing comprehensive firm-level data from the National Manufacture Annual Surveys of South Korea and Thailand, I construct the measure from estimates of revenue functions by industry. The data consists of firms from more than 20 industries in each year from 1982 to 2005 for Korea and from 2001 to 2008 for Thailand. With a total of more than two million observations, I estimate revenue functions for each industry and year. Here, I use three inputs: number of employees(L), fixed asset stock $(\mathrm{K})$, and electricity consumption(E) and two types of functional forms to represent each industry's revenue function.

Second, under market competitive condition, I find that profit maximizing firms deviated their level of electricity usage in production from the profitmaximizing level during the time period for both countries, and I develop a theoretical framework to explain this behavior. Then, I tested the theory using my empirical models. Results support the notion of a hidden environmental value expressed by firms in the form of voluntary deviations from profitmaximizing levels of input demand. The measure used is the gap between the marginal revenue product of electricity and its price. This gap should increase with income, consistent with the Environmental Kuznets Curve literature. My current model provides considerable support for this proposition. Estimates indicate, in most industries, a negative relationship between per-capita income and emissions.

In the final section of the dissertation, I consider the equitable distribution of emissions reduction burden under an international agreement such as the reduction effort, Kyoto Protocol. Both developed and developing countries have to cut their emissions to a specific reduction percentage target. Domestically, I present two extreme scenarios. In the first scenario, manufacturing industries take full responsibility for emissions reductions by curtailing their use of energy without any subsidies from the government. 
Revenue function estimates provide measures of the differential costs imposed on different industries by emissions reductions. In the second scenario, emissions reductions are achieved by changing the mix of electricity generation technologies used by the power generation sector within the country. For the international case, I focus on the fairness of emission reduction responsibility among countries. To be fair to countries at different levels of development and with different rate of carbon emissions, I propose a new method to adjust the timing and rates of emission reductions based on a lifetime cumulative emission per capita. 


\section{Contents}

1 Introduction and Background . . . . . . . . . . . 7

1.1 Korean Environmental background . . . . . . . . . . 11

1.2 Thailand Environmental background . . . . . . . . . 13

1.3 Literature Reviews . . . . . . . . . . . . . . 15

2 Methodology ................... . 20

2.1 Theoretical Models . . . . . . . . . . . 20

2.1.1 Consumer Side . . . . . . . . . . . 20

2.1.2 Producer Side . . . . . . . . . . . . 23

2.2 Data . . . . . . . . . . . . . 26

2.2.1 Korean Data . . . . . . . . . . 26

2.2.2 Thai Data . . . . . . . . . . . . 33

3 Production Function and Stochastic Frontier Estimation . . . 39

3.1 Maximum Likelihood Estimation Method . . . . . . . 40

3.1.1 Cobb-Douglas Production Function . . . . . . 40

3.1.2 Translog production function ........ . 44

3.2 Corrected Ordinary Least Square Method . . . . . . . 44

3.2.1 Output Distance Function, Do . . . . . . . 46

3.2.2 Input Distance Function, Di . . . . . . . . . . 46

4 Environmental Value Measurement . . . . . . . . . . . . . . 49

4.1 Marginal Revenue Product of Electricity . . . . . . . . 49

4.2 Environmental Kuznets Curve . . . . . . . . . . . 54

4.3 World Emissions . . . . . . . . . . . . . 59

5 Reduction Responsibility and Policy Implication of Carbon

Emission Regulations . . . . . . . . . . . . . . . 63

$5.1 \quad$ Domestic . . . . . . . . . . . . 66

5.1.1 Manufacturing Industries . . . . . . . 66

5.1.2 Emissions Reduction through Electric Power

Generation Industry . . . . . . . . . . . . 70

5.1.3 Domestic Policy Implication . . . . . . . . . 72

5.2 International Equity Considerations . . . . . . . . 74

6 Conclusion . . . . . . . . . . . . . . . . 83 


\section{Introduction and Background}

From the warmth of the sparked camp fire to the electrical marvel of Voyager 1 man has sought to harness the power of fire and electricity. The pathway to modern energy production and consumption has been a nonlinear process of discovery. A non-linear process, typically demarcated by stages, of innovations in technology, science, and production techniques. Of course the process is never ending or has not ended yet. The world is still in search of substitutes to the fuels that spark electricity and fire and the technologies, science, and production techniques of today. Moreover, we are in search of eliminating all of the negative or purported negative externalities associated with the production of energy from non-renewable and renewable resources. The purported externalities we intend to address is the ongoing Global Warming issue. Although, we will not address whether the Global Warming or the climate change is entirely man-made or whether there will be a terminal global disaster attributed to the climate change. We will address how much the populations of Korea and Thailand instinctively care about the issue whether they admit or not. We will address if the people in these populations actually juxtapose their incentives to manufacture and consume goods to their desire (if there is a desire) to reduce greenhouse gases ${ }^{1}$.

As a prelude to our main discussion it is important to document how we arrived at the point that we are at today. Beginning in the early $19^{t} h$ century Jean Baptiste Joseph Fourier, a paleoclimatologist, introduced the concept of the greenhouse effect. The greenhouse effect illustrates an idea which suspects a divergence in the modern earth climate from the prehistoric earth climate. According to Weart (2003), Svante Arrhenious began calculating how man's use of carbonaceous material could raise atmospheric temperature. The early research these scientists conducted was profound, however, the primitive technology of their day limited the accuracy of their discoveries. Due to these drawbacks scientific peers, of the time period, dismissed their research outright. Although, nearly 50 years later scientists rediscovered, reevaluated and systematically expanded upon their initial theories.

In the 1950s scientists reevaluated the 19th century scientist research. However, the scientists of this era were aided by a technological leap in high powered computation made possible by computers. Scientists were now able to develop and expand on the climate models initially proposed by Arrhenious. Modern day scientists quickly realized, through their new computations, all of the CO2 emanating from fossil fuels could not be absorbed by the

\footnotetext{
${ }^{1}$ In June 1988, James E. Hansen, Director of the NASA Goddard Institute for Space Studies, confirmed the consensus that global warming is measurably affected by human activities
} 
earths vegetation or oceans and likely were accumulating in the atmosphere at an increasing rate. From these insights the suspicions of the scientific community migrated toward a question of how $\mathrm{CO} 2$ emissions assembling in the atmosphere will impact the climate on earth. There were scientists who believed the climate on earth would gradually cool and others who believed that the climate would warm. However, the majority of these scientists were confident either situation could endanger the future of humanity.

In the 1970s, increasing numbers of scientists were forecasting the effects of greenhouse gases will cause the earth's temperature to rise. These dire forecasts were brought to the full attention of the United Nations and set off a chain of actions intended to find ways to mitigate the effects of greenhouse gases.

First of all, at the United Nations Environment Program (UNEP), International Council for Science (ICSU) and World Meteorological Organization (WMO) scientists gathered at an International Conference in October 1985. The conference titled Assessment of the Role of Carbon Dioxide and Other Greenhouse Gases in Climate Variations and Associated Impacts and at this conference a scientific consensus was declared. The consensus announced that global temperature will be rising and the cause of it is the emission of $\mathrm{CO}_{2}$ and other greenhouse gases. Due to the new consensus, UNEP and the WMO established the Intergovernmental Panel on Climate Change (IPCC). The preeminence of IPCC, in the realm of climate change, is stated on the organization's web page ${ }^{2}$ :

The Intergovernmental Panel on Climate Change (IPCC) is the leading international body for the assessment of climate change. It was established by the United Nations Environment Programme (UNEP) and the World Meteorological Organization (WMO) to provide the world with a clear scientific view on the current state of knowledge in climate change and its potential environmental and socio-economic impacts. The UN General Assembly endorsed the action by WMO and UNEP in jointly establishing the IPCC.

Moreover, in 1992 the United Nations Conference on Environment and Development (UNCED), the United Nations Framework Convention on Climate Change (UNFCCC), an international treaty was opened for signatories. The purpose of the treaty was to stabilize greenhouse gas levels in the atmosphere and to prevent any possibly dangerous man-made climate change environmental impacts. As of May 2011, UNFCCC obtained more than 190 countries signatures. However, the treaty is technically a non-binding legal agreement. Furthermore, the agreement did not set mandatory limits on any emissions for any country.

\footnotetext{
${ }^{2} h t t p: / / w w w . i p c c . c h / o r g a n i z a t i o n / o r g a n i z a t i o n . s h t m l \# . T 5 T a Q a v U P z g$
} 
At Kyoto, Japan in 1997 a new international agreement was introduced. The new agreement, entitled the Kyoto Protocol, remedied the failure of the previous UNFCCC treaty by setting mandatory emission limits to curb greenhouse gas emissions. In addition to the mandatory limits, the Kyoto Protocol also introduced a carbon credit trading system as an economic mechanism to reduce greenhouse gases. The carbon credit trading system relies on a central government of a country to set a maximum level of greenhouse gas emissions for the country. After the maximum level is set, the government then issues permits linked to the production of emissions. These firms are then only allowed to produce as much emissions as the number of permits they hold. If the firms can cut their emissions then the firms will have leftover permits and may sell the permits in a carbon credit trading market to firms which need more permits.

It is also true that most developed countries legally agreed to reduce greenhouse gas emissions in terms of $\mathrm{CO}_{2}$-equivalent by 5.2 percent from their 1990 levels by the end of 2012 by signing on to the Kyoto Protocol. However, one notable industrialized nation missing from the ratification is the United States. There are debates in the US ranging from the validity of man-made global warming to the implementation of a cap and trade system or a carbon tax system to reduce greenhouse gases. The United States also appears to be deeply divided, at least politically, on the viability of a cap and trade system curbing greenhouse gases. To boot the debate in the US, rages on issues pertaining to the egalitarian legitimacy of such a system. In the end, whatever the US decides upon is not our concern in this paper.

Climate change is a global issue that people all over the world have been informed about this issue by the mainstream media since the 1980s. Some of these people have experienced unfortunate natural disasters related to climate change first hand. Yet no one knows exactly what an extreme case of a global warming crisis will entail. Although, statistics from the United Nations International Strategy for Disaster Reduction indicate natural disasters are occurring at an increasingly rate and damages incurred by these disasters are increasing in costs every year ${ }^{3}$. In fact, the IPCC estimates that the global surface temperature is expected to increase up to11.5 ${ }^{\circ} \mathrm{F}(6.4$ ${ }^{\circ} C$ ) in the $21^{\text {st }}$ century ${ }^{4}$. Additionally, the United States National Academy of Sciences (2008) added that the cause of this warmer temperature, most

\footnotetext{
${ }^{3}$ http://www.geo.umass.edu/courses/geo250/isdrocc.pdf

${ }^{4}$ IPCC, 2007: Summary for Policymakers. In: Climate Change 2007: Mitigation. Contribution of Working Group III to the Fourth Assessment Report of the Intergovernmental Panel on Climate Change [B. Metz, O.R. Davidson, P.R. Bosch, R. Dave, L.A. Meyer (eds)], Cambridge University Press, Cambridge, United Kingdom and New York, NY, USA
} 
scientists concur, will primarily originate through the burning of fossil fuels and thus emitting greenhouse gases into the atmosphere.

As stated above it is safe to assume that people have some basic knowledge of the global warming issue. First, Bostrom et al.(1994) stated that most people are acknowledge about Global Warming and many concerns about it. Pelham(2009) reinforced that South Korea and Thailand's respondents which are part of a survey on climate change in 2007 and 2008 demonstrated that more than 90 percent of the sample population believes that human activities are the main contributors to the rise in global temperature. Therefore, We believe most Koreans and Thais more or less care about environmental externalities arising from the burning of fossil fuels, and it would be very convincing that people would incorporate this environmental quality variable inside their utility function, which this idea is supported by the Environmental Kuznets Curve (EKC). The EKC maintains that people care more and more as their income rises about the environment in which the live. Before these people reach a higher income they are only concerned with increasing their income. Once a certain living standard is attained, these same people begin to add more weight to environmental concerns which surround them. Then, it would be challenging but very interesting to see how people naturally value a colorless and scentless gas like $\mathrm{CO}_{2}$.

We began our study with a continuum good utility function from Dornbusch et al.(1980) with the level of CO2 emission as a dis-utility part and we modified the emission demand and supply theoretical framework of Copeland and Taylor(1995) to fit with our empirical analysis. Copeland and Taylor assumed that emission permit is a required input for manufacturing production function and number of emission permits come from government regulation based on a representative individual's maximizing utility condition. However, during the time of non-existence emissions permit market, there was no emission monitoring for all factories. Therefore, in our approach, we used level of electricity consumption as a proxy for emission level of each firm, because, to generate electricity, for both Korea and Thailand, they burn fossil fuels coal, oil, and natural gas, which directly generate $\mathrm{CO}_{2}$ emission as well. Then, we further develop new methods of measurement revealing an environmental quality value from manufacturing firms.

We demonstrate that instead of typical choosing level of profit maximizing, and/or cost minimizing inputs for their production, it seems many firms decisively choose to use less electricity. In other words, firms use less energy than would be expected to reach the firm's typical purpose. This electricity gap is the beginning point of our measurements. However, it is not certain that this gap is representative of how much each manufacturing firm would care about the environment. It could also from some other reasons, such as 
government regulations to use less electricity, other legally binding contracts which aim to reduce emissions through electricity consumption, pressures from eco-friendly NGOs, and/or some pressure from neighboring households.

In the next two sub-sections, we present to you some historical background on environmental laws and regulations, focusing on electricity consumption, and the environmental values of people in Korea and Thailand.

\subsection{Korean Environmental background}

According to Cho (1999), the first environmental law Korea adopts is the Pollution Prevention Act (PPA) in 1963. The law was an aberration, because Korea was just beginning to recover from the Korean War. A war which tore the country in two, devastated their population, and crushed their infrastructure. Thus, Korea at this time was focused on increasing economic prosperity and less on environmental consequences of their prosperity driven production. Korea experienced tremendous growth in Gross National Product (GNP) more than doubling the GNP growth of most other countries. However, the gains were not without cost. Even with the existence of the PPA, since there is no serious enforcement or penalty, the environment of Korea was paying the price of heavy manufacturing. The price on the environment was not as devastating as the toll of war. However, the damage was bad enough to embark on environmental regulatory spree.

The first of the new environmental laws which replaced and reinforced the ineffective PPA was the Environmental Preservation Act (EPA) of 1977. Immediately after the enactment of this law Korea established, in 1979, an Environmental Administration (EA) in order to enforce environmental regulations directly. Moreover, the Korean constitution was amended in 1980 to provide an environmental constitutional right to all Koreans. As the Korean Ministry for the Environment describes in a recently published UN document ${ }^{5}$ :

Article 35 of the Constitution states that all persons have the right to live a life in a healthy and pleasant environment, and the government and people should make efforts to conserve the environment. The same Article stipulates that "the contents and exercise of environmental rights shall be decided by laws", thereby mandating the rights to environmental laws. Environmental laws, thus, can be regarded as laws that specify people's rights as guaranteed by the Constitution, namely, the right for people to live in a sound and healthy environment. That is, people have the basic right to clean water, clean air, and the natural beauty of the land.

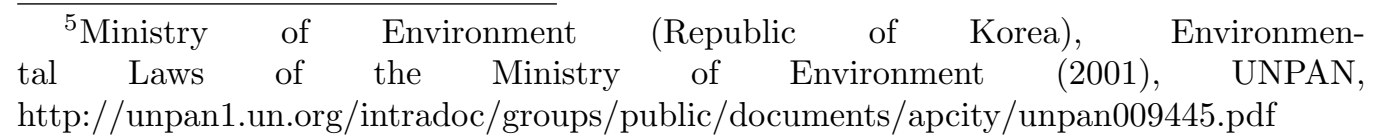


Unfortunately, political turmoil in Korea in the 1980s hindered enforcement of this newly established right. The government became serious about environmental concerns, once again in the 1990s, and pushed environmental concerns to the policy forefront. At this EA was transformed and elevated from an Administration to the Ministry of Environment (MOE) politically signaling the elevation of an environmental policy agenda for the country. Through the education policies, administered by the MOE, Koreans would gradually become more aware of the environmental issues which impact the country. The concern for the Korean and possibly the world's environment continually evolved in this time period as established governmental and business practices became more favorably oriented to environmental concerns. Of course the MOE policies are responsible for some of the changes, nonetheless, it is also true that nongovernmental organizations (NGOs) and public protests had their hands promoting the fore mentioned changes.

Although the environmental changes of the 1990s in Korea did address quality of life issues in Korea these changes did not address CO2-equivalent emissions in the country. Environmental issues, related to our research, were only beginning to be addressed in 2002 with passing of a Framework Act on Environmental Policy (FAEP). FAEP confronts emission limit targeting, Article 20-2, although, it is not specific about what kind of gasses and the levels of emissions. Furthermore, there is no mention of penalties or compliance enforcement. However, this does not mean the Korean government did not attempt to reduce CO2 emissions. Cho(1999) showed that the Korean government educated the populace on the harms resulting from $\mathrm{CO} 2$ emissions after the ratification of UNFCCC. The Korean government also tried to substitute away from greenhouse emitting fossil fuels since the 1980s. The government increased its electricity power generation from nuclear fuel from 8 percent in 1980 to almost 40 percent in the 1990s (Lim and Lee, 2000). However, the UNFCCC treaty did not set mandatory emission limits or specific enforcement mechanisms.

Korea did sign the Kyoto Protocol in 1998 which took effect in 2005. Although, the Kyoto Protocol doesn't specifically obligate Korea to reduce and GHG emission since it was considered a developing nation (AFP, 2008). Therefore, it is yet to be seen if Korea will fully implement the treaties recommendations in reducing GHG emissions.

Korea is growing very fast, according to the IMF (2006). Korea is also 10th largest economy in the World, but according to Yale Center for Environmental Law \& Policy / Center for International Earth Science Information Network at Columbia University(2005), Korea does not rank well in the Environmental Sustainability Index (2005). Korea only ranks $122^{\text {nd }}$ out of 146 countries and consequently receives mounting international pressure to im- 
plement more intensive GHG abatement. According to Shim (2003) Korea is responding to the pressure by entering a program to reduce their emissions to their target in a post Kyoto Protocol period beginning in 2013 and expiring in 2017. Once more, the Korean Ministry of Government Legislation ${ }^{6}$ introduced the Enforcement Decree of the Clean Air Conservation Act in 2008. The Enforcement Decree of Clean Air Conservation Act has real teeth and requires business to install measuring devices to abate the emission of GHGs. Businesses emitting GHGs are required to comply with the act and are required to incorporate abatement equipment immediately if possible, but no longer than one year from the implementation of the Acts regulations. The act was effective as of April 2010. The government then followed up on this legislation by introducing the Framework Act on Low Carbon, Green Growth January, 2010.

Drawing on the background of environmental law and social movements in Korea it is now safe to arrive at some assumptions. The first of which, is that the Korean population is informed and to some extent knowledgeable of environmental issues. A second assumption is that the Korean population is aware that using less electricity will lead to lower amounts of fossil fuel burning and, therefore, less CO2 emissions.

\subsection{Thailand Environmental background}

Unlike Korea, Thailand is classified as a Lesser Developed Country, however, like Korea Thais are concerned about climate change. Over time the concern has mounted, but the country's first environmentally friendly plan was initiated due to the petroleum crisis in the 1970s. In 1973, the Thai government implemented the Principle Plan of Preserving the Energy (PPPE). The PPPE purpose was to counter the shortage of oil by the promotion of electricity consumer conservation. Since, Thailand is an oil importing nation that uses oil to generate electricity the PPPE was an innovative way to deal with fossil fuel constraints the nation faced. Moreover, the PPPE was administered by the Department of Development Renewable Energy and Energy Conservation and its aim was to promote energy efficiency through conservation of energy in large manufacturing firms. The PPPE plan was the sole energy related plan in Thailand until the National Economic and Social Development Plan no. 5 (1982-1986). A plan expanded upon in short time by the National Economic and Social Development Plan no. 6 (1987-1991). These plans did expand the scope of the PPPE from the manufacturing sector to the household sector and other commercial sectors of the economy. On

${ }^{6}$ http://www.moleg.go.kr 
one hand, these plans did not enforce an environmental conservation norm. On the other hand, the plans did try to create an opportunity for the household sector, the manufacturing sector, and the other commercial sectors to privately try and coordinate a private solution in order to solve the Thai natural resource constraints. Although, it is impossible to know if the plans reduced consumption of electricity we can be sure that the plans informed at least some of the populace that there could be monetary rewards from minimizing their electricity consumption.

It was not until 1992 that the government became directly involved, at least in the international realm, in seeking a solution to environmental problems caused by industrial production. At this time Thailand agreed to adopt Agenda 21 a non-binding agreement to develop sustainably. Moreover, in 1993 Thailand domestically implemented a program known as Demand Side Management (DSM), a program which provides a role the government and the Electricity Generating Authority of Thailand (EGAT) to focus on educating the public on conservation with economic incentives and stimulate manufactures to import or produce energy efficient technology. This program is credited with reducing peak demand consumption by 468 megawatts and electricity generation by 2,194 gigawatts resulting in 1.16 million tons of CO2 emissions.

Once again, Thailand has demonstrated its willingness or some intent of reducing pollution by signing onto the Kyoto Protocol in 1999. Though, much like Korea, Thailand as a Less Developed Country was not obligated to implement the recommended policies of the Protocol. It seems as though the government of Thailand would like to at least display to their domestic voting population that they would like to implement these policies at some future date. In and of itself this posturing by the government illustrates that the populace of Thailand is concerned with the issue of climate change to some extent and want their governmental officials to overtly demonstrate to the world their concerns.

Once more, in 2002 the government implemented the second phase of the DSM program in coordination with EGAT. In this phase the government and its energy arm EGAT will or has implemented 330 green leaning rooms to educate the populace in the field of environmental energy conservations and the benefits of electricity conservation. The program also encourages the expansion of energy saving technologies developed in the initial phase of the program.

Meanwhile, a recent Gallup Poll released in April of 2011 reveals that a growing number of Thais, 98 percent to be exact, say that they know 
something or a great deal about global warming or climate change ${ }^{7}$. In fact, this is a 10 percent jump in the reported amount of Thais surveyed by the same Gallup Poll conducted in 2007 through 2008. Moreover, 78 percent of those polled in the 2010 reported that they believed climate change was related to human activities and only 13 percent believed climate change is due to natural causes ${ }^{8}$. This polling data indicates that Thais are concerned with climate change and are knowledgeable of the issue. Therefore, it would also be safe to assert some assumptions here.The first of which, is the Thai population is informed and to some extent knowledgeable of environmental issues. A second assumption is the Thai population is aware that using less electricity will lead to lower amounts of fossil fuel burning and, therefore, less CO2 emissions.

From the background of environmental law and social movements in the two countries with different level of development, it would be very interesting to see whether their manufacturing firms would value the environmental differently. During the time period of our analysis, from 1982 to 2005 in Korea and from 2001-2008 in Thailand, without any direct forces from the government and/or from any international organizations to reduce the $\mathrm{CO}_{2}$ emissions, we showed that, instead of using their electricity inputs at the profit-maximizing level where their marginal revenue product of electricity $\left(M R P_{E}\right)$ should equal the price of electricity $\left(P_{E}\right)$, most of the manufacturing firms tends to use less. This creates a positive gap between $M R P_{E}$ and $P_{E}$ which represents the underutilization of the electricity. Alternatively, it may well represent our new way of measurement of a socially efficient decision to reduce emissions due to a preference for environmental quality which we discuss about in the later sections.

\subsection{Literature Reviews}

Still, some might question the measurement and what would be the reasons for these profit maximizing firms to deviate from their usual purpose to cut their production. A group of professors from Harvard University, Business School and John F. Kennedy School of Government, Reinhardt et al(2008),

\footnotetext{
${ }^{7}$ Julie Ray and Anita Pugliese, Fewer Americans, Europeans View Global Warming as a Threat, Gallup World, last modified April 24, 2012, http://www.gallup.com/poll/147203/Fewer-Americans-Europeans-View-GlobalWarming-Threat.aspx\#2

${ }^{8}$ Julie Ray and Anita Pugliese, Worldwide, Blame for Climate Change Falls on Humans: Americans among least likely to attribute to human causes, Gallup World, last modified April 24, 2012, http://www.gallup.com/poll/147242/Worldwide-Blame-Climate-ChangeFalls-Humans.aspx\#2
} 
examined the concept of manufacturing firms sacrificing profits in the environmental perspective for social interest. They analyzed the issue with four different questions, "May they?", "Can they?", "Do they?", and "Should they?".

From their first question, "May they do so within the scope of their fiduciary responsibilities to their shareholders?", they look at the issue from the legal system perspective. Based on the US, they have found that manufacturing firms may legally scarify their profit on some good public cause, such as saving environment. Many public-minded managerial actions are very likely and effectively protected from any legal challenges by the so called "business judgment rule", even though, a profit maximizing duty for shareholders is judicially supportive. From this question to our study, their did their study based on the US current legal system which could be expected to be more strict than our sample countries in the time period. Hettige et al(1996) also stated that the legal systems in developing countries lack credibility and serious enforcement.

Then, their second question, "Can they do so on a sustainable basis?", they look at the issue from the market competitiveness. They have found that this behavior is often active in imperfect markets or with some government intervention. They showed that, in the short term, firms might suffer from market share loss, but they suggested that, with this attitude of serving the social interest, the firm's reputation in the community could be helpful for the firm and significantly lead to higher profits eventually in the long run. To reinforce this point, according to Laroche et al.(2001), they found that more and more people start to realize that their buying behavior affects and/or causes some environmental problems. Even back in 1989, some people were willing to pay a bit higher for a more environmental friendly products. In year 2001, Laroche et al.(2001) also reported that "Green" products can sell at approximately up to $40 \%$ higher than normal similar kind of products in the market. Therefore, as a producer, they cannot only survive, but they can also make more money from these groups of people. Then, as production managers could actually be the same people who are willing to pay more for better environmental quality, they could also be willing to reduce level of their electricity usage in order to have less emissions in the air they are breathing.

Next," Do firms behave this way?", Reinhardt et al(2008) stated that, even with the growing literature on corporate social responsibility, evidence of profit-sacrificing behavior in the social interest is lacking. Blackman(2010) also added that the most critical obstruction to all environmental value research, including his, in developing countries is simply the lack of credible firm-level data. Here, in our study, we gathered data from the Industrial 
Ministry of each country directly, which should be more reliable than survey data from the individual factories. Moreover, this data set is firm-level data set. We used this data set to estimate the production function and provide some evidence on how manufacturing firms actually behave on this emission cut through their electricity consumptions for their production. After that, we introduced a new way to measure environmental value and presented the value of each industry over time. Then, we test our new measurement with the environmental Kuznets curve (EKC) hypothesis for carbon emissions. Several empirical studies in the previous literature, e.g., Olli et al.(2001), Hartman et al.(1997), and Pegal and Wheeler(1996), indicate that environmental concern is positively related to income. Lee(2000) gave a reason to the relationship that more developed country with more advance technology provides a better chance to get to a better or cleaner environmental resources. Hettige et al(2000) tested the EKC hypothesis, but for industrial water pollution. He used international data cross sectionally estimated. He mentioned about his marginal abatement cost of pollution that, "In static partial equilibrium, cost-minimizing firms with flexible abatement choices will control pollution to the point where their marginal abatement costs equal the price exacted for pollution by affected parties." Other than these, there are a few more papers that try to explain the behaviors in their own way. Kim and Kim(2010) tried to study firm's environmental attitude. They separate the environmental attitude into two parts - environmental concern where firms just think about the environmental issue based on their level of knowledge and information without doing anything about it and environmental action where firms start to do something about the issue such as donation to any environmental charities. In our case, we combine both and called it our environmental value. Our definition is including the thinking process and doing process(cut the emissions by using less electricity in their production). Then, another approach from Tomita and Akutagawa(2009). They tried to measure environmental value by factor analysis. They found out that individual's Environmental Value consciousness is influenced by a set of factors: Information and knowlege, Experience, Education, Individual attributes, and Economics conditions, which is similar to previous EKC literatures. Later, base on this economics condition factor, we created a couple of examinations to test our measurement. One is the relationship between income per capita and our environmental value. The other one is when the financial crisis hit Asia countries in late 1997 to mid 1998. We test how our environmental values would react to this unexpected economic shock.

In our study, we look at the profit maximizing firms who, by necessity, are also cost minimizers. As our concentration is firm's behavior through their electricity consumption, firms do have choice to choose to use electricity 
to the profit-maximizing level at which their marginal revenue product of electricity equals the electricity price. However, we observed a gap between these values and this gap captured our attention as those manufacturing firms are acting in a way that is consistent with them recognizing some kind of invisible price of electricity use on top of their usual electricity price. We called this price a willingness to pay not to emit, or the willingness to give up extra profit the marginal abatement cost of carbon emissions in Hettige's work. Hettige also commented on this price that it would be vary depending on some circumstances, such as some local administrators, national regulators, pressure groups, stockholders, and/or green consumers. His idea aligned with ours that this invisible environmental price level to these manufacturing firms would be influenced by each of these groups, if the level of the emissions exceed a group's acceptable level. Therefore, even if there exists pollution charges, there would be no single price of pollution" ${ }^{\prime \prime}$. This would be the explanation of our results in the later section and cover the firm's behavior question in this paragraph.

We also added another test to help indicate whether or not the gap between electricity's marginal revenue product and price might be identified with environmental abatement effort by the firm. In an according to Jones and Dunlop(1992) based on Buttel's (1975) idea that in an economic crisis, people will first reduce their support on environment. Our data set for South Korea includes the year 1997 when the financial crisis hit many Asian countries including South Korea. Our results of most industries changed with the crisis, consistent with our hypothesis.

And, the last question, should firms carry out such profit-sacrificing activities? They suggested that socially responsible activities that address environmental issues that are unregulated but of significant scientific or political concern such as global climate change, especially in developing countries where even existed regulations are not well enforced, in such cases (i.e., in the absence of government policies), these corporate social responsibility activities may lead to significant gain in net social benefits (Reinhardt et al, 2008). With what we found in our study, people even when they are working and have to make a decision for the production, take their personal utility into account. In fact, a company may make a higher profit if it has a reputation for environmental stewardship.

In the next section, we start with Copeland and Taylor's (1995) theoretical framework to explain our approach to measuring the hidden environmental value of profit maximizing manufacturing firms. Then, we modify it to a

\footnotetext{
${ }^{9}$ For a detailed discussion, see Afsah et al(1996), Dasgupta and Wheeler (1996), and Wheeler (1991).
} 
best fit by means of empirical analysis. Next, we describe our extensive firm level data sets from both Korea and Thailand and point out some important description statistics.

Before we move on to the results, we will discuss and present a couple of estimation techniques used in estimating our production functions. In this section, Cobb Douglas and Translog production functions are estimated by Stochastic Frontier Estimation(SFE). Then, we obtain and compare the estimated technical efficiency indicators of each method. Next, we test whether technical efficiency terms will be affected by the level of carbon emission and other environmental variables or not.

Then, we choose the best fitting model and estimate the results to calculate the gap between $M R P_{E}$ and $P_{E}$. In order to be able to compare our new measurement with the $\mathrm{EKC}$, we will estimate the production function separately by industry and year. So, we can construct a time series data of our estimated environmental value for each industry. Then, according to our theoretical model and the EKC, we will test our measurement by national income per capita including other related environmental control variables.

The last section will develop projections on the appropriate applications of this research study. In the first part of this section, we give some background on a general electricity production, type of power plants, emission factors, and levelized cost. Then, we construct a carbon emission model from electricity production using scientific emission factors by sources of energy - Coal, Oil, Gas, natural gas, and etc. We assume the government has full control in choosing their optimal fuel mixed ratio for the nation's electricity generation. We also assume there are two groups of players in this field. One is the government and the other is the manufacturing sector. Accordingly, we apply the emission reduction regulations, domestically, to our sample countries. Note that our concentration of social responsibility of carbon emission is only through electricity production and consumption. Next, we describe an additional data set that we use in this part. Subsequently, we calculate cost of emission reduction of each of the players in different scenarios.

Finally, we come to the conclusion of which case would be optimal for the society or the country. Lastly, we will apply this case globally. 


\section{Methodology}

We first adopted some of the theoretical framework from Copeland and Taylor(1995). Copeland and Taylor theoretically examine a country with three types of decision makers: governments, consumers, and producers. Copeland and Taylor then develop production functions for these decision makers composed of two inputs, emissions and effective labor. According to the framework, the government moves first by setting the national limit of emissions under the assumption of representative consumer utility maximizing policy. Under the assumed framework, the given product prices and the total emission quotas, consumers will maximize their utility and exemplify the supply side of the emission market. Alternatively, producers will maximize their profits and create demand for the emissions in term of permits.

For the purposes of our framework we use three inputs in the production function, number of employees (L), fixed asset stocks (K), and electricity usage (E). As mentioned in our introduction, any emission regulations leading to electricity usage control in Korea during the time period does not exist. Consequently, the government can no longer be one of our decision makers. Therefore, our analysis will illustrate how producers can still maximize their profits under consumer maximizing utility conditions.

\subsection{Theoretical Models}

Section 2.1 lays out the details of the economic models we use to examine consumers and producers, respectively.

\subsubsection{Consumer Side}

In this subsection, we assume people more or less embed an environmental value variable in their utility function. Furthermore, the environmental value variable will have some effect on individual's decision even when they have to make a production decision. A process we examine further in subsection 2.1.2 It is appropriate to start with the continuum consumption goods utility function designed by Rudiger Dornbusch et al. (1980) with constant budget shares, $b(\mathrm{z})$, and transform it to a discrete version for our analysis. Our social welfare function, $U_{t}$, will be:

$$
U_{t}=\sum_{\forall i} b_{i t} \ln \left[x_{i t}\right]-\beta_{t} \frac{\left(\sum_{\forall N} \sum_{\forall i} \sum_{j=1}^{J_{i t}} e_{j i t}^{N}\right)^{\gamma}}{\gamma}
$$


where $b_{i t}$ is the percentage share of income to goods from industry i, $b_{i t} \in[0,1]$ that satisfies $\sum_{\forall i} b_{i t}=1 . x_{i t}$ is the total consumption amounts of goods from industry $\mathrm{i}$ in year t by everyone in the country. We then assume all firms in the same industry produce identical outputs. To restate this assumption in other words, it does not matter which firm is producing the output. $\beta_{t}$ expresses how much people care about the total pollution emissions. $\gamma$ is a degree of how bad the effect of the total pollution could be. Therefore, $\beta_{t}$ and $\gamma$ should be positive and if $\gamma \geq 1$, the marginal value of emissions reduction is a non-decreasing function of emissions. $J_{i t}$ denotes the total number of firms are in industry i at time t. The superscript $N$ denotes a country. The term, $\sum_{\forall N} \sum_{\forall i} \sum_{j=1}^{J_{i t}} e_{j i t}^{N}$, represents the world total emission, $e_{W_{t}}$, from all nations at time t. We must point out here, $\mathrm{CO}_{2}$ does not only have an effect on the emission area, but also accumulates in the worldwide atmosphere and causes the whole worlds temperatures to rise. Therefore, need to use the worlds total emission and not just the level of emission in a particular area or country. One other point must be made here. Our consumer utility function doesnt account for the historical accumulation of each country's emissions.

Expanding on the definition of $b_{i t}$, let $I_{t}$ denote national income. It is evident now the total income share paying for good i would be $b_{i t} . I_{t}$. Moreover, the expenditure from consumers is, in fact, the revenue to producers. Therefore:

$$
b_{i t} \cdot I_{t}=P_{i t} \cdot x_{i t}
$$

$P_{i t}$ is the product price and if we assume that people consume what they produce, total consumption of goods i must be equal to total production by all the firms composing industry i, $x_{i t}=\sum_{j=1}^{J_{i}} Y_{j i t}$; where $J_{i t}$ is the total number of firms from industry i at time t. Accordingly, since all firms in the industry are assumed to be price takers, we can state $P_{i t} \cdot x_{i t}=\sum_{j=1}^{J_{i}} T R_{j i t}$. Now summing equation(2), we arrive at

$$
I_{t}=\sum_{\forall i} \sum_{j=1}^{J_{i}} T R_{j i t}
$$

Given the goods prices and accounting for the precept consumers maximizing their utility. We may now substitute $x_{i t}=b_{i t} . I_{t} / P_{i t}$ and $e_{j i t}=\epsilon_{t} . E_{j i t}$ in equation (1), we arrive and define the indirect utility function for the representative consumer: 
$V_{t}=\sum_{\forall i} b_{i t} \ln \left[b_{i t}\right]-\sum_{\forall i} b_{i t} \ln \left[P_{i t}\right]+\ln \left[I_{t}\right]-\beta_{t} \frac{\left(\sum_{\forall i} \sum_{j=1}^{J_{i}} \epsilon_{t}^{k} \cdot E_{j i t}^{k}+\sum_{\forall N \neq k} \sum_{\forall i} \sum_{j=1}^{J_{i t}} e_{j i t}^{N}\right)^{\gamma}}{\gamma}$

The superscript $\mathrm{k}$ denotes our sample country. Where each country has different level of emission-electricity factor, $\epsilon_{t}$. The term, $\sum_{\forall N \neq k} \sum_{\forall i} \sum_{j=1}^{J_{i t}} e_{j i t}^{N}$, shows the rest of the world's total level of emissions.

On the producer side, when profit maximizing firms did not use their electricity input at their optimal level, $E_{j i t}^{*}$ from equation (14), it is possible firms did not only maximize their profit, but were also maximizing social welfare at the same time. Furthemore, from the first order condition of the indirect utility function equation (4) combined with $I t$ from equation (3), we can find a firm's utility maximizing electricity input level,

$$
E_{j i t}^{V *}=\alpha_{E_{i t}} \cdot\left(\frac{T R_{j i t}}{\sum_{\forall i} \sum_{j=1}^{J_{i}} T R_{j i t}}\right) \cdot\left(\frac{1}{\beta_{t} \cdot \epsilon_{t} \cdot e_{W_{t}}^{\gamma-1}}\right)
$$

It is evident from the equation above, the socially optimal level of Electricity of firm $\mathrm{j}$ in industry $\mathrm{i}$ has a positive relationship with the electricity intensity of goods i and with the firm's total revenue relative to national income. The environmentally optimal $\mathrm{E}$ has an inverse relationship with how much they care about the emissions, $\beta_{t}$, with how bad emissions could be, $\gamma_{t}$, and with the world total emissions.

Electricity inputs have two side effects on consumers, on one hand, more electricity means higher level of production. Thus, people can consume more and if people can consume more utility levels rise. On the other hand, increasing electricity usage means more fossil fuels are needed to be burnt to generate electricity. The burning of fossil fuels will ultimately culminate in higher levels of emissions and will ultimately lower utility levels. In fact, the social optimal level of Electricity derives from the point that marginal benefit is equal its marginal cost. If the level of electricity input is greater than the optimal level, the representative individual will obtain a lower level of utility. Therefore, we can also view this value as a firm's limit of electricity input. Moving forward, we multiply equation (5) by $\epsilon_{t}$ and sum up the value of both sides for all firms and industries ultimately arriving at the national 
optimal level of emission of country $\mathrm{k}$ or the national emission limit, $\overline{e_{t}^{k}}$ :

$$
\overline{e_{t}^{k}}=\sum_{\forall i} \sum_{j=1}^{J i} e_{j i t}^{V *}=\left(\frac{1}{\beta_{t} \cdot e_{W_{t}}^{\gamma-1}}\right) \sum_{\forall i} \sum_{j=1}^{J i}\left(\frac{\alpha_{E_{i t}} \cdot T R_{j i t}}{I_{t}}\right)
$$

Using the indirect utility function, we can also find the electricity price from consumer side for each firm as if it is not given. For a given product prices, $P_{y}$, electricity price can be obtained from $P_{E_{j i t}}=\partial I_{j i t} / \partial E j i t$. Consequently, if firms make decisions according to people's utility maximization, in equilibrium, $I_{j i t}=T R_{j i t}$, for electricity price of firm $\mathrm{j}$ from industry i at time $t$, the first order condition of the indirect utility function implies

$$
P_{E_{j i t}}=\frac{\alpha_{E_{i t}} \cdot T R_{j i t}}{E_{j i t}}-\beta_{t} \cdot \epsilon_{t} \cdot\left(e_{W_{t}}\right)^{\gamma-1} \cdot \sum_{\forall i} \sum_{j=1}^{J_{i}} T R_{j i t}
$$

Recalling that the $\alpha_{E_{i t}} . T R_{j i t} / E_{j i t}$ is the $M R P_{E_{j i t}}$ from the profit maximizing firms in the previous section. Using Copeland and Taylors (1995), theoretical value of the marginal cost of pollution abatement, $\tau=\beta_{t} \cdot\left(e_{W_{t}}\right)^{\gamma-1} \cdot I_{t}$. Note that our $\sum_{\forall i} \sum_{j=1}^{J_{i}} T R_{j i t}$ is $I_{t}$. We now are able to rewrite equation (7) as $P_{E_{j i t}}=M R P_{E_{t}}-\epsilon_{t} \cdot \tau_{t}$ or $M R P_{E_{t}}-P_{E_{j i t}}=\epsilon_{t} \cdot \tau_{t}$. The new equation could help explain the mysterious gap between $M R P_{E_{t}}$ and $P_{E_{t}}$. Without limits set on emissions by the government, assuming people are knowledgeably informed of the direct relationship between electricity and emissions, people will naturally turn off the electricity when electricity use reaches their utility maximizing level. Is a reason why there would be a hidden desire for environmental quality limiting the total level of emissions naturally from equation (6). Our motivation is to reveal equation $6 \mathrm{~s}$ unit value using the theoretical framework just outlined. We will accomplish this task by applying an extensive data set to our empirical models and evaluating the results. In the subsequent subsection, we formulate producer profit maximizing decisions in conjunction with a utility maximization condition.

\subsubsection{Producer Side}

Copeland and Taylor's (1995) two input production function treats pollution as an input that can be substituted with effective labor to produce good $z$, a continuum of emission-intensity, $z \in[0,1]$, where 0 is the cleanest and 1 is the dirtiest. Denoting $\mathrm{Y}(\mathrm{z})$ as an output of a good with an energy-intensity z, $L_{e}$ as number of effective laborers and $e$ as a level of emissions, they specified a constant return to scale continuum good production function as follows: 


$$
Y(z)=L_{e}^{1-\alpha(z)} e^{\alpha(z)}
$$

In our model, emissions, rather than being a productive input, are for tractability treated as an unavoidable accompaniment to the electricity input, issuing proportionally to the electricity use: emissions, $e=\epsilon$. $E$, where $\epsilon$ is a national emission factor calculated from a linear summation of electricityemission factors, $\epsilon_{s}$, by type of electricity generation power plant, $s$ - coal, natural gas, oil, hydroelectric, and nuclear, and percentage to the total electricity production, $\% E P_{s}$, from a particular source $s$ :

$$
\epsilon_{t}=\sum_{\forall s}\left[\epsilon_{s} \cdot\left(\% E P_{s t}\right)\right]
$$

For our production function, we assume that all firms from the same industry in the same year would have the same production function. The only difference is the level of their inputs, L, K and E. Therefore, our three input Cobb-Douglas production function would be:

$$
Y_{j i t}=A \cdot L_{j i t}^{\alpha_{L}} \cdot K_{j i t}^{\alpha_{K}} \cdot E_{j i t}^{\alpha_{E}}
$$

; where $\mathrm{A}$ is the production efficiency and the subscript $j, i$, and $t$ denote firm $j$ from industry $i$ at time $t$ under the assumption that all firms from the same industry would produce identical outputs First, we assume that these firms are profit maximizing. Second, from our data set, all firms from the same industry will take the same product price. Each firm will choose their inputs to maximize their profit, total revenue(TR), $P_{i t} . Y_{j i t}$, minus total cost(TC):

$$
\max _{\{L, K, E\}} \Pi_{j i t}=P_{i t} . Y_{j i t}-T C_{j i t}
$$

We assume that it is very difficult to change level of fixed asset stock and number of employees in a single time period relative to the electricity usage. Therefore, firms will maximize their profits by choosing the level of electricity usage, E, given their current level of L and K.

When the emission permit system does not exist, the firm's total cost would be:

$$
T C_{j i t}=w_{j i t} \cdot L_{j i t}+r_{j i t} \cdot K_{j i t}+P_{E_{t}} \cdot E_{j i t}
$$

where $w$ is an annual wage rate, $r$ is the interest rate plus the depreciation rate, and $P_{E}$ is the price of electricity. Our conjecture, at this point, is all firms in a year will face the same interest rates, depreciation rates and prices. The constant emission per unit cost, or whether a permit price for every unit of emission, or a self-imposed psychic cost of emissions, $\tau$, making 
the total cost of production, $w \cdot L+r \cdot K+P_{E} \cdot E+\tau . e$. Emissions are a linear function of electricity usage, $e=\epsilon$. $E$ where all firms share the same level of electricity power distribution from different sources, for example, $1 \mathrm{kWh}$ of electricity usage, no matter what location, in Korea at time $t$ will have the same $\% E P_{s} ; \forall s=$ coal, natural gas, oil, hydro power, and nuclear. Now we can write an equation of the total cost in terms of only the three inputs:

$$
\begin{aligned}
T C_{j i t} & =w_{j i t} \cdot L_{j i t}+r_{j i t} \cdot K_{j i t}+P_{E_{t}} \cdot E_{j i t}+\tau_{j i t} \cdot\left(\epsilon_{t} \cdot E_{j i t}\right) \\
& =w_{j i t} \cdot L_{j i t}+r_{j i t} \cdot K_{j i t}+\left(P_{E_{t}}+\tau_{j i t} \cdot \epsilon_{t}\right) \cdot E_{j i t}
\end{aligned}
$$

As mentioned earlier, there are currently no emission regulations in Korea during the data set time period. Consequently, if there is no psychic cost of emissions, then firms should maximize their profits by their total cost in equation (12) and set their optimal level of $\mathrm{E}$ where their $M R P_{E}$ equal to $P_{E}$. From the first order condition from equation (11) without any permit costs, we have:

$$
\begin{aligned}
\frac{\partial \Pi}{\partial E_{j i t}} & =\frac{\alpha_{E} \cdot T R_{j i t}}{E_{j i t}}-P_{E_{t}}=0 \\
E_{j i t}^{*} & =\frac{\alpha_{E} \cdot T R_{j i t}}{P_{E_{t}}}
\end{aligned}
$$

; where $M R P_{E_{j i t}}=\alpha_{E} \cdot T R_{j i t} / E_{j i t}$. From the above equation (14), the profit maximizing level $E$ input depends on total revenue, electricity intensity, and price. If the price of electricity rises, the quantity demanded as an input will go down. When TR or $\alpha$ increase, this $E_{j i t}^{*}$ would be increasing as well. Without any regulations or enforcements on electricity usage and/or emissions, production firms should be able to reach the level of $\mathrm{E}$ input to maximize their profit easily.

In fact, the empirical result section, shows most firms' $M R P_{E}$ is greater than $P_{E}$, implying these firms are under-utilizing electricity at a given level of the other inputs. The empirical evidence suggests a possible positive psychic cost of emissions, or in other words that the producers may voluntarily reduce their emissions levels due to environmental concerns. Producers did not use the electricity at the optimal level, $E_{j i t}^{*}$ even though the government is not enforcing emission level requirements. Instead firms acted as if they used the total cost in equation (13). The results imply, if any firms' $M R P_{E}$ is lower than $P_{E}$ firms are over-utilizing electricity relative to the profit-maximizing level.

Expanding on the previous subsection, producers who make production decisions are also representative individuals who embed an environmental 
value in their utility function. The environmental value instinctively influenced producers decisions even taking into account the firm's profit maximization responsibility.

In the next section, we will describe our data sets and how we transformed the theoretical part to empirical analysis model with all available data we have.

\subsection{Data}

To achieve the goal of this paper, we first concentrate on the production function. Copeland and Taylor (1995) begin with a continuum good production function in their theoretical framework. We follow their framework and transform their continuum good production into discrete form. At this point, firm level input-output data sets specifically containing a wide variety of outputs or goods with basic input information were sought out. Our data set needs inputs containing information on number of workers, level of capital investment, among other descriptive qualities. Furthermore our data set needed to include information on the level of electricity usage by each firm. During our search we discovered firm level electricity usage information is not publicly published. Most likely data meeting our specifications is confidential or is quite costly to purchase. However, we did manage to obtain two comprehensive firm level data sets for Korea and Thailand.

\subsubsection{Korean Data}

In this section we use very extensive annual raw data obtained from the Korean Annual Survey of Manufactures produced by the Korean Industrial Ministry. However, company names and even company identification numbers are not obtainable from the data, therefore, limiting our panel data to industrial categories. We did manage to obtain input-output information for each firm in 23 industries annually from 1982 to 2005 . We do obtain input information on number of employees (L), the total annual wage paid to all employees in a firm (wL), the level of fixed asset stock which functions as the capital input $(\mathrm{K})$ for our analysis, and the total expenditure on electricity in a year $\left(T C E=P_{E} \cdot E\right)$. The data set is also limited by the information we obtained for output. We were unable to acquire pertaining to production quantity for each firm. Although, we did find data providing firm level annual total revenue for firm product (TR). In total, our data contains almost 2 millions observations with, on average, greater than 1,000 firms a year for each industry. Each industry in the data set is categorized by two digit Standard Industrial Classification (SIC) code. 


\section{Table 1}

Korean Market Share and number of firms on average by Industry

\begin{tabular}{lll}
\hline SIC - Industry Name & $\begin{array}{l}\text { Market Share } \\
(\%)\end{array}$ & $\begin{array}{l}\mathrm{N} \\
\text { (firms) }\end{array}$ \\
\hline 15 - Food and Beverages & 7.97 & 5,597 \\
16 - Tobacco & 1.71 & 19 \\
17 - Textiles & 6.46 & $7,938 *$ \\
18 - Wearing apparel & 2.38 & 6,877 \\
19 - Leather and Footwear & 1.6 & 2,203 \\
20 - Wood & 0.9 & 1,910 \\
21 - Paper & 2.42 & 2,253 \\
22 - Publishing and Printing & 1.55 & 3,923 \\
23 - Refined petroleum & 8.09 & 246 \\
24 - Chemicals & $9.45 *$ & 2,587 \\
25 - Rubber and Plastics & 4.36 & 5,837 \\
26 - Other Nonmetallic mineral & 3.9 & 3,599 \\
27 - Basic metals & 8.85 & 1,909 \\
28 - Fabricated metal & 4.14 & $9,025 * *$ \\
29 - Machinery and Equipments & 7.47 & $10,823 * * *$ \\
30 - Office and Computing & 2.47 & 608 \\
31 - Electrical machinery & 6.91 & 4,358 \\
32 - Electronic & $13.07 * * *$ & 3,616 \\
33 - Medical and Precision & 0.94 & 1,815 \\
34 - Motor vehicles & $9.9 * *$ & 2,693 \\
35 - Other Transport & 3.29 & 749 \\
36 - Furniture and others & 1.75 & 4,729 \\
37 - Recycling & 0.15 & 335 \\
\hline
\end{tabular}

Table 1 shows the list of the industries in our data set sorted by the SIC code in the first column. Columns two and three show each industry's percentage of total output ("market share") on average ${ }^{10}$ and the on average number of firms.

The stars shown in table 1 and 2 represent the top three industries for each variable. Three stars designates the number 1 ranking, two stars designate the second rank, and one star designates the third rank. Table one

\footnotetext{
${ }^{10}$ Market share of an industry i in year $t$ would be the total amount of all firms' total revenue in the industry divided by the total amount of firms' total revenue in that year, MarketShare $_{i t}=\frac{\sum_{j=1}^{J_{i}} T R_{j i t} x 100}{\sum_{\forall i} \sum_{j=1}^{J_{i}} T R_{j i t}}$
} 
lets us observe that the electronic industry is the largest industry in terms of its domestic market share. The electronic industry maintains a market share just above $13 \%$ on average for these past 25 years. Slightly behind the electronic industry is the motor vehicles industry market share at $9.9 \%$ and the chemical industries captures $9.45 \%$ market share. The ranking in terms of number of firms, the machinery and equipment industry is composed of almost eleven thousand firms on average in each year. The machinery and equipment industry is followed by the fabricated metal industry containing slightly above 9,000 firms and the textile industry containing almost 8,000 firms. The on average number of firms provides an idea of how many observations we have for each production function regression, for each industry, and for each year.

As shown in the third column, the tobacco industry will be a problem when we run the separate regression for each year and industry. For the tobacco industry, we could only run the regression by industry, however, not over time. Another industry with relatively few observations is the refined petroleum product industry. Since the Korean ministry of industry decided to change their industrial coding after 1990 to match up with current day SIC code, a few of the firms might have qualified to be in the other industries. The observations for the refined petroleum product industry began dropping after 1990 from over 300 each year to just over 60 in 1991. Then, the number of the firms under the category of refined petroleum product industry increases gradually to read 100 in the year 2003. Even though refined petroleum does not have so many firms the size of its market share, on average, is ranked number five in the Table.

Since the electricity input we have is total electricity expenditure in terms of millions of Won. It will be of greater practicality to run our production function with electricity usage in terms of quantity, gWh, input. Thus, we turn our attention to firm level electricity prices to find out the amount of electricity usage for each firm. Again, there is no report on this directly, therefore, we find a reliable source for an annual average electricity price for industrial manufacturing firms. We start by incorporating data derived from the government electric utility company, Korea Electric Power Corporation (KEPCO). KEPCO, at the time, controlled over 93 percent of power generation in Korea. KEPCO was also the sole company responsible for all power transmission and distribution in Korea. Thus, we derive our price for electricity from the KEPCO reported annual power sold in gWh and revenue in millions of Won by groups of consumers: Residential, Commercial, Educational, Industrial, Agricultural, and Street-lighting. Each group had a different electricity rate. The new data now provides us with the ability to calculate the annual average electricity rate in Won $/ \mathrm{kWh}$ for the industrial 
sector. However, it is important to point out KEPCO only published this information in 1982, 1991, and then yearly from 1999. Therefore, we decided construct and use an average electricity price of the year 2000, base year, to convert the electricity price index to an annual average electricity price for the rest of the years in our data set. Even though this price index is not specific for the manufacturing sector, Cho et al(2007) ${ }^{11}$ provides significant evidence that KEPCOs general price stabilization policy is considered the consistency of the price gap between residential rate and industrial rate since 1980. Additionally, the electricity rate trend reported matched up very well with the electricity price index trend that we obtained from the Bank of Korea. Hence, this price index is acceptable for us to calculate the rest of the annual average industrial electricity rate for the rest of the year. The year 2000 is the base year of this price index, $P_{E_{t}}^{\text {index }}=P_{E_{t}} / P_{E_{2000}}$, so we obtained the $P_{E_{2000}}$ from the $2000 \mathrm{KEPCO}$ power sale report ${ }^{12}$. In the year 2000, KEPCO's total electricity revenue from the manufacturing sector was $8,008,201$ million Won and total power sold to the sector was 137,372 $\mathrm{gWh}$, so the manufacturing annual average electricity price of the year $2000, P_{E_{2000}}$, would have been 58.296 Won per $\mathrm{kWh}$. Therefore, we can calculate the rest of the rates, as shown in the figure 1 below.

\section{Figure 1}

Korean Industrial Electricity Rate from 1980 to 2005

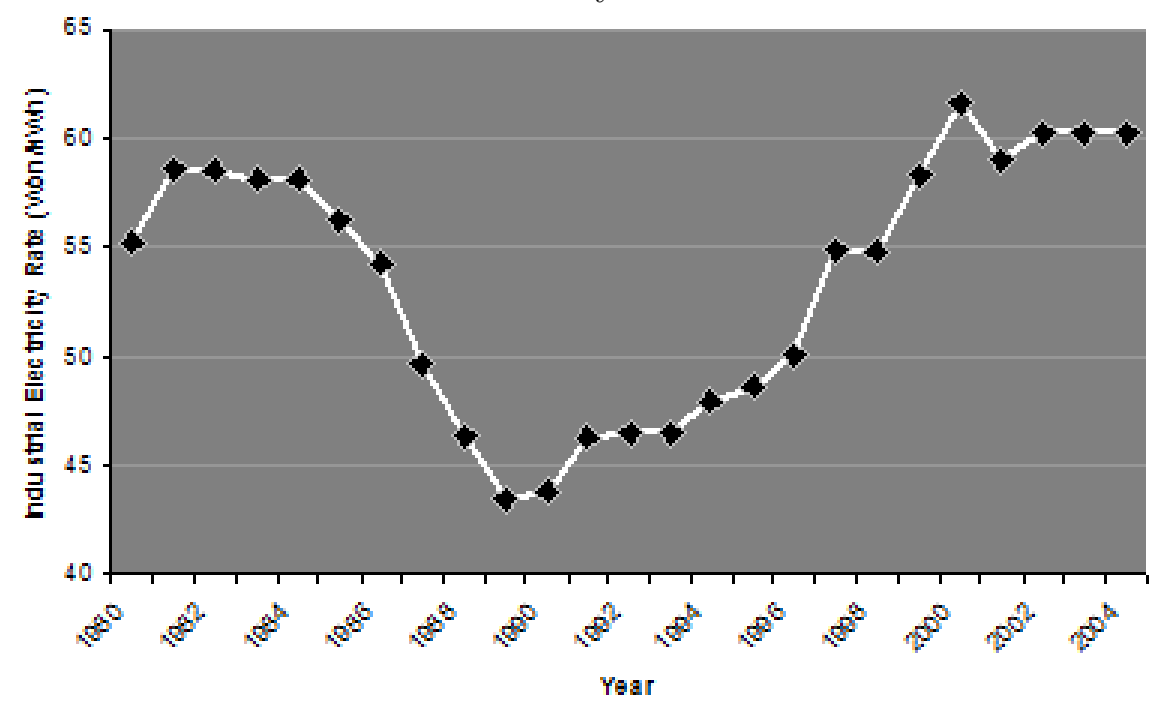

\footnotetext{
11/Chang Hyeun Cho, Gurcan Gulen, and Michelle Michot Foss, "Electricity and Natural Gas Sectors in Korea: Synthetically Overview and Recent Developments", KIET Industrial Economic Review v12 n2 March 2007

${ }^{12} \mathrm{http}: / /$ www.kepco.co.kr/eng/
} 
Figure $1^{13}$, displays how the Korean manufacturing electricity price trend varied from 1980 to 2005 . First, the rate slightly increased from $55 \mathrm{Won} / \mathrm{kWh}$ to almost $60 \mathrm{Won} / \mathrm{kWh}$ in 1982 . Then, the rate began and kept falling to its lowest point at $43 \mathrm{Won} / \mathrm{kWh}$ in 1990. In the 1990s, electricity price rose and approached its peak at $61.55 \mathrm{Won} / \mathrm{kWh}$ in 2001. At which point, the electricity price is more or less stable. We have found some explanation of these various price trends from the percentage share of electricity production from different types of power generation energy sources.

We obtained annual reports on power production of each type of electricity power plant in each year. KEPCO reported that there are five different main types: coal, oil, gas, nuclear, and hydro power plants. Figure 2 illustrates the trend of the electricity production share of each energy source by power plant. We rank them from the highest emission per $\mathrm{kWh}$, coal- $965 \mathrm{~g}$ $\mathrm{CO} 2$ equivalent/kWh, at the bottom, to the cleanest hydro electricity power generation- $15 \mathrm{~g} \mathrm{CO} 2$ equivalent $/ \mathrm{kWh}$, at the top of the figure (Bloomfield et al, 2003).

\section{Figure 2}

Korea Electricity Production Share by Sources of Energy

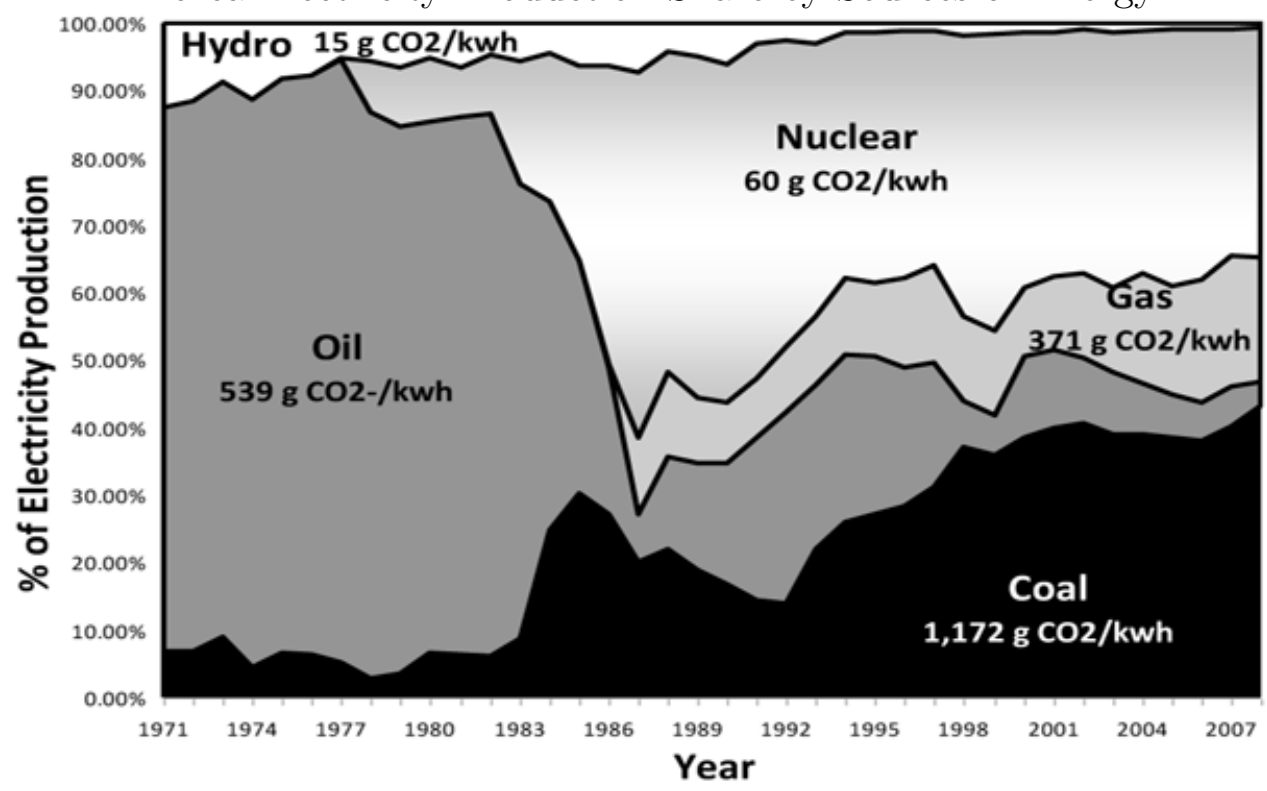

As shown in figure $2^{14}$, in the very early 1980 s, Korean electricity was mainly dependent on oil power generation, but it declined sharply from about $80 \%$ to less than a $10 \%$ share of the Korean total electricity production in

\footnotetext{
${ }^{13}$ Source: KEPCO, http://www.kepco.co.kr/eng/

${ }^{14}$ Source: World Bank, World Development Indicator 2006 CD
} 
the late 1980s, because of the rise in the production share of nuclear power. The change to nuclear power caused the electricity rate to decline, as shown in figure 1. Then, in the 1990s, the shares of electricity from coal and gas increased, especially coal. The electricity price responded inversely to the decreasing ratio of nuclear power production. During the infamous Asian financial crisis from late 1997 to 1998, there was an obvious cut in electricity production from the expensive energy source, oil, and a slight cut from gas and coal power plants.

Table 2

Korean Industry Average Input per Year

\begin{tabular}{llll}
\hline SIC - Industry Name & $\begin{array}{l}\mathrm{L} \\
\text { (thousand) }\end{array}$ & $\begin{array}{l}\mathrm{K} \\
\text { (Billion Won) }\end{array}$ & $\begin{array}{l}\mathrm{E} \\
\text { (gWh) }\end{array}$ \\
\hline 15 - Food and Beverages & 183 & 11,100 & 4,613 \\
16 - Tobacco & 8 & 347 & 86 \\
17 - Textiles & $282 * * *$ & 9,220 & 8,255 \\
18 - Wearing apparel & 175 & 1,445 & 577 \\
19 - Leather and Footwear & 72 & 988 & 555 \\
20 - Wood & 34 & 1,223 & 658 \\
21 - Paper & 59 & 5,595 & 5,063 \\
22 - Publishing and Printing & 76 & 2,905 & 783 \\
23 - Refined petroleum & 15 & 3,318 & 1,383 \\
24 - Chemicals & 130 & $21,700 * *$ & $14,076 * *$ \\
25 - Rubber and Plastics & 178 & 7,877 & 5,490 \\
26 - Other Nonmetallic mineral & 108 & 8,825 & 7,071 \\
27 - Basic metals & 109 & $18,300 *$ & $16,107 * * *$ \\
28 - Fabricated metal & 177 & 7,541 & 3,824 \\
29 - Machinery and Equipments & $259 *$ & 12,400 & 4,063 \\
30 - Office and Computing & 36 & 1,978 & 524 \\
31 - Electrical machinery & 213 & 5,672 & 2,581 \\
32 - Electronic & $274 * *$ & $30,600 * * *$ & $9,428 *$ \\
33 - Medical and Precision & 45 & 1,412 & 432 \\
34 - Motor vehicles & 205 & 16,300 & 5,278 \\
35 - Other Transport & 75 & 9,465 & 1,272 \\
36 - Furniture and others & 97 & 2,278 & 912 \\
37 - Recycling & 4 & 315 & 157 \\
\hline
\end{tabular}

After the crisis subsided, the electricity production ratio from oil power plants was still in decline. Instead of reverting production back to oil fire plants, higher production ratios mostly divert to gas power plants and slightly to coal fire power plants. After the year 2000, the ratio between each source 
becomes more stable which could explain why the price of electricity was quite stable as well. From this electricity production share of different energy sources, we can calculate the $\epsilon_{t}$, the Korean total emission factor for year t in grams of $\mathrm{CO} 2$ equivalent per $\mathrm{kWh}$, from the equation (9). After obtaining the price of electricity, we calculate each firms electricity usage and present it in terms of an industry average in table 2 .

Table 2 illustrates the average value of each input of the whole industry. For example, we added up all firms' electricity usage in the industry, i, for each year and calculated the average and then reported it in this table. The purpose of this table is to reveal the aggregate amount of each input within industry that has been used in its production on average over these 25 years.

The electronic industry has not only had the highest share in the market, but also had all of its input in the top three ranking. The total fixed asset stock of the electronic industry is almost 10,000 billion Won more than the chemicals product industry's and almost two times more than the basic metal industry. The chemicals product industry and the basic metal industry ranked number two and three in the input category, respectively. For the number of employees, there is no big difference in input category among the top three industries - textiles, electronic, and machinery and equipments. These industries, on average, employ 282,274, and 259 thousand total workers in their industries, respectively. Moreover, examining the industry's total electricity usage we find, basic metal, chemicals, and electronic industries use the most electricity in a year on average which are $16 \mathrm{k}, 14 \mathrm{k}$, and $9.5 \mathrm{kgWh}$. In the next section, we will compare the coefficients of each input with this industry's total input statistic.

Using this extensive firm level data set will be enough to construct a revenue function for each industry in each year. First, we decided to separate each production function regression, because we believe different products from different industries will require different production functions. Second, we tried to examine how production function of each industry would change in each year. In addition, we plan to see in what way our new measurement of environmental values changes over time and compare it with the prediction of the Environmental Kuznet Curve. The Environmental Kuznet Curve theorizes the value of environmental goods increases with as income increases. In order to compare, we obtain the Korean real income per capita from the World Development Indicators 2007. From this source, we also obtain some other possible control variables, which are world emissions, neighboring countries' emissions, life expectancy, population, and population density. The description of these variables is provided in the next section. 


\subsubsection{Thai Data}

For Thailand data set, we gathered the annual survey on Thailand industries directly from Thailand Ministry of Industry. The construction of the data was almost the same as the Korean data. We were able to obtain firm level inputs - L,K, and E, and output, as a product value of all industries except the Recycling industry, which was not available. The Thai data set was a lot smaller. The Ministry of Industry only sent out 1,200 surveys in total each of the years. Consequentially, some of the industries, in some years, do not have enough observations to run annually separated production function regressions. On top of that, we only have access to this survey data from the year 2001 to 2008 .

Table 3

Thailand Market Share on average and number of firms by Industry

\begin{tabular}{lll}
\hline SIC - Industry Name & $\begin{array}{l}\text { Market Share } \\
(\%)\end{array}$ & $\begin{array}{l}\mathrm{N}^{* T} \\
\text { (firms) }\end{array}$ \\
\hline 15 - Food and Beverages & $13.24^{*}$ & $1,488^{* * *}$ \\
16 - Tobacco & 0.13 & 24 \\
17 - Textiles & 4.73 & $8166^{*}$ \\
18 - Wearing apparel & 0.87 & 424 \\
19 - Leather and Footwear & 1.05 & 320 \\
20 - Wood & 0.31 & 192 \\
21 - Paper & 0.69 & 224 \\
22 - Publishing and Printing & 0.90 & 264 \\
23 - Refined petroleum & $23.70 * * *$ & 72 \\
24 - Chemicals & $15.74 * *$ & 960 \\
25 - Rubber and Plastics & 7.11 & $1,152 * *$ \\
26 - Other Nonmetallic mineral & 2.44 & 624 \\
27 - Basic metals & 2.10 & 168 \\
28 - Fabricated metal & 2.71 & 568 \\
29 - Machinery and Equipments & 5.03 & 464 \\
30 - Office and Computing & 0.26 & 32 \\
31 - Electrical machinery & 1.80 & 224 \\
32 - Electronic & 8.89 & 312 \\
33 - Medical and Precision & 0.76 & 104 \\
34 - Motor vehicles & 4.07 & 368 \\
35 - Other Transport & 1.41 & 112 \\
36 - Furniture and others & 2.07 & 488 \\
\hline
\end{tabular}


Table 3 shows the average "market share 15 " of each industry over the time period. The refinery petroleum product holds the highest average market share at $23.70 \%$ with on average less than firms operating each year. The reason behind that is this industry was formerly run by the government. Even nowadays, most of these companies' shares are still held by the government. The other industry in the same situation as the refinery petroleum industry is the tobacco industry. The runner up of the market share criteria is the chemical and the third is the food industry.

The highest number of firms goes to Food and Beverages industry at 1,488 firms or on average of 186 firms per year. Since the ministry only sent out 1,200 surveys each year, unlike Korean data, which are comprehensive, we change our way to deal with some of the industries with low number of observations, including Tobacco, Refined petroleum product, Office and computing, Medical and precision, and other transport equipment industries.

Therefore, when we estimate the production function of these industries, we will estimate it only by industry, not through time. Other than that, since there are only 8 years, in the later section we will demonstrate in what way our new measurement is moving with the nation's income per capita. Consequently, we will not be able to test for it with Thailand data.

Figure 3

Comparing Thailand Electricity price to Korea and the USA ${ }^{16}$

Electricity Price

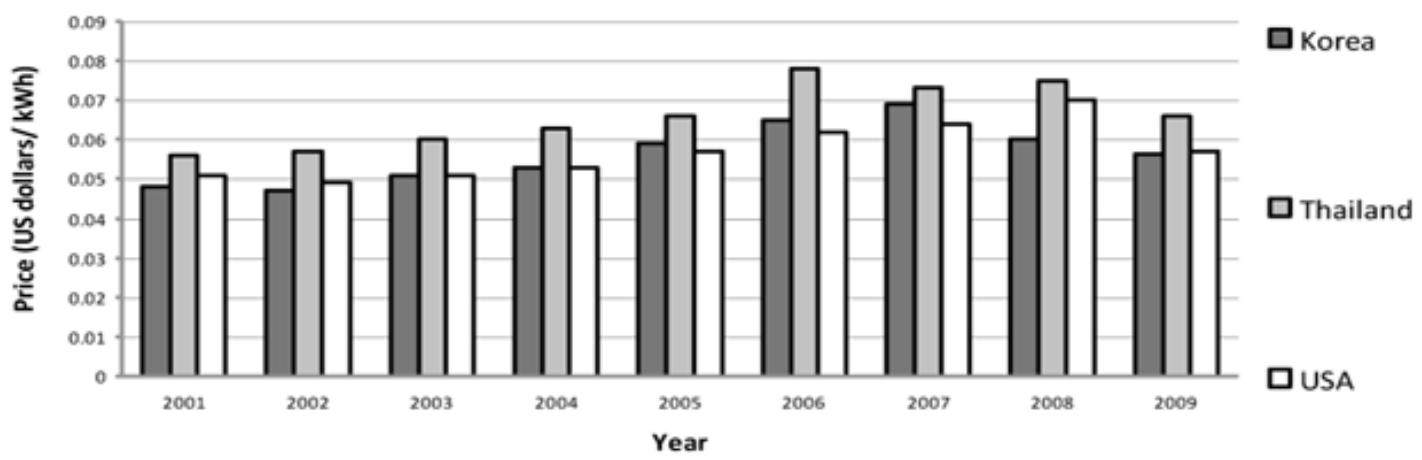

Actually, from the survey we can obtain the level of electricity consumption in $\mathrm{kWh}$ directly. However, a few factories filled out the survey with

\footnotetext{
${ }^{15}$ The term "market share", what we are referring here, is simply the share of each industry in the country's total revenue output.

${ }^{16}$ International Energy Agency, Energy Prices \& Taxes - Quarterly Statistics, Fourth Quarter 2009
} 
only their total cost of electricity. The industrial electricity price in Thailand over the past 10 years has changed little. We obtained the electricity price data from EGATT directly. In figure 3, we present the Thai electricity price over time in comparison with Korean electricity price and the USA electricity price. All prices are in US dollars per $\mathrm{kWh}$. It is important to take into account the electricity prices in this figure are the countries average price of electricity, taking residential, commercial rate into account as well. Moreover, the least developed among these three countries paid the most per unit of electricity. The reason behind this might have to deal with fuel mixed ratio for power generation and the energy price in Thailand. We delve into these details in the last section of this research paper.

\section{Figure 4}

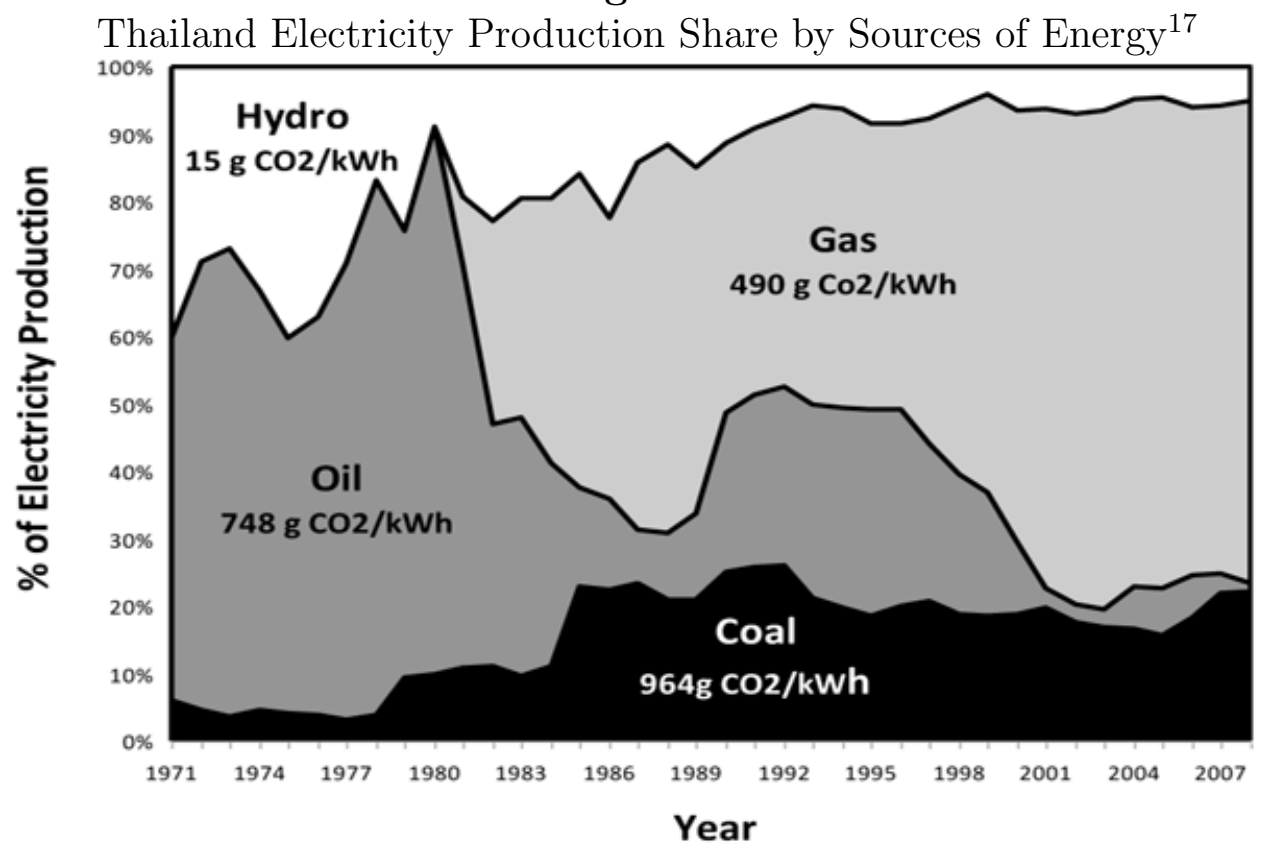

For now, as shown in figure 4, we can see that Thailand doesn't have any nuclear power plants in the country, yet. Since the operating variable cost per unit of generation of one unit of electricity from a nuclear power plant is relatively a lot cheaper than any other fossil fuel energy sources. It is possible nuclear power plant production is the reason why electricity price in Thailand is, in general, more expensive than electricity prices in Korea and the US. In figure 4, we also present the $\mathrm{CO}_{2}$ emission factor by source of type

\footnotetext{
${ }^{17}$ Retrieved from http://databank.worldbank.org/
} 
of fossil fuel used to generate electricity. Note here, the electrical emission factors presented here are the average values retrieved from $\operatorname{IEA}(2011)^{18}$.

Examine the Thai overall electricity emission factor as well as the Korean electricity emission factor presented in figure 5. Korea starts from dirtier electricity production in the early 1970s, relative to Thailand. If we look back at the figure 2, the increase in the ratio of oil power production in Korea drove the emission factor up even beyond Thailand's emission factor in the early 1980s.

\section{Figure 5}

Thailand Vs. Korea Electricity Emission Factor over Time

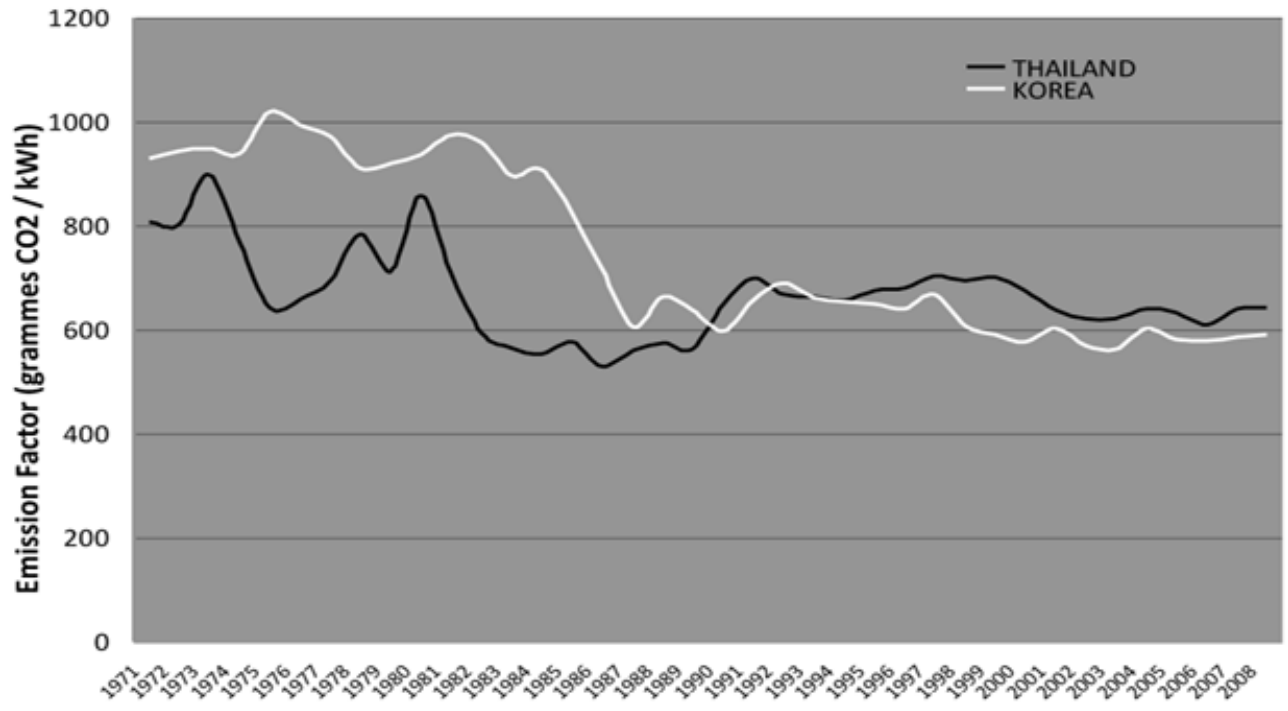

Korea, as documented before, moved toward cleaner and cleaner production per unit of electricity with increased electricity generation from nuclear power plants. Nuclear power production most likely caused the sharp drop off in dirtier emission towards the end of the 1980s. For Thailand, as we stated in the background section, in the early 1980s, the government of Thailand started to worry about the financial impact of the rising oil prices. Consequently the government of Thailand switched to using more gas turbine power generation plants. We can observe the sharp drop off in figure 4 of the electricity generation share of oil power plants. Since then, with discovery their own sources of natural gas in the gulf of Siam, power generation from gas power plants became larger and larger. If we look at the emission factor trend over time, even though Thailand emissions did not decrease as much as Korean emissions, power production in Thailand does not emit much more

\footnotetext{
${ }^{18} \mathrm{CO} 2$ Emissions from Fuel Combustion (2011 Edition), IEA, Paris.
} 
carbon dioxide than Korea. Even though Korea produces electricity using nuclear technology.

Figure 6

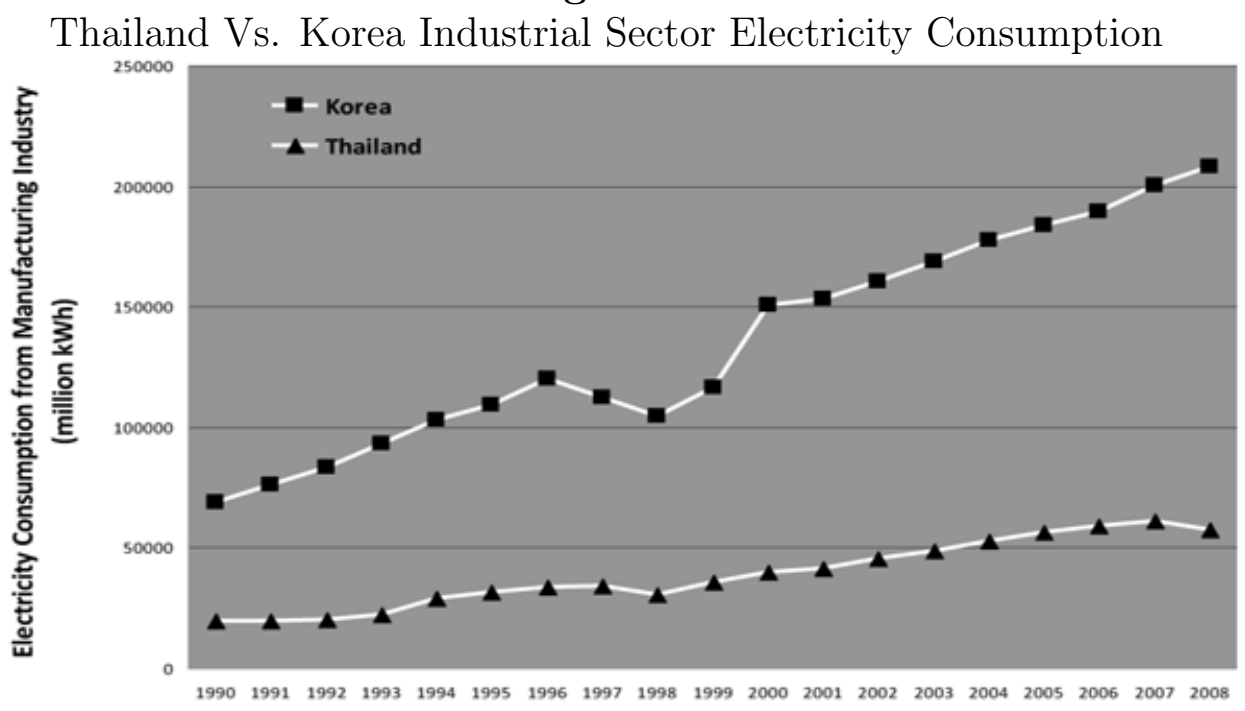

In figure 6, we show how much electricity manufacturing industries from Korea and Thailand used in their production. We can see that Korean industries consumed a lot more than Thai industries. In the third quarter of 1997 when the Asian financial crisis hit, manufacturing industries had to cut some of their production. As a result, both Thailand and Korea electricity consumption from the industrial sector dropped. Then, right after the crisis, the Korean manufacturing industry's electricity consumption behavior stroke back sharply, as seen in the figure 6, from 1999 to 2000. At this point Koreans manufacturing industry's electricity consumption reverts back to their business as usual consumption behavior.

Table 4, demonstrates how much of each inputs, on average, and per year the whole industry requires to produce their output. As expected, the heavy electricity consumption industries are chemical, non-metallic, and textile industries, food, rubber, and textile industries require more laborers in their production. Obviously, the highest capital requirement industries are the refined petroleum products and chemicals, respectively.

Before we started to estimate any production functions in the next section, we decided to leave two Korean industries out of our analysis. One is the tobacco industry because of very low number of observations, 19 firms on average. Plus, they do not have any observations from 2002. The other one is the furniture and other product industry. This industry has too many different types of products, so its production function would not be accurate 
enough to represent one type of goods. Similarly, for Thai data, as shown on table 3 , number of observations of the tobacco, the refined petroleum, and the office and computing industries are too low to run separate production function regression.

Table 4

Thailand Industry Average Inputs

\begin{tabular}{llll}
\hline SIC - Industry Name & $\begin{array}{l}\mathrm{L} \\
\text { (thousand) }\end{array}$ & $\begin{array}{l}\mathrm{K} \\
\text { (Billion Baht) }\end{array}$ & $\begin{array}{l}\mathrm{E} \\
\text { (gWh) }\end{array}$ \\
\hline 115 - Food and Beverages & $71^{* * *}$ & $36^{*}$ & 863 \\
16 - Tobacco & 1 & 1 & 13 \\
17 - Textiles & $33^{*}$ & 20 & $1,038^{*}$ \\
18 - Wearing apparel & 19 & 2 & 35 \\
19 - Leather and Footwear & 15 & 3 & 65 \\
20 - Wood & 5 & 1 & 41 \\
21 - Paper & 6 & 3 & 151 \\
22 - Publishing and Printing & 5 & 2 & 32 \\
23 - Refined petroleum & 2 & $77 * * *$ & 683 \\
24 - Chemicals & 27 & $60 * *$ & $1,963 * * *$ \\
25 - Rubber and Plastics & $43 * *$ & 26 & 910 \\
26 - Other Nonmetallic mineral & 15 & 34 & $1,332 * *$ \\
27 - Basic metals & 4 & 14 & 351 \\
28 - Fabricated metal & 10 & 9 & 167 \\
29 - Machinery and Equipments & 13 & 11 & 151 \\
30 - Office and Computing & 2 & 1 & 16 \\
31 - Electrical machinery & 9 & 6 & 257 \\
32 - Electronic & 30 & 13 & 293 \\
33 - Medical and Precision & 5 & 3 & 45 \\
34 - Motor vehicles & 19 & 16 & 189 \\
35 - Other Transport & 4 & 5 & 62 \\
36 - Furniture and others & 16 & 14 & 676
\end{tabular}

Other than these exclusions, we set some criteria to eliminate some survey errors. First, we look at all the input-output variables from the survey data, L, K, TCE, and TR. We assume these variables should not be negative. Then, we are only interested in operating firms, so we leave out all the firms that have any zero inputs and/or outputs. Afterward completing these adjustments, we check all the units of each variable and make sure they have the same unit before making any estimations. After some unit corrections, TR, TCE, and $\mathrm{K}$ are all in millions of Won, $\mathrm{E}$ is in $10^{9} \mathrm{Wh}$ or $\mathrm{gWh}$, and the electricity price, $P_{E}$ is in Won/kWh. In total, we lost almost 200,000 observations which is roughly 10 percent of the data set we have. 


\section{Production Function and Stochastic Fron- tier Estimation}

Our earlier proposition, of one of our three main focuses involved using production function estimation with technical efficiency to enhance our environmental measurement results later on. Naturally, it is almost impossible for any firms or factories to keep producing at their full potential all the time. In this section, we will apply more realistic estimation to our theoretical model making sure we ensure a good measurement of technical efficiency in order remove issues involving production inefficiency from our environmental value measurement, $M R P_{E}-P_{E}$, as much as possible.

First, as we promised, we present two production functions. One, the nonlinear functional form used in this production function estimation field for long time, is the Cobb Douglas production function. This is also the functional form we use in the theoretical section. Many people like it, because it is easy to calculate and it permits the imposition of homogeneity of elasticity of substitution. Moreover, the imposition of homogeneity of elasticity of substitution will be one of the ideal requirements for the distance function. The other functional form we use here is the translog production function. The translog production function is also selected by many authors, according to Coelli and Perelman(1999), because it is more flexible than the Cobb Douglas. However, the translog function is not elasticity of substitution restricted. Additionally, according to Klein(1953), the Cobb Douglas is not concave in the output dimensions.

To measure production efficiency the literature on frontier estimation can be classified into the deterministic frontier and stochastic frontier. The deterministic frontier does not contain a stochastic term for measurement error, where the realized output deviate from the frontier by a technical efficiency term. The representatives are Data Envelopment Analysis (DEA) and Free Disposable Hull (FDH) estimators, where no functional forms of the frontiers are assumed. It is nonparametric in this sense. The stochastic frontier includes both random measurement error and technical efficiency term, typically as a composite error term, absolute normal and normal. Aigner, Lovell and Schmidt (1977) wrote a classical paper on the subject defining it as purely parametric. Second, non-parametric and parametric estimation shows up in both frontiers now (Simar and Wilson, 2008).

In our study, we have a primary aim to capture either technical efficiency or inefficiency out of our everyday production function. The optimal input can be chosen given the situation by decision makers who realize their company's efficiency level and take it into account. 
Here, we use the estimation technique to obtain the value of production efficiency in two ways. The first way is the Maximum Likelihood Estimation (MLE) with a one-tailed technical efficiency term and accounting for random noise. The second way is to estimate a distance function with the Corrected Ordinary least Square (COLS) estimation. The later estimation methods require making the appropriate selection of production function and, as stated above, the ideal functional form to estimate distance function is using a translog production function. The requirement for using a translog production function is, because if fulfills all three ideal requirements, according to Coelli and Perelman (1999). The first requirement is to be flexible. The second requirement is it should be easy enough to calculate. The last requirement of the function is it should allow the imposition of homogeneity.

The organization of this section will start from the MLE method for both Cobb Douglas and Translog to estimate the technical efficiency. Then, it is time to estimate the distance function. According to Klein (1953), we will only use the translog functional form and following Lovell et al (1994) we will use the Corrected Ordinary Least Square (COLS) method to estimate the distance function.

\subsection{Maximum Likelihood Estimation Method}

\subsubsection{Cobb-Douglas Production Function}

Consistent with the Cobb-Douglas production function in the theoretical section, equation(10), our empirical work employs a log-linear specification with some modifications. First, we do not have data for output, $Y_{j i t}$, of each firm. We do have their product value or their total revenue from their product, $T R_{j i t}$. From our assumption of all firms from the same industry in the same year are price takers, we multiplied product price, $P_{i t}$, to both sides of the production function equation(10). Then, we also apply the stochastic production frontier method to our estimation. We added the technical efficiency term, $T E_{j i t}=e^{-u_{j i t}} \leq 1$, to create a Cobb-Douglas revenue function:

$$
T R_{j i t}=P_{i t} \cdot A \cdot L_{j i t}^{\alpha_{L}} \cdot K_{j i t}^{\alpha_{K}} \cdot E_{j i t}^{\alpha_{E}} \cdot e^{-u_{j i t}} \cdot e^{\nu_{j i t}}
$$

where $u_{j i t} \geq 0$ since $T E_{j i t}=1$ when firm $\mathrm{j}$ obtains the feasible maximum output, and $\nu_{j i t}$ is a random shock distributed two-sided normally.

Then, we take a natural logarithm on both sides of our Cobb-Douglas production function equation and estimate using the following regression.

$$
\ln T R_{j i t}=\widehat{\alpha_{0_{i t}}}+\widehat{\alpha_{1_{i t}}} \ln L_{j i t}+\widehat{\alpha_{2_{i t}}} \ln K_{j i t}+\widehat{\alpha_{3_{i t}}} \ln E_{j i t}-u_{j i t}+\nu_{j i t}
$$


This stochastic frontier estimation using composite error terms, where $u_{j i t}$ is the distribution for the inefficiency term as half-normal.

Table 5 provides each input's estimated coefficients on annual average by industry. We estimated the above regression by industry and year separately, because we have to observe in what way the estimated coefficients change over and time across industries. Later, we can construct a time series data of our environmental value for each industry to test congruently with the nation's income per capita. Then, we will compare our findings with the Environmental Kuznets Curve in a later section. In addition, in the last section of this study, these estimated coefficients will be used to calculate possible cost of reducing a firm and the industries emissions after carbon emissions reduction regulations are enforced.

From the log-linear equation (16), the estimated $\widehat{\alpha_{0_{i t}}}$ would equal to $\ln P_{i t}+\ln A_{i t}$. Others estimated coefficients, $\widehat{\alpha_{1 i}}, \widehat{\alpha_{2_{i t}}}$, and $\widehat{\alpha_{3_{i t}}}$, comparing to the production function, equation(10), are $\alpha_{L}, \alpha_{K}$, and $\alpha_{E}$ respectively.

Table 5

Korea Input Coefficients with Technical Efficiency on annual average

\begin{tabular}{llll}
\hline SIC - Industry Name & $\mathrm{L}$ & $\mathrm{K}$ & $\mathrm{E}$ \\
\hline 15 - Food and Beverages & 0.719 & 0.190 & 0.380 *** \\
17 - Textiles & $0.960^{*}$ & 0.140 & 0.109 \\
18 - Wearing apparel & 0.682 & 0.194 & 0.329 \\
19 - Leather and Footwear & 0.747 & $0.270 * *$ & 0.264 \\
20 - Wood & 0.888 & 0.064 & $0.340^{*}$ \\
21 - Paper & 0.914 & 0.142 & 0.147 \\
22 - Publishing and Printing & 0.892 & 0.115 & 0.170 \\
23 - Refined petroleum & 0.801 & 0.199 & $0.373 * *$ \\
24 - Chemicals & 0.868 & 0.180 & 0.197 \\
25 - Rubber and Plastics & 0.854 & 0.136 & 0.208 \\
26 - Other Nonmetallic mineral & 0.726 & 0.171 & 0.331 \\
27 - Basic metals & 0.743 & 0.228 & 0.182 \\
28 - Fabricated metal & $0.970 * *$ & 0.139 & 0.118 \\
29 - Machinery and Equipments & $1.012 * * *$ & 0.093 & 0.122 \\
30 - Office and Computing & 0.866 & 0.254 & 0.090 \\
31 - Electrical machinery & 0.823 & 0.185 & 0.178 \\
32 - Electronic & 0.774 & $0.269 *$ & 0.107 \\
33 - Medical and Precision & 0.954 & 0.139 & 0.103 \\
34 - Motor vehicles & 0.896 & 0.142 & 0.184 \\
35 - Other Transport & 0.843 & 0.116 & 0.246 \\
37 - Recycling & 0.694 & $0.278 * * *$ & 0.195 \\
\hline
\end{tabular}

From the estimated production function, we can also calculate the effec- 
tive labor from the equation (8) in the theory section, $L_{e}=\left(L^{\widehat{\alpha_{1}}} K^{\widehat{\alpha_{2}}}\right)^{1 /\left(1-\widehat{\alpha_{3}}\right)}$. From that, the coefficient of $\mathrm{E}, \widehat{\alpha_{3_{i}}}$, could be used to represent level of electricity intensity ${ }^{19}$, which also could be used to refer to pollution intensity. Surprisingly, the top three highest electricity usage industries - basic metals, chemical, and electronic industries, as shown in table 2 from the Data section, are ranked number 12,9 , and 19 in electricity intensity. These basic results show us the electricity intensity does not directly vary with the level of electricity consumptions.

Table 6

Thailand Input Coefficients with Technical Efficiency on annual average

\begin{tabular}{llll}
\hline SIC - Industry Name & $\mathrm{L}$ & $\mathrm{K}$ & $\mathrm{E}$ \\
\hline 15 - Food and Beverages & 0.283 & 0.368 & $0.429 * *$ \\
17 - Textiles & 0.582 & 0.232 & 0.232 \\
18 - Wearing apparel & 0.711 & 0.107 & 0.146 \\
19 - Leather and Footwear & 0.599 & 0.247 & 0.239 \\
20 - Wood & 0.711 & 0.104 & 0.044 \\
21 - Paper & 0.567 & 0.054 & 0.229 \\
22 - Publishing and Printing & 0.692 & 0.133 & 0.363 \\
23 - Refined petroleum & 0.532 & $0.399 *$ & $0.425 *$ \\
24 - Chemicals & 0.255 & 0.385 & 0.351 \\
25 - Rubber and Plastics & 0.582 & 0.228 & 0.184 \\
26 - Other Nonmetallic mineral & 0.486 & 0.231 & 0.320 \\
27 - Basic metals & 0.189 & 0.215 & $0.546 * * *$ \\
28 - Fabricated metal & 0.336 & 0.285 & 0.369 \\
29 - Machinery and Equipments & 0.746 & 0.312 & 0.191 \\
30 - Office and Computing & $0.757 *$ & 0.035 & 0.028 \\
31 - Electrical machinery & 0.592 & 0.176 & 0.290 \\
32 - Electronic & $0.970 * * *$ & 0.262 & 0.016 \\
33 - Medical and Precision & $0.782 * *$ & 0.042 & 0.394 \\
34 - Motor vehicles & 0.606 & $0.448 * *$ & 0.047 \\
35 - Other Transport & 0.618 & $0.458 * * *$ & 0.015 \\
36 - Furniture & 0.545 & 0.256 & 0.299
\end{tabular}

Table 6 shows the estimated coefficients of all inputs for each of the Thailand manufacturing industry. As we mentioned earlier in the Data section, some Thai industries have a small number of observation. Therefore, when

\footnotetext{
${ }^{19}$ Electricity intensity could be calculate from the ratio of electricity cost and cost of effective labor, $P_{E} E / W_{e} L e$, where $W_{e}$ is a the return to a unit of effective labor. From the cost minimization, this ratio is equal to $\widehat{\alpha_{3_{i t}}} /\left(1-\widehat{\alpha_{3_{i t}}}\right)$. Therefore, the $\widehat{\alpha_{3_{i t}}}$ could represent the intensity of the electricity, $\frac{\partial E_{\text {intensity }}}{\partial \widehat{\alpha_{3 i t}}}>0$
} 
we ran the regressions with Thai data and discovered there are not enough observations many times. The most problematic industry is the tobacco, which we decided to leave out from any of the estimations.

Table 7

Technical Efficiency from Cobb Douglas, SFE

\begin{tabular}{lll}
\hline SIC - Industry Name & $\begin{array}{l}\text { Korea } \\
(\%)\end{array}$ & $\begin{array}{l}\text { Thailand } \\
(\%)\end{array}$ \\
\hline 15 - Food and Beverages & $99.56^{*}$ & 64.04 \\
16 - Tobacco & 58.29 & 79.02 \\
17 - Textiles & $99.74^{* *}$ & $99.38^{*}$ \\
18 - Wearing apparel & $99.86^{* * *}$ & 69.46 \\
19 - Leather and Footwear & 75.63 & 54.80 \\
20 - Wood & 51.70 & 48.97 \\
21 - Paper & 54.95 & 51.87 \\
22 - Publishing and Printing & 58.66 & $99.39 * *$ \\
23 - Refined petroleum & 93.62 & 98.30 \\
24 - Chemicals & 60.78 & 44.49 \\
25 - Rubber and Plastics & 60.87 & 99.29 \\
26 - Other Nonmetallic mineral & 60.76 & 58.32 \\
27 - Basic metals & 95.52 & 99.40 \\
$2 * *$ \\
28 - Fabricated metal & 60.53 & 74.09 \\
29 - Machinery and Equipments & 69.61 & 53.37 \\
30 - Office and Computing & 99.21 & 76.19 \\
31 - Electrical machinery & 61.69 & 51.74 \\
32 - Electronic & 69.35 & 52.79 \\
33 - Medical and Precision & 61.56 & 99.24 \\
34 - Motor vehicles & 81.27 & 45.83 \\
35 - Other Transport & 74.30 & 57.68 \\
36 - Furniture & 61.31 & 99.15 \\
\hline
\end{tabular}

Our results for Thailands industries are similar to the results for Korean industries. The top electricity consuming industries are Chemicals and nonmetallic. Moreover they do not show a sign on being high pollution intensity industries. In the next table, we obtain the Technical Efficiency from the Stochastic Frontier Estimation from both countries. We put it together for comparison purpose. 


\subsubsection{Translog production function}

Here, we use a Translog production function with 3 inputs, L,K and E with one output - product value TR.

$$
\begin{aligned}
\ln \left(T R_{i t}\right)= & \alpha_{0}+\alpha_{L} \ln \left(L_{i t}\right)+\alpha_{K} \ln \left(K_{i t}\right)+\alpha_{L} \ln \left(E_{i t}\right) \\
& +\alpha_{L 2}\left(\ln \left(L_{i t}\right)\right)^{2}+\alpha_{K 2}\left(\ln \left(K_{i t}\right)\right)^{2}+\alpha_{E 2}\left(\ln \left(E_{i t}\right)\right)^{2} \\
& +\alpha_{L K} \ln \left(L_{i t}\right) \ln \left(K_{i t}\right)+\alpha_{L E} \ln \left(L_{i t}\right) \ln \left(E_{i t}\right)+\alpha_{K E} \ln \left(K_{i t}\right) \ln \left(E_{i t}\right) \\
& +v_{i t}-u_{i t}
\end{aligned}
$$

The Technical Efficiency terms, by industry, of both Korea and Thailand are presented in table 8 .

From the technical efficiency results from both production functions and table 6 and table 7 , we observe the top rank efficiency industries are almost the same for both countries. Some industries perform better in the Cobb Douglas production function and some did the other way around. Over all and on average, for both functional forms Korea performs slightly better than Thailand with a technical efficiency of $73 \%$ from Cobb Douglas and $78 \%$ from translog. Thailands technical efficiency is $71 \%$ from Cobb Douglas and $69 \%$ from translog on average.

\subsection{Corrected Ordinary Least Square Method}

We decided to use this way of estimation to compare the results with the SFE, because this COLS method does not require formulating a new distribution function of the inefficiency term. The COLS method has an interesting way of creating the production boundary. Once more, the basic idea of the distance function is the difference between estimated outputs and inputs. It provides another way of measuring production efficiency and it allows us to estimate multiple outputs. In our case, we only have one output. Therefore, this distance function represents the efficiency of production of firm/ factory $\mathrm{j}$ to the highest efficiency firm. Therefore, when the distance function equals zero, the firm is at full efficiency, according to Coelli and Perelman (1999) ${ }^{20}$. This approach is different from how Greene's (1990) corrected OLS. Greens correction was developed to avoid a severe multicollinearity problem. On the other hand, our "corrected" term refers to an intercept correction adding the error term in order to create a production efficiency distance between the highest output level firm and a firm in the same industry and year (Coelli and Perelman, 1999). The distance function would look like this in translog functional form:

\footnotetext{
${ }^{20}$ for more estimation details, please follow Coelli and Perelman(1999)
} 


$$
\begin{aligned}
\ln \left(D_{i t}\right)= & \alpha_{0}+\alpha_{T R} \ln \left(T R_{i t}\right)+\alpha_{L} \ln \left(L_{i t}\right)+\alpha_{K} \ln \left(K_{i t}\right)+\alpha_{E} \ln \left(E_{i t}\right) \\
& +\alpha_{L 2}\left(\ln \left(L_{i t}\right)\right)^{2}+\alpha_{K 2}\left(\ln \left(K_{i t}\right)\right)^{2}+\alpha_{E 2}\left(\ln \left(E_{i t}\right)\right)^{2} \\
& +\alpha_{L K} \ln \left(L_{i t}\right) \ln \left(K_{i t}\right)+\alpha_{L E} \ln \left(L_{i t}\right) \ln \left(E_{i t}\right) \\
& +\alpha_{K E} \ln \left(K_{i t}\right) \ln \left(E_{i t}\right)
\end{aligned}
$$

; where $\mathrm{D}$ is the distance function Therefore, the full efficiency is when the term $\ln (\mathrm{D})=0$, or $\mathrm{D}=1$, vice versa.

\section{Table 8}

Technical Efficiency from Translog, SFE

\begin{tabular}{lll}
\hline SIC - Industry Name & $\begin{array}{l}\text { Korea } \\
(\%)\end{array}$ & $\begin{array}{l}\text { Thailand } \\
(\%)\end{array}$ \\
\hline 15 - Food and Beverages & $97.71^{*}$ & 54.81 \\
16 - Tobacco & 56.41 & 78.04 \\
17 - Textiles & $99.75 * *$ & 87.98 \\
18 - Wearing apparel & $99.78^{* * *}$ & 63.36 \\
19 - Leather and Footwear & 99.44 & 55.17 \\
20 - Wood & 52.24 & 53.42 \\
21 - Paper & 62.02 & 51.66 \\
22 - Publishing and Printing & 70.74 & $99.40 * * *$ \\
23 - Refined petroleum & 92.31 & 99.04 \\
24 - Chemicals & 60.34 & 45.29 \\
25 - Rubber and Plastics & 69.23 & $99.08 *$ \\
26 - Other Nonmetallic mineral & 68.99 & 56.72 \\
27 - Basic metals & 93.91 & $99.29 * * *$ \\
28 - Fabricated metal & 80.76 & 61.05 \\
29 - Machinery and Equipments & 69.89 & 57.08 \\
30 - Office and Computing & 85.51 & 76.23 \\
31 - Electrical machinery & 62.11 & 55.85 \\
32 - Electronic & 69.38 & 54.06 \\
33 - Medical and Precision & 62.73 & 68.56 \\
34 - Motor vehicles & 81.40 & 45.53 \\
35 - Other Transport & 86.00 & 58.72 \\
36 - Furniture & 88.36 & 98.29 \\
\hline
\end{tabular}

Therefore, the distance function, D, would take the value between 0 and $1,0 \leq D \leq 1$ (Coelli and Perelman,1999). 


\subsubsection{Output Distance Function, Do}

Then, we conventionally impose the homogeneity constraint to the distance function. For now, let $\mathrm{x}$ and $\mathrm{y}$ stands for input and output, respectively. The homogeneity in output would imply that $\operatorname{Do}(\mathrm{x}, \gamma \mathrm{y})=\gamma \operatorname{Do}(\mathrm{x}, \mathrm{y})$, for any $\gamma>0$. Then, we set $\gamma=1 / T R$, since our output, y, is TR. We have

$$
\begin{aligned}
\ln \left(D o_{i t} / T R_{i t}\right)= & \alpha_{0}+\alpha_{L} \ln \left(L_{i t}\right)+\alpha_{K} \ln \left(K_{i t}\right)+\alpha_{E} \ln \left(E_{i t}\right) \\
& +\alpha_{L 2}\left(\ln \left(L_{i t}\right)\right)^{2}+\alpha_{K 2}\left(\ln \left(K_{i t}\right)\right)^{2}+\alpha_{E 2}\left(\ln \left(E_{i t}\right)\right)^{2} \\
& +\alpha_{L K} \ln \left(L_{i t}\right) \ln \left(K_{i t}\right)+\alpha_{L E} \ln \left(L_{i t}\right) \ln \left(E_{i t}\right) \\
& +\alpha_{K E} \ln \left(K_{i t}\right) \ln \left(E_{i t}\right)
\end{aligned}
$$

Then, we move the Do term to the right hand side. We have

$$
\begin{aligned}
-\ln \left(T R_{i t}\right)= & \alpha_{0}+\alpha_{L} \ln \left(L_{i t}\right)+\alpha_{K} \ln \left(K_{i t}\right)+\alpha_{L} \ln \left(E_{i t}\right) \\
& +\alpha_{L 2}\left(\ln \left(L_{i t}\right)\right)^{2}+\alpha_{K 2}\left(\ln \left(K_{i t}\right)\right)^{2}+\alpha_{E 2}\left(\ln \left(E_{i t}\right)\right)^{2} \\
& +\alpha_{L K} \ln \left(L_{i t}\right) \ln \left(K_{i t}\right)+\alpha_{L E} \ln \left(L_{i t}\right) \ln \left(E_{i t}\right)+\alpha_{K E} \ln \left(K_{i t}\right) \ln \left(E_{i t}\right) \\
& -\ln \left(D o_{i t}\right)
\end{aligned}
$$

This is basically the negative form of the usual translog. We would follow the method of estimation of Lovell et al. (1994). First, we run the regression normally. Then, we obtained the OLS residual and interpret it as the natural $\log$ form of the output distance function. Next, we take the minimum value(the largest negative) of the OLS error terms and add it to the intercept, $\alpha_{0}$, so that the highest production firm would have $\mathrm{D}=0$. Note that on the left hand side is the negative value of $\ln (\mathrm{TR})$, that is why we have to add the largest negative number to it to get the highest value possible of the output in each particular industry. After that, we recalculate the error terms for the model. Then, the output distance function of an industry i would be the exponential of its corrected OLS residual.

\subsubsection{Input Distance Function, Di}

Similarly, the homogeneity in input would imply that $\operatorname{Do}(\gamma \mathrm{x}, \mathrm{y})=\gamma \operatorname{Do}(\mathrm{x}, \mathrm{y})$, for any $\gamma>0$. Then, we set $\gamma=1 / E$. We have

$$
\begin{aligned}
\ln \left(D i_{i t} / E_{i t}\right)= & \alpha_{0}++\alpha_{T R} \ln \left(T R_{i t}\right)+\alpha_{L} \ln \left(L_{i t} / E_{i t}\right)+\alpha_{K} \ln \left(K_{i t} / E_{i t}\right) \\
& +\alpha_{L 2}\left(\ln \left(L_{i t} / E_{i t}\right)\right)^{2}+\alpha_{K 2}\left(\ln \left(K_{i t} / E_{i t}\right)\right)^{2} \\
& +\alpha_{L K} \ln \left(L_{i t} / E_{i t}\right) \ln \left(K_{i t} / E_{i t}\right)
\end{aligned}
$$


Then, we move the Do term to the right hand side. We have

$$
\begin{aligned}
-\ln \left(E_{i t}\right)= & \alpha_{0}++\alpha_{T R} \ln \left(T R_{i t}\right)+\alpha_{L} \ln \left(L_{i t} / E_{i t}\right)+\alpha_{K} \ln \left(K_{i t} / E_{i t}\right) \\
& +\alpha_{L 2}\left(\ln \left(L_{i t} / E_{i t}\right)\right)^{2}+\alpha_{K 2}\left(\ln \left(K_{i t} / E_{i t}\right)\right)^{2} \\
& +\alpha_{L K} \ln \left(L_{i t} / E_{i t}\right) \ln \left(K_{i t} / E_{i t}\right)-\ln \left(D i_{i t}\right)
\end{aligned}
$$

Table 9 show the results from the input, output distance function for both Thailand and Korea.

Table 9

Thailand and Korea Distance Function in(\%)

\begin{tabular}{lllll}
\hline & \multicolumn{2}{c}{ Thailand } & \multicolumn{2}{c}{ Korea } \\
\cline { 2 - 5 } & Di & Do & Di & Do \\
\hline 15 - Food and Beverages & 13.89 & 11.31 & 13.24 & 3.37 \\
17 - Textiles & 28.75 & 23.90 & 9.69 & 2.35 \\
18 - Wearing apparel & 28.42 & 36.56 & 12.78 & 2.35 \\
19 - Leather and Footwear & 36.12 & 37.79 & 17.97 & 6.02 \\
20 - Wood & 29.29 & 36.21 & 23.00 & 12.00 \\
21 - Paper & 36.77 & 41.63 & 21.00 & 8.48 \\
22 - Publishing and Printing & 45.91 & 33.81 & 16.94 & 5.88 \\
23 - Refined petroleum & 94.00 & 90.00 & 26.81 & 20.96 \\
24 - Chemicals & 25.13 & 16.93 & 13.98 & 7.41 \\
25 - Rubber and Plastics & 21.01 & 13.67 & 17.29 & 7.54 \\
26 - Other Nonmetallic mineral & 23.63 & 15.25 & 16.93 & 6.21 \\
27 - Basic metals & 52.32 & 58.14 & 9.73 & 5.92 \\
28 - Fabricated metal & 32.35 & 22.76 & 15.34 & 4.76 \\
29 - Machinery and Equipments & 26.23 & 16.77 & 13.27 & 5.22 \\
30 - Office and Computing & 32.64 & 21.97 & 15.51 & 5.74 \\
31 - Electrical machinery & 42.60 & 47.10 & 17.14 & 7.39 \\
32 - Electronic & 32.27 & 26.88 & 10.49 & 5.02 \\
33 - Medical and Precision & 68.90 & 84.53 & 14.32 & 10.07 \\
34 - Motor vehicles & 35.71 & 30.12 & 9.79 & 4.26 \\
35 - Other Transport & 76.43 & 77.70 & 18.45 & 11.15 \\
36 - Furniture & 19.71 & 11.50 & 15.62 & 4.53 \\
\hline
\end{tabular}

To estimate the input distance function, we use the same procedure when estimating the output distance function except instead of obtaining the minimum value of the OLS residual, we obtain the maximum value (the largest positive). Then, we add it to the intercept and recalculate the corrected OLS residual. We used the same idea as the output distance function. Here, we 
add the largest positive number, because the highest efficiency firm/factory would use the lowest level of input, in our case here is the level of electricity consumptions. In this input distance set up, the distance refers to how much more input a firm has to use to produce the same level as the highest efficiency firm in the industry. Then, the input distance function of an industry i would also be the exponential of its corrected OLS residual.

From the table 9, we observe the much lower average technical efficiency from all industries for both countries, relative to the technical efficiency from the MLE. One of the reasons could be that this distance function is estimated from COLS technique, deterministic model. This technique does not account for any noise, but also did not assume any functional form distribution. Basically, this technical efficiency here from the distance function estimation showed how firms in the industries efficiently produced their product relatively to the top best in the industry at the time. Therefore, in some industries with lots of small novice firms/ factories, the average technical efficiency would be lower than some small number of firms in an industry and not much competition. For example, the refined petroleum product industry in Thailand is mostly under government control and has a very small number of firms, on average nine firms, as shown in the table 3.

Now, the input and output distance function demonstrates a different perspective in evaluating the technical efficiency measurement. For the output function, it is almost the same idea with the technical efficiency term from the MLE method. The term represents the idea of how many units of production goods the firms should achieve given the amount of inputs they have. For the input distance function, we look at the efficiency from the input perspective. At a given level of output, or at the current amount of the production we have, how much more unit of inputs that we have used more than we were supposed to. The distance represents the technical efficiency from the input distance function angle. 


\section{Environmental Value Measurement}

After we took care of the technical efficiency part from the production function, we obtained the estimate coefficients from the previous section to calculate firm marginal revenue product taking technical efficiency into account. Then, the environmental value that is hidden on top of the electricity price can be revealed.

\subsection{Marginal Revenue Product of Electricity}

From the theoretical section, profit maximizing firms will keep increasing an input until the marginal revenue product of the input equals the input price. In our case, the choice of input for producers is electricity, E. We assume the other inputs, L and K, are relatively harder to change within a short time frame and are exceedingly costly as shown in table 4. From our Cobb-Douglas production frontier estimation results in the previous section, we can calculate $M R P_{E_{j i t}}$ for each firm. Keep in mind each firm will exhibit different levels of MRPE according to the levels of their inputs. If firm A and firm $B$, from the same industry $i$ at time t, have the exact same level of all inputs, their $M R P_{E}, M R P_{E_{A i t}}=M R P_{E_{B i t}}$ would be exactly the same, since we assume all firms from the same industry in the same year will have the same production function. In the Korean economy as mentioned in the first section, profit-maximizing firms will have increase their usage of electricity until the marginal revenue product of electricity $\left(M R P_{E}\right)$ equals the price of electricity $P_{E}$. Since we estimate the revenue function, we have:

$$
M R P_{E_{j i t}}=\frac{\partial T R_{j i t}}{\partial E_{j i t}}
$$

From the above equation (23), with the same product price for all firms within the same year and industry, since our regression also ran separately that way, $\left(\partial T R_{j i t} / \partial E_{j i t}\right)$. Therefore, from our regression equation (16), our estimated $M R P_{E_{j i t}}$ will be:

$$
M \widehat{R P}_{E_{j i t}}=\widehat{\alpha_{3_{i t}}} \cdot\left(\frac{\widehat{T R}_{j i t}}{E_{j i t}}\right)
$$

At a given level of other inputs of firm $\mathrm{j}$ from industry $\mathrm{i}$ at time $\mathrm{t}$, we can rewrite the estimated $M R P_{E_{j i t}}$

$$
M \widehat{R P_{E_{j i t}}}=\widehat{\alpha_{3_{i t}}} \cdot e^{\widehat{\alpha_{0_{i t}}}} \cdot L_{j i t}^{\widehat{\alpha_{1 i t}}} \cdot K_{j i t}^{\widehat{\alpha_{2 i t}}} \cdot E_{j i t}^{-\left(\widehat{1-\alpha_{3 i t}}\right)}
$$


We can easily see the relationship of $M R P_{E_{j i t}}$ and $E_{j i t}$ is negative since $\widehat{\alpha_{3_{i t}}}<1$, shown graphically in the figure 3 below. Now, we will use this value of each firm to compare with the electricity price, $P_{E}$. We propose if there is no gap between these two values, the particular firms are already at their profit maximizing electricity input level, $\mathrm{E}^{*}$, in the figure 7 , where $M R P_{E}^{*}=P_{E}$. Then, if there is a gap, we can separate into two cases, underutilizing and over-utilizing of the electricity input. The under-utilizing of the electricity input means a firm at a certain level of $L$ and $K$ used the electricity input for production less than at their optimal level, $E^{u}<E^{*}$. From the figure 3 , since the under-utilizing firm stopped their electricity usage at $E^{u}$, their $M R P_{E}^{u}$ is above $P_{E}$ at the point $u$. This gap represented by $\epsilon \tau^{u}$ is the per unit value we propose as the willingness to pay to not use one more unit of electricity. It also demonstrates a willingness to pay not to emit one more $\mathrm{CO}_{2}, \tau^{u}$. For the over-utilizing case, at the point o, a firm used more electricity than the profit-maximizing amount, and the gap between its $M R P_{E}^{o}$ and $P_{E}$ is $\epsilon \tau^{o}$. From our definition, $\epsilon \tau^{o}$ would be less than zero and $\epsilon \tau^{u}$ is greater than zero.

\section{Figure 7}

Marginal Revenue Product of Electricity and Electricity Price

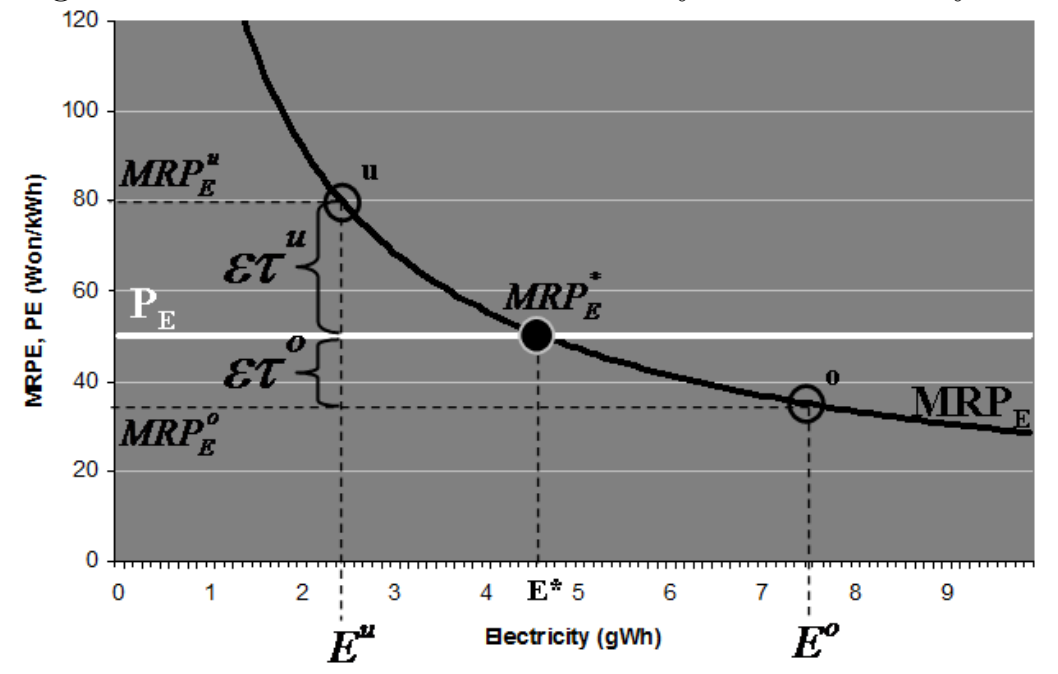

Take Notice here both $\epsilon \tau^{u}$ and $\epsilon \tau^{o}$ are in units of Won/kWh. The electricity to emission factor, $\epsilon$, is in the unit of grams of $\mathrm{CO}_{2}$-equivalent $/ \mathrm{kWh}$. Therefore, our willingness to pay to not emit one more gram of emission, $\tau$, is in Won/gram $\mathrm{CO}_{2}$-equivalent. According to our theoretical model, this value represents levels of environmental concern of each firm takes into account naturally as a part of their cost of production and their actual cost function and could follow the equation (13). Then, we can calculate value of $\epsilon \tau$ and 
$\tau$ from profit maximizing condition, $M R P_{E}$ equal to $P_{E}+\epsilon . \tau$, so that:

$$
\begin{aligned}
\widehat{\epsilon_{t} \cdot \widehat{\tau}_{j i t}} & =M \widehat{R P}_{E_{j i t}}-P_{E_{t}} \\
\widehat{\tau_{j i t}} & =\frac{1}{\epsilon_{t}}\left(M \widehat{R P}_{E_{j i t}}-P_{E_{t}}\right)
\end{aligned}
$$

We have introduced a new method to measure an environmental value from a manufacturing firm represented by the estimated values of these two variables, $\epsilon \tau$ and $\tau$. We propose people in the production sector take their utility function into account even while they are producing consumption goods. Therefore, instead of pure profit maximization, they naturally also maximize their utility and set an invisible limit on their emissions. Then, they maximize their profit under that constraint. They have put an invisible price on top of their normal electricity rate by $\epsilon \tau$ per unit of electricity which could be transformed to per unit of $\mathrm{CO}_{2}$ emission, $\tau$ as shown in the second and third column of both table 10 and 11 .

Table 10

Median of Korea Industry Environmental values on average

\begin{tabular}{llll}
\hline SIC - Industry Name & $\begin{array}{l}\epsilon . \tau \\
(\mathrm{Won} / \mathrm{Wh})\end{array}$ & $\begin{array}{l}\tau \\
\left(\mathrm{Won} / \mathrm{g}-\mathrm{CO}_{2}\right)\end{array}$ & std. err. \\
\hline 15 - Food and Beverages & 1.88 & 3.52 & 0.009 \\
17 - Textiles & 0.37 & 0.7 & 0.010 \\
18 - Wearing apparel & 2.27 & 4.29 & 0.205 \\
19 - Leather and Footwear & 2.03 & 3.87 & 0.036 \\
20 - Wood & $3.22 *$ & $6.08 * *$ & 0.018 \\
21 - Paper & 2.32 & 4.33 & 0.020 \\
22 - Publishing and Printing & 2.06 & 3.88 & 0.101 \\
23 - Refined petroleum & $5.36 * * *$ & $10.49 * * *$ & 0.615 \\
24 - Chemicals & $3.24 * *$ & $6.04 *$ & 0.031 \\
25 - Rubber and Plastics & 1.18 & 2.27 & 0.020 \\
26 - Other Nonmetallic mineral & 1.87 & 3.5 & 0.039 \\
27 - Basic metals & 0.96 & 1.82 & 0.016 \\
28 - Fabricated metal & 0.9 & 1.68 & 0.004 \\
29 - Machinery and Equipments & 1.65 & 3.1 & 0.007 \\
30 - Office and Computing & 1.64 & 3.01 & 0.210 \\
31 - Electrical machinery & 3.13 & 5.96 & 0.046 \\
32 - Electronic & 1.85 & 3.41 & 0.228 \\
33 - Medical and Precision & 1.3 & 2.41 & 0.013 \\
34 - Motor vehicles & 1.45 & 2.75 & 0.013 \\
35 - Other Transport & 3.09 & 5.65 & 0.101 \\
37 - Recycling & 1.56 & 2.9 & 0.053 \\
\hline
\end{tabular}


We first obtain the median of each industry for every year. Then, in each industry we average those medians and present our findings in tables 10 and 11 for both Korea and Thailand.

Table 10 demonstrates each industry values the environment differently. Moreover, it is quite interesting to examine the petroleum product industry. The petroleum product industry exhibits a high rate of technology substitution for electricity and is willing to pay the most on average.

Table 11

Median of Thailand Industry Environmental values on average

\begin{tabular}{llll}
\hline SIC - Industry Name & $\begin{array}{l}\epsilon . \tau \\
(\text { Baht } / \mathrm{kWh})\end{array}$ & $\begin{array}{l}\tau \\
\left(\mathrm{Baht} / \mathrm{kg}-\mathrm{CO}_{2}\right)\end{array}$ & std. err. \\
\hline 15 - Food and Beverages & 31.41 & 58.56 & 3.95 \\
16 - Tobacco & 10.65 & 20.25 & 1.90 \\
17 - Textiles & 7.87 & 14.48 & 2.02 \\
18 - Wearing apparel & 20.16 & 36.91 & 18.10 \\
19 - Leather and Footwear & 18.62 & 34.58 & 5.26 \\
20 - Wood & -1.35 & -2.5 & 34.69 \\
21 - Paper & 13.71 & 26.26 & 9.61 \\
22 - Publishing and Printing & $57.28 * *$ & $107.18 * *$ & 6.07 \\
23 - Refined petroleum & $47.06 *$ & $86.29 *$ & 31.62 \\
24 - Chemicals & 23.16 & 42.68 & 14.77 \\
25 - Rubber and Plastics & 8.9 & 16.66 & 1.25 \\
26 - Other Nonmetallic mineral & 8.23 & 15.06 & 4.20 \\
27 - Basic metals & $59.68 * * *$ & $108.31 * * *$ & 64.80 \\
28 - Fabricated metal & 37.64 & 69.52 & 5.67 \\
29 - Machinery and Equipments & 15.59 & 28.97 & 17.74 \\
30 - Office and Computing & -7.28 & -13.16 & 15.12 \\
31 - Electrical machinery & 24.22 & 45.36 & 19.77 \\
32 - Electronic & -4.61 & -8.64 & 13.90 \\
33 - Medical and Precision & 42.52 & 79.44 & 40.81 \\
34 - Motor vehicles & 0.36 & 0.67 & 14.53 \\
35 - Other Transport & -1.66 & -3.08 & 22.45 \\
36 - Furniture & 34.93 & 64.36 & 4.80 \\
\hline
\end{tabular}

On the other hand, the textile industry exhibits the lowest rate of technology substitution and is willing to pay the least. It is not a clear our environmental values are inversely related with how much firms would have to pay for the other inputs to keep their production level constant. With this environmental concern, they could have just stopped using one more unit of electricity at the actual level they used at a given level of the other inputs. From 
this assumption, firms reach their equilibrium between income they have generated and the emission level they can take.

The data in table 11 mark clear differences between industries in Thailand and Korea. For instance, some of Thailand's industries showed some negative value of the estimated $\epsilon . \tau$, which means those industries are over utilizing electricity consumption. In other words, they used too much electricity. In some cases, this could be explained by government subsidies. Government subsidies create a false sense of costs so subsidized firms who are provided an electricity price lower than the market price are likely to keep using electricity until they reach the point that their marginal product revenue of electricity is equal to electricity's actual price.

Actually, table 10 only gave us a snap shot of each industry. With our extensive data set, it allowed us to delve deeply into how an industry will value the environment differently throughout time. Using this capability which previous literature does not have access to we will discuss how our estimated value and its movement throughout time could be a good measurement for the hidden value of $\mathrm{CO}_{2}$ emission for each firm and industry.

In general, there could be a few reasons why firm's marginal revenue product of electricity might be diverged from their electricity price for other reasons than their natural desire for emission reduction. A few of these reasons are: mismanagement, production managers may mistakenly use too much or too little electricity than their profit-maximizing amount, it could be managers or firms agree to maximize something other than profit, it could be just a measurement error, or misreporting of the variables in our data set. Outside of these factors, firms might also be monopsony in their input markets, although, this situation seems very unlikely in the case of electricity usage. The final scenario may be ruled out in South Korea where most of the power generation is controlled by the government. We would not rule the case, if we determined Chaebol firms use strong government connections and political networks behind the scenes to manipulate the market. However, in the end we do not consider such episodes in our study. However, in our study, we already took care of any inefficiency and some random errors. Furthermore, in none of these cases is there any reason to believe a firmlevel gap between $M R P_{E}$ and $P_{E}$ depends on income? Anyway, in the next section, we test our new measurement, the gap between $M R P_{E}$ and $P_{E}$, with income as stated in the well-known literature on the Environmental Kuznets Curve. 


\subsection{Environmental Kuznets Curve}

From our theoretical section, our estimated emission price, $\widehat{\tau}$, shows it depends on levels of the representative individual's income. This relationship between income and environmental value is somewhat similar to the Environmental Kuznets Curve idea. Since the presence of an environmental Kuznets curve is well-supported in the literature (Hettige et al., 2000), if our measure of environmental effort is valid we would expect that it would increase with per capita income. Unlike the rest of the EKC literature, since the EKC is an inverted $\mathrm{U}$ curve presenting relationship between environmental quality, and income per capita as Grossman and Krueger(1991) establish the reasons for the inverse $\mathrm{U}$ in typical EKC regressions, which use pollution emissions as a dependent variable. The inverse- $U$ shape in most EKC regressions comes about, because emissions and income both rise with industrial activity. Efforts to reduce emissions rise with income, since environmental quality is a normal good. The emissions curve, therefore, starts with a positive slope with respect to income when income (and consequently the demand for environmental quality) is low, but as income increases the demand for environmental quality rises and so the curve's slope changes to negative. In our case, we use the environmental effort, unlike the other approaches, which use pollution level as the dependent variable, and this environmental effort should rise monotonically with income, so we do not need a nonlinear (i.e., quadratic) specification. Plus, from what we derived before, $\tau=\beta_{t} .\left(e_{W_{t}}\right)^{\gamma-1} \cdot I_{t}$ (Copeland and Taylor, 1994). Therefore, we choose to use the linear function here.

If our $\widehat{\tau}$ is truly driven by the marginal harm caused by emission through electricity generation process, then it should be sensitive to income level. In other words, it should increase with income. If not, it may just be a random gap caused by general inefficiency or measurement error. Therefore, we test the proposition by regressing GDP per capita $\left(\right.$ gdpcap $\left._{t}\right)$, on our firm-level estimates of $\epsilon_{t} \cdot \widehat{\tau}_{j i t}$ for each industry and also pooled regression with industry fixed effects.

$$
\widehat{\epsilon_{t} \cdot \widehat{\tau}_{j i t}}=\gamma_{0}+\gamma_{1} g d p c a p_{t}+\omega_{j i t}
$$

The $\omega$ is the error term. The $\gamma_{1}$ is the coefficient that we expect to be positive and significant. In the above regression, we use the real value of GDP per capita (base year 2000), and its lag, in case of some delayed effect as shown in table 12. Therefore, the unit of the income per capita coefficient is Won/kWh per US dollar. We also ran this regression with log-log linearly just to obtain the elasticity of income for our measurement. The results from both models are similar in terms of their coefficients' sign. From our pooled 
regressions with industry fixed effects, we found that one percent increase in income per capita would lead to $0.4 \%$ increase in the willingness to pay to emit less emissions.

Note all of the estimated $\gamma_{1}$ coefficients are significant at $1 \%$. The results also show almost all of the coefficients are positive except the ones from the petroleum product and office product industries. Other than that, statistically the coefficients of the lag values and its current values are about the same. The magnitude of the coefficients from the real GDP per capita showed a greater effect on the environmental value.

Table 12

EKC: Income per Capita

\begin{tabular}{lllll}
\hline SIC - Industry Name & \multicolumn{3}{c}{ Nominal } & \multicolumn{2}{c}{ Real } \\
\cline { 2 - 5 } & $\mathrm{t}$ & $\mathrm{t}-1$ & $\mathrm{t}$ & $\mathrm{t}-1$ \\
\hline 15 - Food and Beverages & 0.166 & 0.171 & 0.251 & 0.256 \\
17 - Textiles & 0.015 & 0.015 & 0.024 & 0.024 \\
18 - Wearing apparel & 0.018 & 0.018 & 0.035 & 0.039 \\
19 - Leather and Footwear & 0.054 & 0.057 & 0.085 & 0.090 \\
20 - Wood & 0.163 & 0.170 & 0.243 & 0.251 \\
21 - Paper & 0.192 & 0.198 & 0.290 & 0.296 \\
22 - Publishing and Printing & 0.132 & 0.137 & 0.202 & 0.205 \\
23 - Refined petroleum & -0.028 & -0.024 & -0.028 & -0.029 \\
24 - Chemicals & 0.234 & 0.243 & 0.347 & 0.351 \\
25 - Rubber and Plastics & 0.029 & 0.030 & 0.045 & 0.046 \\
26 - Other Nonmetallic mineral & 0.226 & 0.237 & 0.331 & 0.341 \\
27 - Basic metals & 0.021 & 0.021 & 0.033 & 0.034 \\
28 - Fabricated metal & 0.014 & 0.014 & 0.023 & 0.023 \\
29 - Machinery and Equipments & 0.076 & 0.079 & 0.120 & 0.121 \\
30 - Office and Computing & -0.125 & -0.129 & -0.226 & -0.259 \\
31 - Electrical machinery & 0.194 & 0.202 & 0.292 & 0.298 \\
32 - Electronic & 0.035 & 0.030 & 0.055 & 0.036 \\
33 - Medical and Precision & 0.080 & 0.082 & 0.124 & 0.123 \\
34 - Motor vehicles & 0.044 & 0.044 & 0.074 & 0.073 \\
35 - Other Transport & 0.474 & 0.471 & 0.822 & 0.812 \\
37 - Recycling & 0.071 & 0.087 & 0.115 & 0.151 \\
Pooled & 0.122 & 0.157 & 0.205 & 0.233 \\
\hline
\end{tabular}

As displayed in the table 12 , each industry responded differently to the increase in the income. The most sensitive industries were the other transport, place, ship, and train, Chemical, Other non-metallic industries. On the other hand, the fabricated metal, textile, and wearing apparel industries are the least sensitive to the income. 
The last row of the table 12 shows the estimated coefficients of a pooled model with industry fixed effects and it shows the production section of the South Korea economy could be willing to pay 0.122 Won more per every one $\mathrm{kWh}$ when they are one US dollar richer. In other words, when a Korean is one more US dollar richer, on average, the manufacturing sector would increase their effective electricity price by 0.122 Won per $\mathrm{kWh}$ and include it in their profit maximizing process to choose their optimal electricity input.

After we found out that the income effect on our estimated environmental values are positive and significant we continue onto another test, since there was an unexpected event in the late 1997, the Asian Financial Crisis. During this crisis Korean real GDP per capita dropped by more than 7.5 percent. This sudden decrease in income could have affected some industries more or less. We take this crisis as our external shock. As stated in Kim (2010), Jones and Dunlap (1992), and Buttel (1975), during an economic crisis the people's support for environmentalism is the first scapegoat. People tend to first withdraw their environmental support to take care of the economic situation. In this part, we test our findings with their statement.

To see how the industries would respond to the shock, from the regression equation (28), we run two separate regression models, before and after the crisis, by industry. Note that we defined the after crisis period from 1998 to 2008. We also did the Chow test ${ }^{21}$ and found out that before and after models are significantly different at $1 \%$ level for all of the industries, but the Basic metal product industry. Meaning most industries were affected by the crisis. Therefore, in table 12, we can ignore the results from the industry.

Table 13 shows the regression results from a before and after income effect model. The results are very interesting. The magnitudes of the income effect to the willingness to pay for emission reduction from 16 out of 21 industries decline and eleven of them decline enough to even change the direction of the income effect to negative. The income effect for the rest of the industries increase and, surprisingly, the income effect of the Petroleum industry increases enough to change its sign to positive. Each affected industry was affected by the serious financial crisis differently.

If we just compared total revenue for the whole industry between the year 1997 and 1998, on average, each industry loses almost 10\%. Only a few industries still enjoyed their growth, but most of those industries experienced slower growth and delayed effects, such as the chemical and the other trans-

\footnotetext{
${ }^{21}$ an econometric test of whether the coefficients in two groups of linear regressions are equal. The test statistic, $\frac{\left(S S R_{r}-S S R_{u}\right) / k}{S S R_{u} /(N-2 k)}$, follows the $\mathrm{F}$ distribution with $\mathrm{k}$ and $\mathrm{N} 2 \mathrm{k}$ degrees of freedom, where $S S R_{r}$ the sum of squared residuals of the restricted model, $S S R_{u}$ the sum of squared residuals from the unrestricted models, $\mathrm{k}$ is the number or estimated parameters, in our case is 2 , and $\mathrm{N}$ is the number of total observations.
} 
port industries. Only the petroleum industry seemed to grow handsomely during the crisis, but the very next year the industry faced a much slower, but still positive growth. This could explain why income did not have a positive effect for the Petroleum industry. On the other hand, the wearing apparel product industry lost the most, 34\%. To make up for the huge loss, after the crisis, the industry tends to move their electricity usage toward its optimum level, less under-utilized, even with the income per capita rising. These reasons could be applied to explain the other industries' behavior as well.

Table 13

EKC: Before and After the 1997 Financial Crisis

\begin{tabular}{lllll}
\hline SIC - Industry Name & \multicolumn{3}{c}{ Nominal } & \multicolumn{2}{c}{ Real } \\
\cline { 2 - 5 } & Before & After & Before & After \\
\hline 15 - Food and Beverages & 0.199 & 0.047 & 0.257 & 0.070 \\
17 - Textiles & 0.044 & -0.075 & 0.055 & -0.112 \\
18 - Wearing apparel & 0.147 & -0.257 & 0.193 & -0.392 \\
19 - Leather and Footwear & 0.091 & -0.059 & 0.125 & -0.107 \\
20 - Wood & 0.173 & 0.043 & 0.228 & 0.032 \\
21 - Paper & 0.197 & 0.014 & 0.256 & 0.026 \\
22 - Publishing and Printing & 0.075 & -0.004 & 0.113 & -0.004 \\
23 - Refined petroleum & -0.162 & 0.299 & -0.102 & 0.398 \\
24 - Chemicals & 0.135 & 0.184 & 0.167 & 0.296 \\
25 - Rubber and Plastics & 0.008 & 0.003 & 0.021 & -0.002 \\
26 - Other Nonmetallic mineral & 0.158 & 0.442 & 0.202 & 0.625 \\
27 - Basic metals & 0.015 & 0.028 & 0.028 & 0.036 \\
28 - Fabricated metal & 0.038 & -0.067 & 0.053 & -0.108 \\
29 - Machinery and Equipments & 0.066 & 0.027 & 0.095 & 0.040 \\
30 - Office and Computing & 0.166 & -0.559 & 0.277 & -0.815 \\
31 - Electrical machinery & 0.162 & 0.129 & 0.211 & 0.182 \\
32 - Electronic & -0.030 & -0.101 & -0.052 & -0.139 \\
33 - Medical and Precision & 0.068 & -0.184 & 0.092 & -0.253 \\
34 - Motor vehicles & 0.118 & -0.007 & 0.162 & -0.017 \\
35 - Other Transport & 0.292 & 0.716 & 0.486 & 1.072 \\
37 - Recycling & 0.321 & 0.070 & 0.533 & 0.088 \\
\hline
\end{tabular}

These results reasonably demonstrate why firms and/or people in the manufacturing sector have shifted the weight of the environmental concern in their utility function to be more concerned about income. The manufacturing sector needed to make up for the loss they experienced during the financial crisis. 
The test results from this test also confirmed with the earlier statement from Kim (2010), Jones and Dunlap (1992), and Buttel (1975) that people would first reduce the environmental support to cover their economic loss. Most industries became less under-utilized in electricity input consumptions due to the economic crisis.

There is no doubt one day South Korean in the manufacturing sector will shift their interest back to where they were. Then, their income will once again have a positive effect on their emission value.

The results from table 13 show some inverse relationships between income and our environmental values which is suspicious to us. One could think that 1997 and 1998 are the years of the crisis. One would also expect the crisis effect to be greatest in these years, so we offer an additional test concentrating on those years. A regression with tau on the left hand side, with dummies for crisis years and the income variable:

$$
\widehat{\epsilon_{t} \cdot \widehat{\tau}_{j i t}}=\gamma_{0}^{c}+\gamma_{1}^{c} \text { gdpcap } t+\gamma_{2}^{c} D_{\text {post }}+\gamma_{3}^{c} D_{\text {post }} g d p c a p_{t}+\gamma_{4}^{c} D_{97-98}+\omega_{j i t}
$$

; where $D_{\text {post }}$ is a dummy variable taking the value of one, if the year is greater than 1998, zero otherwise. $D_{97-98}$ is a dummy variable for the crisis years of 1997 and 1998. Its value will be zero, if the year is not equal to 1997 or 1998.

Our hypothesis for this test is when the crisis hit most firms were in shock and their production/revenue decreased almost immediately. Some industries involved in high capital investment, such as: the electronics, chemicals, and basic Metal industries should be the hardest hit. These industries are burdened by interest and debt payments, they cannot reduce the amount of their capital quickly and labor contracts may have been ridged. It is completely rational to believe the easiest way to cut short-run costs would be to cut electricity consumption. From our revenue function, since capital cannot change quickly in the short-run, even the number of employee might not be able to change very quickly in the short-run at least not as rapidly as the amount of electricity consumption. We, therefore expect to see a positive number of the $\gamma_{4}^{c}$.

Table 14 presents the coefficient, $\gamma_{4}^{c}$, of the crisis year dummy variable. As we expected, we can see all of the coefficients are positive which means during the crisis years, 1997-1998, industries under-utilized electricity inputs, because of their economic condition reason. The sharp increase in the value of Tau during these years does not mean people care more about the environmental during the crisis, but because electricity input is the easiest to variable to cut in the very short-run to reduce their cost of production during a low demand period. 
Table 14

Coefficient for Financial Crisis Period Dummy

\begin{tabular}{ll}
\hline SIC - Industry Name & $\gamma_{4}^{c}$ \\
\hline 15 - Food and Beverages & $1,523.46$ \\
17 - Textiles & 804.30 \\
18 - Wearing apparel & 885.13 \\
19 - Leather and Footwear & 634.03 \\
20 - Wood & $1,353.20$ \\
21 - Paper & $3,320.55 * *$ \\
22 - Publishing and Printing & $2,087.90$ \\
23 - Refined petroleum & $1,738.84$ \\
24 - Chemicals & $1,395.55$ \\
25 - Rubber and Plastics & 655.04 \\
26 - Other Nonmetallic mineral & 816.88 \\
27 - Basic metals & $2,161.68^{*}$ \\
28 - Fabricated metal & 66.23 \\
29 - Machinery and Equipments & 720.91 \\
30 - Office and Computing & 289.38 \\
31 - Electrical machinery & $1,030.92$ \\
32 - Electronic & $3,083.83 * *$ \\
33 - Medical and Precision & 819.33 \\
34 - Motor vehicles & 973.98 \\
35 - Other Transport & $1,828.63$ \\
37 - Recycling & 873.47
\end{tabular}

The results from table 14 also help explaining some negative coefficients in the table 13. During the crisis years, all of the industries cut or use a lot less electricity for their production to minimize their cost. Some more than the others. Consequently, we observed some huge increases in the value of Tau in some industries. which, in our regression model for table 13 were where high value Tau happened to be in the year people who received lower income right after the crisis in 1998. For those industries which experienced huge increase in Tau, their income coefficient was negative.

\subsection{World Emissions}

From the previous section, we showed that our new measurement of environmental values depending on income, aligned with our theoretical set up and previous literature on income and the environment. In this section, Tomita and Akutagawa (2009) used a method of factor analysis to obtain a measure of environmental value consciousness, and they found the living area in 
fact strongly influence environmental value. In our theoretical section, we also took the local environment into consideration, as shown as in equation (1). Emissions from other areas/countries would have some effect on our representative individual. Additionally, Kim (2010), whose research on environmental attitudes of three East Asia countries including Korea, Japan, and China, state these countries' different historical trajectories after the World War II raise some doubts on environmental protection cooperation. Therefore, research could be insightful on how Korean reacts to its neighbors emissions in our study. Simultaneously we can test our measurement again with emissions from other countries embedded in the representative individual's utility function equation (1).

In our data set, we obtained data of world total emissions, $e_{W}$ from the World bank. So we set up another regression model to estimate the effect of these emission variables on our $\widehat{\epsilon_{t} \cdot \tau}$. Since we already showed that real income per capita is significant. Our next regression model would be:

$$
\widehat{\epsilon_{t} \cdot \tau_{j i t}}=\gamma_{0}+\gamma_{1} \operatorname{rgdpcap}{ }_{t}+\gamma_{3} e_{W_{t}}+\omega_{j i t}
$$

Then, we also obtained country emission levels of South Korea neighboring countries, China, and Japan from the World Bank as well, to see whether there is a significant country-specific effect or not. The following table 15A shows a summarized statistic of each country's emissions and the world emissions as well. In the second column, the mean is calculated from annual emissions on average from the year 1982 to 2005. China in the past three decades has been emitting $\mathrm{CO}_{2}$ by a sharply increasing rate. Still, since the population in China is over billions of people its emissions per capita is still much lower than both South Korea and Japan. South Korea seems to emit the least, but, in fact, their emission level has been rising at an increasing rate as well and their emission per capita reached the same level as Japan's since the year 1997. Then, they took the direct hit from the financial crisis causing their level of emissions per capita went down. However, it went back up to the Japanese level again in 2003. On the other hand, Japan's total emission had been increasing at a decreasing rate and also stable after 1998. Their emissions per capita are also the same way.

Table 15A

Country Emission Summarized Statistics in Million Ton of $\mathrm{CO}_{2}$

\begin{tabular}{lllll}
\hline Total Emissions & Mean & Std. Dev. & Min & Max \\
\hline South Korea & 353.08 & 111.29 & 134.30 & 490.18 \\
China & $3,273.27$ & $1,014.69$ & $1,450.31$ & $5,609.48$ \\
Japan & $1,177.17$ & 101.56 & 934.56 & $1,267.91$ \\
World & $23,861.01$ & $2,589.42$ & $18,682.74$ & $29,205.74$ \\
\hline
\end{tabular}


For this part, we start by putting both of the neighboring countries' emissions and South Korea itself into the model including the rest of the world emissions, $e_{W}^{-k}$, where -k stands for not including country $\mathrm{k}$ and, in the current model, country k represents China, Japan, and South Korea. The country-specific emission regression model would be:

$$
\widehat{\epsilon_{t} \cdot \tau_{j i t}}=\gamma_{0}+\gamma_{1} \text { rgdpcap }_{t}+\gamma_{3} e_{W_{t}}^{-k}+\gamma_{4} e_{C h n}+\gamma_{5} e_{J p n}+\gamma_{5} e_{S k r}+\omega_{j i t}
$$

Note that we also include crisis dummy variables and the industry fixed effect into this model, since we run a pooled regression here. Next, we will experiment on some combinations of these neighbor country emission variables. In the next table, we present the results from five regression models. Each column exhibits a result from a model. Each Row presents independent variables that would be used in each model. The variable, "The Rest", in the last row refers to the rest of the world emissions excluding the emission of the above mentioned countries used in a model. If there is not any country's emission in a model, such as model (2) representing the regression equation (30), the variable, "The rest", would be the world total emissions without subtracting any country's emissions. All the numbers in the table are the values of each coefficient. Three stars, two stars, and one star would represent significant level of one percent, five percent, and ten percent respectively.

Table 15B

Emissions Regression Models

\begin{tabular}{llllll}
\hline Variables & $(1)$ & $(2)$ & $(3)$ & $(4)$ & $(5)$ \\
\hline rgdpcap & $0.26^{* * *}$ & $0.07^{* * *}$ & $0.41^{* * *}$ & $0.40^{* * *}$ & $0.27^{* * *}$ \\
Emissions & & & & & \\
S. Korea & $0.43^{* *}$ & & $0.58^{* * *}$ & $0.55^{* * *}$ & $0.41^{* *}$ \\
China & $0.06^{* * *}$ & & & $0.02^{* * *}$ & \\
Japan & $-0.45^{* * *}$ & & & & $-0.48^{* * *}$ \\
The Rest & $0.07^{* * *}$ & $0.15^{* * *}$ & $0.02^{* * *}$ & $0.02^{* * *}$ & $0.06^{* * *}$ \\
\hline
\end{tabular}

From the regression results shown in table 15B, the estimated coefficients of real GDP per capita are all positive and significant at one percent level. It is quite noticeable all South Korea coefficients are positive, significant, and reach the highest magnitude of our estimated environmental values. The result indicates that people in Korea care more about how much they emit $\mathrm{CO}_{2}$ domestically than what the other countries emit. According to Kim (2010), Korea places the highest and most significant value on environmental attitude among the three countries. Their egoistic value toward environment in Kim's study is also significant, so we could use their findings to help explain 
our results. Even though $\mathrm{CO}_{2}$ is invisible and odorless, people care about domestic emission levels. Once more, emission levels from China are also significant and positive in all models, although, very small magnitude relatively, meaning that when China pollutes more, Korean willingness to pay for emission reduction would be more. On the other hand, Japanese emissions present negative effects on both models and they are significant. A possible explanation could be that Koreans look at Japan as if there are their important competitor. Therefore, when Japanese increase their emissions, Korean could be very competitive, so their willingness to pay for less emissions would decline. Another possible explanation might be that Japan is downwind of Korea, so their emissions are not directly observable by the Koreans.

Last but not least, the Rest of the world emission variable is significant in all models as we expected according to the theory. Moving forward to the coefficients of the rest of the world's emission variable, all are positive and significant. As expected the world results align with our theory rather well. Therefore, $\widehat{\tau}$ could reveal important information about how much we do care about our surrounding environment. Not only do we care in our spare time, but evidence supports we care even while we are working. We also care how this value would change according to our utility function. 


\section{Reduction Responsibility and Policy Impli- cation of Carbon Emission Regulations}

The human quest to harness the power of electricity has been long and arduous, characterized by quantum leaps in technological progress. The origins of this seminal process were rooted, at least in the West, with the invention of a practical steam engine in the 1760s. From these early beginnings the process of discovery slowly diffused and then ultimately emerged in the form of the remarkable coal-fired electric generating station, developed by Thomas Edison in $1882^{22}$." From this point forward, humankind was on an endeavor to create increasingly powerful generating stations and experimenting with a diverse array of natural resources to fuel these stations. Over time, the process of experimentation has progressively streamlined the efficiency of electrical production including the reduction, per unit of $\mathrm{kWh}$ production, of potentially hazardous pollutants. Some of the efficiency gains have been obtained by chasing a substitution effect caused by skyrocketing prices of energy and some have been due to extraordinarily painful industrial disasters ${ }^{23}$. This being said, humankind is still searching to expand the availability of inexpensive electricity around the world and minimize the impact on humanity caused by its production.

Today there are many different types of electricity generators. For instance, there are oil, coal, hydro, nuclear, geothermal, solar, wind, and natural gas generators just to name a few of the categories. However, not all of the generators are capable of meeting base load demand generation. Base load demand is is a minimum demand for electricity that occurs throughout the day ${ }^{24}$. Moreover, the technology generators employ are subject to different supply constraints associate with the diverse types fuels used to power the generators. The renewable natural resources are not currently dependable sources of base load power production are solar and wing generation. Solar and wind generation are subject to weather conditions, while nuclear and geothermal and hydro are relatively constant and put online at the immediately. Hydroelectric plants are typically used to meet high load demand

\footnotetext{
${ }^{22}$ World Coal Institute, How Coal is Used, History of Coal Use, Last visited March 20, 2007, http://www.worldcoal.org/pages/content/index.asp?PageID=107

${ }^{23}$ Note: There have been many disasters throughout history in the production of energy. The most famous are nuclear meltdowns like Chernobyl, Three Mile Island, and Fukushima, however, pulverized coal explosions rocked many cities during the early 20th Century.

${ }^{24}$ U.S Congressional Research Service, Power Plants: Characteristics and Costs (RL34746; November 13, 2008), by Stan Kaplan, pg. 3, last visited 4/26/2012 [http://www.fas.org/sgp/crs/misc/RL34746.pdf]
} 
(peak hours), because the community not only depends on a dam to meet electricity needs, but also to provide potable water and irrigation water. On the other hand oil, coal, and natural gas prices can determine the profitability and even the viability of a power plant in the short-run. If the price of the non-renewable resource hampers the profitability of a power plant, the longrun solution would be to substitute away from the non-renewable resource by acquiring new technology. An example of this very process, at least in the United States, occurred with oil-fired plants, because of the high fuel cost. (The Power-plant and Industrial Fuel Use Act 1978 also played a key role in the decline of petroleum-fired power plants). As the U.S. Congressional Research Service points out:

In 1978, oil-fired plants produced $22 \%$ of the nation's electricity. By 2007 the oil fired share was less than $2 \%$. Significant construction of new oil-fired plants is not expected.

To satisfy intermediate and peak demand hydro plants, nuclear plants and geothermal plants can provide relatively low variable cost energy to the grid. For this reason alone, these plants are highly important in satiating demand. However, to quench peak demand a number of high variable cost coal and natural gas turbine generators are called upon. The technology behind these high variable cost generators are derived from jet engine designs and are quite expensive to run.

The variability of fuel prices are significant costs in the production of electricity around the world. However, natural endowments of a nation also influence the economic viability of utilizing the natural resource and technologies developed around the resource. While international trade can mitigate some of the limitations a nation may face in exploiting certain natural resources for electricity production, endowments are of great importance. Since this article deals with Korea and Thailand it is necessary that we explore the types of natural endowments available to develop within the nation. According to the United States Energy Information Administration, Korea has 138.89 million short tons of recoverable coal and Thailand has 1365.76 million short tons of recoverable coal available to exploit ${ }^{25}$. Meanwhile, Korea has no proved reserves of natural gas and Thailand has 11.03 trillion cubic feet of proved reserves of natural gas ${ }^{26}$.

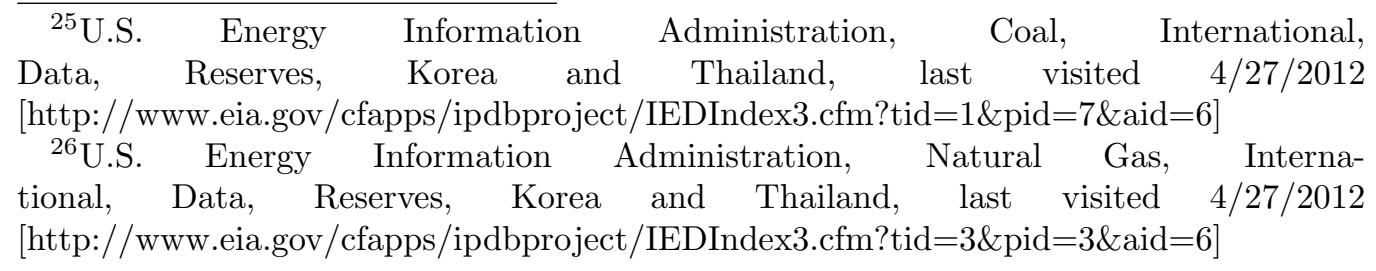


Moreover, it is important to our research to demonstrate the amount of $\mathrm{CO}_{2}$ released from different types of fuel used for electrical production. While, the data presented here is a standard calculation of different subcategories of North American fuel sources. There are differences which depend on geographic deposits and localities, however, the actual release doesn't substantially change from the table below ${ }^{27}$.

Table 16

Emission Factor by Type of Fuel

\begin{tabular}{llll}
\hline Fuel Sources & $\begin{array}{l}\text { Energy } \\
\left(\mathrm{Lbs} \text { of } \mathrm{CO}_{2} / \mathrm{Mil} . \mathrm{Btu}\right)\end{array}$ & $\begin{array}{l}\text { Heat } \\
(\mathrm{Mil} . \mathrm{Btu} / \mathrm{kWh})\end{array}$ & $\begin{array}{l}\text { Electricity } \\
\left(\mathrm{Lbs} \mathrm{CO}_{2} / \mathrm{kWh}\right)\end{array}$ \\
\hline Bituminous & 205.57 & 0.0101 & 2.02 \\
Sub-bituminous & 212.7 & 0.0101 & 2.10 \\
Lignite & 215.4 & 0.0101 & 2.12 \\
Natural Gas & 117.08 & 0.0104 & 1.12 \\
Distillate Oil (No. 2) & 161.39 & 0.0120 & 1.57 \\
Distillate Oil (No.6) & 173.91 & 0.0102 & 1.70 \\
\hline
\end{tabular}

Natural gas releases substantially less amounts of CO2 than coal or distillates (as stated above distillates have become cost prohibitive fuels in electricity production). Once more, in recent years, natural gas price has fallen worldwide, due to advances in fracking techniques. Natural gas prices marked by the spot price of Henry Hub (72 dollars per thousand cubic meters of gas) are near 20 year lows. The fall in price has offset the historical determinants which favor coal plants:

Natural gas has also been consistently more expensive than coal. The comparatively low cost of coal partly compensates for the high cost of building coal plants, while the high cost of natural gas negates part of the capital cost and efficiency advantages of combined cycle technology.

The advancement in fracking technology could not have come at a better time. As the price of natural gas has fallen in real terms and relative to the price of coal it is an opportune time to exploit its full potential in electricity production. Just as important to the economic viability of the fuel is the levelized cost of an electrical plant. The EIA stipulates the definition of the levelized costs of plants as follows: ${ }^{28}$ :

\footnotetext{
${ }^{27}$ U.S. Energy Information Administration, Frequently Asked Questions, How much carbon dioxide is produced per kilowatt hour when generating electricity with fossil fuels, last visited $4 / 27 / 2012$

${ }^{28}$ EIA, Levelized Cost of New Generation Resources in the Annual Energy Outlook 2011, last visited $4 / 27 / 2012$
} 
Levelized cost represents the present value of the total cost of building and operating a generating plant over an assumed financial life and duty cycle, converted to equal annual payments and expressed in terms of real dollars to remove the impact of inflation. Levelized cost reflects overnight capital cost, fuel cost, fixed and variable O\&M cost, financing costs, and an assumed utilization rate for each plant type.

The levelized cost of each source of energy is one major concern for a power company. Assuming once regulation on carbon emissions is imposed countries will be forced to change the ratio among energy sources to generate electricity, holding national power production constant. For example, power companies may reduce power generation from coal power plants and increase power generation from nuclear power plants. We use the information on levelized cost to approximate the total cost to reach the emission reduction target from this electricity generation sector. In our case, the government has some intervention power to control this fuel mix ratio, so, in this section, the government might be able to take full responsibility on carbon reduction, let the manufacturing industry sector take full responsibility by themselves, or anything in between.

For the manufacturing industries, we made another assumption that they have to reach their current production level. Therefore, they have to cut their electricity consumption to reduce level of emissions, and they have to increase the level of other inputs to maintain production.

Our purpose in this section is to simulate a scenario displaying the effects from an emission reduction. Governments can gain insight through this scenario to determine adequate policies of emissions reductions and who will be affected by the emissions reductions. It may turn out the electric power generation industry or manufacturing companies bear the brunt of the costs of an emissions reduction. On the other hand, the cost of an emissions reduction may be composed of mix of the two bearing the costs. Our next task is to shine light on a way to help resolve the ongoing international emission reduction responsibility negotiations on fairness between developed and less developed countries. For our purposes we concentrate on South Korea and Thailand.

\subsection{Domestic}

\subsubsection{Manufacturing Industries}

We used two extreme cases to see the boundary of the effects of the emission reduction policy when it is imposed. First, domestically, we start to see the effect on manufacturing industries, if the government pushes them to take the full responsibility of achieving the reduction without any subsidy. 
According to our data and production function, we estimated in an earlier section, our analysis begins with table 5 . The input coefficients from table 5 are used to calculate the emissions elasticity of output. For example, $\widehat{\alpha_{3_{i t}}}=\frac{\partial \ln \left(T R_{j i t}\right)}{\partial \ln \left(E_{j i t}\right)}=\frac{\partial T R_{j i t} / T R_{j i t}}{\partial E_{j i t} / E_{j i t}}=\frac{P_{i t} \partial Y_{j i t} / P_{i t} Y_{j i t}}{\partial E_{j i t} / E}=\frac{\partial Y_{j i t} / Y_{j i t}}{\partial E_{j i t} / E_{j i t}}=$ electricity input elasticity of output. $Y_{j i t}$ is an output for firm j from industry i at time t and $P_{i t}$ does not depend on E, according to our assumption that all firms are price takers. The elasticity allows us to conclude, if the government decides to impose a one percent reduction in emissions, there would be a one percent reduction of electricity usage. From our set up, e $=\epsilon$.E, so that, $(d e / e) * 100=(d E / E) * 100$, which means that a one percent decrease in emission would cause one percent decrease in electricity as well. Therefore, if we control other input levels and cut one percent of electricity, from the table 5, we can see that the policy would have an effect on the food and beverage industry the most. Their firms would lose on average 0.3 percent of output and, in our case, revenue as well. On the other hand, the office and computing, medical and precision, electronic, and textile industries would lose roughly around 0.1 percent. It is important to point out, the electronics industry is the largest industry in Korea.

Assuming no input substitution is unrealistic, so we decided to calculate the Marginal Rate of Technical Substitution, MRTS, for L, $d L / d E=$ $-\frac{\partial T R / \partial E}{\partial T R / \partial L}=-\frac{L \cdot \partial \ln T R / \partial \ln E}{E \cdot \partial \ln T R / \partial \ln L}=-\frac{L . \widehat{3_{3 i t}}}{E \cdot \widehat{\alpha_{1 i t}}}$. For $\mathrm{K}, d K / d E=-\frac{K \cdot \widehat{\alpha_{3 i t}}}{E \cdot \widehat{\alpha_{2}}}$. We then take an annual average and present MRTS by industry as shown in table 17. The numbers in the table are supposed to be negative, because there are amounts of the other inputs that have to increase/decrease in order to keep the constant level of output when electricity input was cut/increases by one gWh. However, for the sake of simplicity, table $17^{29}$ displays all numbers as positive, because we are focusing on the effect of reducing emissions and the reactive cut in electricity consumption to the other inputs. These numbers represent the amount of each input needed to maintain a constant level of output when electricity usage is cut by one gWh.

The star ranking system in table 17 designates the least affected industries. Three stars represents the least affected industry, the second star represents the second least affected industry and one star represents the third

\footnotetext{
${ }^{29}$ If we take a look at the third and the fourth columns of table 17 , it is evident the electricity input is the least expensive relative to capital and labor. In addition, the least affected industries of both columns were the textile and electronics industries. We may then ascertain that 53.43 million Won of electricity would be substitutable with 183 million Won in labor, or 1.7 billion Won in fixed asset stocks, respectively. This fact actually supports our assumption, for a firm's production input decision, that the electricity input is the easiest and low-cost alternative to control relative to the other inputs. This is true especially, in the short-run.
} 
least affected industry. Meanwhile, Table 17's second column stresses the substitution effect on the number of employees needed to compensate for a one gWh reduction of electricity. For instance, the textile and fabricated metal industry need 23 more workers to compensate for the reduction of electricity. Whereas, the wearing apparel firm owners will not be so happy to reduce their current electricity usage, because they will incur the cost of hiring 264 employees.

Table 17

Annual Average of Korean Marginal Rate of Technical Substitution

\begin{tabular}{llll}
\hline SIC - Industry Name & $-\mathrm{dL} / \mathrm{dE}$ & $-\mathrm{w} . \mathrm{dL} / \mathrm{dE}$ & $-\mathrm{dK} / \mathrm{dE}$ \\
\hline 15 - Food and Beverages & 106 & 761 & 7,883 \\
17 - Textiles & $23^{* * *}$ & $183^{* * *}$ & $1,913 *$ \\
18 - Wearing apparel & 264 & 1,940 & 3,336 \\
19 - Leather and Footwear & 142 & 1,105 & 2,165 \\
20 - Wood & 88 & 688 & 18,803 \\
21 - Paper & 30 & $287 *$ & 4,491 \\
22 - Publishing and Printing & 54 & 544 & 6,299 \\
23 - Refined petroleum & 79 & 624 & 7,736 \\
24 - Chemicals & 39 & 470 & 6,257 \\
25 - Rubber and Plastics & 43 & 417 & 3,262 \\
26 - Other Nonmetallic mineral & 74 & 687 & 7,346 \\
27 - Basic metals & 33 & 383 & 2,026 \\
28 - Fabricated metal & $23 * * *$ & $244 * *$ & 2,453 \\
29 - Machinery and Equipments & $25 *$ & 297 & 5,113 \\
30 - Office and Computing & 36 & 447 & $1,772 * *$ \\
31 - Electrical machinery & 89 & 797 & 3,474 \\
32 - Electronic & 42 & 508 & $1,756 * * *$ \\
33 - Medical and Precision & 34 & 356 & 3,177 \\
34 - Motor vehicles & 36 & 372 & 4,378 \\
35 - Other Transport & 60 & 832 & 10,280 \\
37 - Recycling & 29 & 386 & 3,344 \\
\hline
\end{tabular}

The third column in the table is derived from the second column. The third column is computed by multiplying the second column by each industries annual average wage, $\mathrm{w}$. The column demonstrates how much money, on average, these industries would need to cover the reduction in emissions costs. Furthermore, table 17's rankings from the second and the third columns are slightly different due to differences in each industry's wage. For example, the textile industry and the fabricated metal industry will add 23 additional workers. However, the textile industry will only suffer an increased labor 
cost of 183 Won. The fabricated metal industry will suffer an increase of 244 Won in labor costs. The differential is determined by higher average wages in the fabricated metal industry. It is important to point out the heaviest toll is imposed on the wearing apparel industry amounting to nearly two billion Won.

Table 17's fourth column illustrates the increased amount of money industries have to invest in fixed asset stocks to keep output constant due to the one gWh cut. The results designate the electronics industry, the office and computing industry, and the textile industry will require the least amount of additional capital investment to keep output constant. On average, these industries will need 1.76, 1.77, and 1.91 billion Won of additional capital investment. Additionally, the results project the wood and wooden product industry would be affected the most, if they decide to substitute capital for the cut in electricity. The two industries would need more than 18 billion Won to cover the cost of one gWh cut in order to keep production constant.

It is important to note, the electricity price is $53.43 \mathrm{Won} / \mathrm{kWh}$, on average and the Korean electricity emission factor is 543.54 grams of $\mathrm{CO}_{2}$ equivalent $/ \mathrm{kWh}$. Therefore, cutting one $\mathrm{gWh}$ of electricity would save 53.43 million Won and reduce $\mathrm{CO}_{2}$ emission by $0.543 \mathrm{kt}$ of $\mathrm{CO}_{2}$-equivalent. According to the Kyoto protocol, its mission states that the Annex I countries ${ }^{30}$ have to reduce their $\mathrm{CO}_{2}$ emission by $5.2 \%$ from the 1990 emission level. South Korea is not in the Annex I group, so they do not have to cut any emissions, yet.

Upon further examination of table 17, we can find out how much a $5 \%$ cut in emission from 1990 level could have affected Korean industries. Our data set, in 1990, shows total emissions from manufacturing industries were $23,040 \mathrm{kt} \mathrm{CO}_{2}$-equivalent. If the $5 \%$ reduction in emissions is based on electricity production then a $5 \%$ reduction in emissions would be similar to a $5 \%$ reduction in electricity usage. In 1990, our total amount of electricity used was $55,085 \mathrm{gWh}$ and $5 \%$ would have been $2,754.25 \mathrm{gWh}$. There were 63,870 manufacturing firms in the industrial sector. If we distributed this reduction responsibility equally among firms, regardless of firm size, each

\footnotetext{
${ }^{30}$ Annex I countries: There are 41 Annex I countries and the European Union is also a member. These countries are classified as industrialized countries and countries in transition: Australia, Austria, Belarus, Belgium, Bulgaria, Canada, Croatia, Czech Republic, Denmark, Estonia, Finland, France, Germany, Greece, Hungary, Iceland, Ireland, Italy, Japan, Latvia, Liechtenstein, Lithuania, Luxembourg, Malta, Monaco, Netherlands, New Zealand, Norway, Poland, Portugal, Romania, Russian Federation, Slovakia, Slovenia, Spain, Sweden, Switzerland, Turkey, Ukraine, United Kingdom, United States of America - As of today, the United State of America is the only country in the Annex I group that has not ratified the protocol, yet.
} 
firm will have to reduce $0.043 \mathrm{gWh}$.

Now, we are looking at the greatest and the least affected industries. To keep their level of output constant, from the table 17, obviously, firms would decide to hire more labor substituting for the electricity reduction, because it is a lot less expensive than replacing it with capital investment. The most affected industry is the wearing apparel industry which has to hire $0.043 \times 264$ $=11$ more workers costing nearly 84 million Won. If the firm is selected from the textile industry, it would only have to hire 1 worker costing the firm only 7.89 million Won. Therefore, with the decrease in electricity cost of 2.3 million Won (0.043x53.43 million), firms from the other industries still have to pay for more labor and would cost somewhere between 5.59 million Won and 81.7 million Won or roughly $\$ 5,000$ and $\$ 80,000$ in additional costs per year.

These results suggest the reduction of emissions might be too big of a burden for some small firms in some industries. Therefore, we suggest if any governments are about to impose an emission reduction policy, they cannot assign one emission reduction level for the whole nation as the above example. A policy maker should take each industry production function into their consideration before the regulation is imposed. Ideally, the equitable method for assigning emissions reductions could begin by monitoring each firms emissions through its electricity usages. Another possible solution is to subsidize some high reduction cost industries such as wearing apparel, leather and footwear, and other transportation product industries in the beginning and gradually reduce the amount of the subsidy yearly.

In the next subsection, we show how much the government has to pay, if they take the full emission reduction responsibility through regulation of the electricity power generation industry.

\subsubsection{Emissions Reduction through Electric Power Generation In- dustry}

In this part, we begin with the scenario that the government would impose the carbon emission reduction only on the electricity generation industry. The only way the electric generation industry can reduce their emissions is through shifting a portion of electricity generation from dirtier energy sources to cleaner sources. The electricity generation industry must accomplish these feats under the condition of maintaining enough power generation serve the usual demand of electricity from the manufacturing industry and general businesses.

We begin our analysis from the emission reduction target. Let $E_{t}$ be the total electricity consumption from the manufacturing indusry sector at 
time t. We can calculate the national electricity emission factor, $\epsilon_{t}$, from the equation (9). Therefore, initially, at time t, total emissions, $e_{t}$, from the manufacturing industry sector is $\epsilon_{t} E_{t}$. Then, if the government impose the $\mathrm{x}$ percent reduction target at a given the business as usual condition, holding level of $E_{t}$ constant, the national emission factor, $\epsilon_{t}$ has to reduce by $\mathrm{x}$ percent instead. The target emission factor would be $\epsilon_{t}^{*}=(1-x) \epsilon_{t}$. For emission factor, $\epsilon_{k}$, for each type of fuel source used to produce electricity, we first take that as a given scientific number and not changing over time. The other constraint condition is the maximum total generation capacity for each type of power plant. For simplicity, we assume that at the initial point all of the power plants are already at their capacity. Therefore, any additional MW of electricity needed for each type of power plant would cost $L C_{s}$, the levelized cost for energy source s- Coal, Oil, Gas, Nuclear, for power plants, and we also assume that this levelized cost remains constant over time.

However, before that, we have to understand the concept of switching fuel sources for electricity production. First, for simplicity, let assume that there are only two sources of fuel, "C" for clean and " $\mathrm{R}$ " for the rest. Then, let set the initial proportion to $\rho$ and $(1-\rho)$, respectively. Therefore, we can calculate national emission factor, $\epsilon=\rho . \epsilon_{C}+(1-\rho) \cdot \epsilon_{R}$. Then, if the government imposes an $x \%$ reduction, the new national emission factor, $\epsilon^{*}$, has to be $(1-x)$ of what it used to be. So, we can calculate a new proportion of the electricity generated from clean energy source,

$$
\rho_{t}^{*}=\frac{(1-x) \epsilon_{t}-\epsilon_{R}}{\epsilon_{C}-\epsilon_{R}}
$$

After we obtain the $\rho^{*}$, we can calculate the change in the proportion, $\rho^{*}-\rho=(-x . \epsilon) /\left(\epsilon_{C}-\epsilon_{R}\right)$. By default, $\epsilon_{C}<\epsilon_{R}$. Therefore, the proportion of electricity production from clean energy source would have to be increased as we expected. Therefore, for the change in the proportion of the rest, $\left(1-\rho^{*}\right)$ $(1-\rho)=(x . \epsilon) /\left(\epsilon_{C^{-}} \epsilon_{R}\right)$. Now, we know that we have to increase proportion of electricity generation from the cleaner source and this additional cost to the country would be $L C_{C}$. $(x . \epsilon) /\left(\epsilon_{R^{-}} \epsilon_{C}\right)$. $E P_{t}$, where $E P_{t}$ is the total electricity production at time t. If the number is positive, that means it is practical to use that energy source to reduce the emissions.

Now, we applied this approach to the Korean and Thai data. Here, we look at one source of energy for electricity production at a time. Then, we compare the additional cost of switching. We retrieved an estimated total system levelized cost data on average for each power plant, hydro, nuclear, and gas combine cycle, from the Energy Information Administration ${ }^{31}, L C_{\text {hydro }}$

\footnotetext{
${ }^{31}$ Annual Energy Outlook 2011. Dec 2010, DOE/EIA-0383(2010) operation and main-
} 
$=\$ 86.4 / \mathrm{MWh}, L C_{\text {nuclear }}=\$ 113.9 / \mathrm{MWh}, L C_{\text {gas }}=\$ 66.1 / \mathrm{MWh}$.

Table 18

Total Additional Cost by \% Carbon Emission Reduction (in Million USD)

\begin{tabular}{lllll}
\hline \% Reduction & \multicolumn{2}{c}{ Korea } & \multicolumn{3}{c}{ Thailand } \\
\cline { 2 - 5 } & Hydro & Nuclear & Hydro & Nuclear \\
\hline 1 & 38.9 & 38.9 & 12.0 & 18.2 \\
5 & 194.6 & 193.4 & 60.1 & 91.2 \\
10 & 389.2 & 388.6 & 120.1 & 182.3 \\
15 & 583.8 & 582.8 & 180.2 & 273.5 \\
20 & 778.4 & 777.1 & 240.3 & 364.7 \\
25 & 973.0 & 971.4 & 300.3 & 455.8 \\
30 & $1,167.6$ & $1,165.7$ & 360.4 & 547.0 \\
40 & $1,556.8$ & $1,554.3$ & 480.5 & 729.3 \\
50 & $1,946.0$ & $1,942.8$ & 600.7 & 911.7 \\
\hline
\end{tabular}

Table 18 presents the estimated additional cost of increasing electricity production from hydro, and nuclear power plants to keep the level of electricity consumption at their business as usual level ${ }^{32}$. The first column displays the level of emission reduction as a percentage of their current emissions. We observe, in Korea, to switch from any higher emission factor energy sources, such as coal and oil, to either hydro or nuclear would not be much different. Nuclear is slightly cheaper. Actually, we also calculated the additional cost when we switch to produce more electricity from gas turbine power plants, but the cost is much higher than hydro and nuclear, so it would not make sense for the government or KEPCO to choose gas as their optimal choice.

In Thailand, it is opposite from Korea, hydro power plants produce about 30 percent less expensively than nuclear power plants. Therefore, it would be more cost effective for the Thai government to generate their electricity from hydro power plants under this condition.

\subsubsection{Domestic Policy Implication}

To compare both extreme cases, we start with the assumption that the manufacturing industries are going to continue production at historical rates.

tenance cost of Coal power plant $=\$ 28.6 / \mathrm{MWh}$

${ }^{32}$ Another possible way out is to considering natural gas, which may be the option in some cases and cleaner energy source than coal and widely used in power generation these days in order to combat CO2 emissions, since suitable hydro sites may not be available, and nuclear plants take nearly a decade to construct, assuming that the public accepts their construction at all(Zheng and Padalos, 2010). 
With 5\% emission reduction, from table 17 , the additional cost is $\$ 194.3$ million. We have to take out the operating and maintenance cost of Coal power plants $=\$ 28.6 / \mathrm{MWh}$. Therefore, the final extra cost of switching power generation from Coal to Nuclear power plants is $\$ 144.57$ million $^{33}$.

We have 63,870 manufacturing firms in total. If we tried to spread this cost to each firm equally, each of them seems likely to pay roughly 2.27 million Won. From the subsection 5.1.1, we can see that even a firm from the lowest cost industry still has to pay 5.59 million Won. Therefore, if all of the cost is still at this level, we suggest the government should first take the reduction responsibility through the electricity power generation industry. Then, the less affected industries should bear the cost of initial enforcement. The government should, overtime, gradually distribute the costs to industries likely to be affected the most by the new enforcements.

In short, the government should be the one who take the responsibility first, especially, in the case of South Korea. Switching to generate more power from a nuclear power plant will probably be better in the future when they need more power. Actually, from figure 2, we can observe that the proportion of power generation from nuclear power plants is growing as the country becomes more and more developed. Therefore, Korea is already moving in the right direction as supported by our research results. Furthermore, when a carbon credit trading market exists, Korean electricity producers can also make some extra income by selling the left over permits. The scenario is especially likely to be played out when more industries take on the emission reduction responsibility.

A different scenario is likely to play out in Thailand, according to Wongkhomton et al., (2011), they do not have nuclear technology, yet. Even though the study proposes a possible/suitable location to build the power plant and the cabinet has approved the nuclear power plant project its proposal in 2006 . The scenario is unlikely to gain much traction, because many Thai citizens still believe that a nuclear power plant could be very harmful to society. The belief of catastrophic accident at nuclear plant is deeply embedded in the Thai citizenries psyche not to mention the externalities nuclear waste production and disposal represent. So, there is great pre-existing social resistance to the development of a nuclear power plant. Wongkhomton et al, presuppose without a large educational campaign targeting the entire population and a major change in the collective consciousness of the Thai people it is difficult

\footnotetext{
${ }^{33}$ This is the estimate cost derived from the difference in the levelized cost between coal and nuclear power plant at a given level of electricity production to serve people's demand. Therefore, this number represents the extra cost on top of the coal power plant that the industry has to bear, if they choose to build a new nuclear power plant instead of coal power plant
} 
to imagine the construction of a nuclear plant in Thailand. Furthermore, Paweewun (2011) from the Wall Street Journal also reported that after the melt down nuclear disaster in Fukushima, Japan last year, the National Energy Policy Council delayed the project for another three years. Considering these obstructions, we suggest Thailand should invest in hydroelectric power plants. Assuming the existence of suitable sites for new hydropower stations, our research indicates hydroelectric electricity generation is the feasible least cost alternative to replace coal fire power generators to reduce emissions.

\subsection{International Equity Considerations}

Since the Kyoto protocol was signed, there has been an ongoing international debate about what level of emission reduction would be fair to both developed and developing countries addressing the fairness of the carbon permit distribution. There are several ways to define fairness as Vinuales (2011) mentioned are frequently discussed in the UNFCCC. One could say

...the largest share of historical and current global emissions of greenhouse gases originated in developed countries. Therefore, per capita emissions in developing countries are still relatively low and the share of global emissions originating in developing countries will grow to meet their social and development needs.

Ringius et al(2002) added there are five fairness principles in international climate negotiations, Egalitarian: "Every individual has an equal right to pollute or to be protected from pollution", Sovereignty: "All nations have an equal right to pollute or to be protect from pollution; current levels of emission constitutes a status quo right", Horizontal: "Countries with similar economic circumstances have similar emission rights and burden sharing responsibilities", Vertical: "The greater the ability to pay, the greater economic burden", and Polluter pays: "The economic burden is proportional to emissions (eventually including historical emissions) sharing abatement cost across countries in proportion to emission levels". Here, in this part of our study, we have an objective to promote fairness of emission reduction, so we came up with a new time frame model to serve all of these fairness principles.

It is a prototype model based on time frame to determine the fairness of emission reduction between countries. We can start with the Horizontal and Vertical principles. Basically, these two principles come together, because when we refer to the Horizontal where similar levels of development in countries should have rights to reduce and/or to emit the same amount. It does imply to the Vertical idea that countries with different level of economic situation should responsible for emission reduction differently. Therefore, in 
our time frame model, countries with higher level of development should reduce the emissions earlier than the less developed ones. This would serve the Vertical principles. Then, countries with the same development level should start the emission reduction at the same time. These two principles are the foundation of our model. Then, we use the rest of the principles built up on this foundation. Our mathematical model is not based on each principle separately, but we have to use all together to construct the complete international time frame fairness model. So it seems we will need refer back to these two principles mathematically when we finish constructing the model.

Next, we applied idea of the Egalitarian and Sovereignty principles, which also come together in our case, because we use country level data, $\mathrm{CO}_{2}$ emissions and population, to derive a representative individual's annual emission level who lives in country $\mathrm{A}$ at time $\mathrm{t}, \frac{e_{t}^{A}}{p o p_{t}^{A}}$. Both principles focus on equal rights to pollute which could be applied to use as a right to ideally reduce the same level of emissions for each representative individual from different countries $^{34}$. This point alone will bump against the Horizontal and Vertical principles, if we just aim to set up the same level of emission per capita for all countries, because each country enters at different levels of economic circumstances. Therefore, we bring in the Polluter pays principle to connect all the dots together. How so? Simply, we have to clean up what we have been polluting. Our approach is different from usual fairness argument that refer to very long historical data according to Vinuales (2011). We narrow down to an individual's lifetime emissions. This point would serve well under the Polluter pays principle in a sense that people who emitted would have to cut only the amount they have emitted in their lifetime, but not what other people in the past did. To present this additional idea mathematically, we calculate the cumulative emission per capita for each representative individual from each country as presented in equation(33) below.

$$
\operatorname{ecap}_{t_{0}, T}^{A}=\sum_{t=t_{0}}^{T} \frac{e_{t}^{A}}{\operatorname{pop}_{t}^{A}}
$$

where $\operatorname{ecap}_{t_{0}, T}^{A}$ is a cumulative emission per capita of a representative individual who was born in year $t_{0}$ from country $\mathrm{A}, \mathrm{T}$ is the year that the country

\footnotetext{
${ }^{34}$ Here, we are talking about an ideal criterion where people from any countries do have right to produce and/or reduce the same amount of carbon emissions, in the unit of kt of $\mathrm{CO}_{2}$ per person. Since, people from different countries, produce emissions at different levels, to use emission per capita directly would be unfair to either side. That is why do we have to bring in other criteria to construct a model that can cover all conditions to make it the most fair possible
} 
A's government decide to cut their national emissions, $e_{t}^{A}$ and $p o p_{t}^{A}$ is the national level of emission and population of a country A at time $t$, respectively. The setup we use in our model provides flexibility in calculating the cumulative emissions of a representative individual from different generations by changing the year of birth, $t_{0}$.

Now, we work our way back to the Egalitarian and Sovereignty principles. With representative individual's cumulative emissions, we propose that it would be fair, if this individual should have an equal right to reduce emissions at the same rate as the others based on their very own historical cumulative emissions. This point would solve the problem with the Vertical principle, because a person from more developed countries are more likely to emit more in their lifetime cumulatively.

Now, mathematically, let $\mathrm{X}$ be a percentage emission reduction rate for a country. For example the Kyoto Protocol aims to set a reduction target to reduce $5.2 \%$ of their 1990 's emission level, so $\mathrm{X}$ is $5.2 \%$. Therefore, $\mathrm{X}$ becomes an emissions target of country A. Then, we define a reduction burden, RB, as an amount of emissions that country A has to reduce to reach the target emission level.

$$
R B_{t}^{A}=e_{t}^{A}-[1-X] e_{1990}^{A}
$$

The next step is to divide the reduction burden, $\mathrm{RB}$, by population of the country A at time t. Then, we have the reduction burden per capita at year $\mathrm{t}$ for the country A, RBcap $p_{t}^{A}=R B_{t} /$ pop $_{t}^{A}$, which represents the emission reduction burden of a representative individual in country $A$ at time t. Now, we can find a ratio between this reduction burden and current cumulative emissions,

$$
\% R B_{t_{0}, T}^{A}=\frac{R B \operatorname{cap} p_{t}^{A} \times 100}{\operatorname{ecap}_{t_{0}, T}^{A}}
$$

The Egalitarian and Sovereignty principles will be addressed by each individual's ratio between emission reduction burden and cumulative emissions should be equal across countries when they start to cut the emissions, $\% R B_{t_{0}, T}^{A}=\% R B_{t_{0}, T}^{B}$. From our time frame model ${ }^{35}$, we look for the right

\footnotetext{
${ }^{35}$ which later on in this section, we also introduce another way of using this model to calculate what would be the fair reduction percentage rate, if both countries have to cut the emission at the same time. Or stated another way, a reduction in emissions for a person in a poor country with few emissions carries a much larger cost in terms of lost utility than a reduction in emissions for a person in a rich country who is emitting a lot. Much like a progressive tax system, whereby a person who has emitted more must begin reductions sooner than one who emits less.
} 
timing, $\mathrm{T}$, for the less developed country to start cutting their emissions after the more developed one has already done so. At this point, we also satiate the Vertical principle and if both of these countries are at the same stage of development and/or emission behavior, the result will necessitate both countries should have the same $\mathrm{T}$, start cutting time.

To see the picture clearly, lets follow a numerical example, we start cumulating from a time assumed to be the year our representative individual was born, for example, set $\mathrm{T}=2010$. Then, set $t_{0}=1960$, for the generation of 50 year old people, or set $t_{0}=2000$, for a young teenager generation. Hence, we will have the percentage of reduction burden at time $t$ relative to the total level of emissions they have been emitting for all of their life until the year T, 2010.

It would be "fair" to a representative individual from different countries, if both of them can face the same percentage of reduction burden. Now, from an international policy planner perspective, how are we going to propose to both countries and negotiate an agreement to reduce their emission levels. In our set up model, we have two tools. First, we set up the reduction time, $\mathrm{T}$, for more developed one to reduce first at the agreement rate, $X \%$ of their 1990 emissions. Then, at the time $\mathrm{T}+\mathrm{t}^{* 36}$, no sooner or later than that to make it fair for both countries, the less developed one should start the cut the emission at the very same rate $X \%$ of their own 1990 emissions as well.

The second tool that we can use is the rate of reduction itself in case we want both of them to start at the same time. So, assuming that both countries have to start reducing emissions at the same time, $\mathrm{T}$, then, if the rate of reduction is the same, it would be unfair for the less developed one, because the less developed one would have to bear the higher reduction burden per what they have been emitting cumulatively ${ }^{37}$. Therefore, the

\footnotetext{
${ }^{36} \mathrm{t}^{*}$ here would be the most fair amount of time which depend on age generation of each country. Our model offer a very flexible model allowing us to even calculate this optimal time, $\mathrm{t}^{*}$, not only for same age generation of both countries, but also allow us to calculate this $\mathrm{t}^{*}$ for different age generations and country comparisons as well. Later, in the suggestion paragraph, we suggest that one possible international agreement solution could be using life expectancy of each country to get the starting point of each country. Then, calculate the $\mathrm{t}^{*}$ that could be the most fair for both countries. Why? Because, we can argue, for a representative individual from different countries, an individual could live longer another individual, so the country with the longer life can emit more cumulatively. It is necessary to take account of a life expectancy factor. For the future research suggestions, if one could develop the model further bringing in the effects of population growth into the model or introducing dynamics in the model would be quite interesting.

${ }^{37}$ According to our model, we judge from the percentage of a representative individual reduction burden, $\mathrm{kt} \mathrm{CO}_{2}$, per their current cumulative emissions. An individual from a more developed nation tends to have higher cumulative level of emissions, if we compare both countries with the same age generation.
} 
more developed country should take a higher percentage of reduction burden. Now, the question is "by how much more?" We can simply calculate the answer from set both countries' percentage of reduction burden, equation (35), equal to each other. We know the value of all variables except $\mathrm{X}$ of country A and B.

To make it more simple, let country A more developed than country B, then $X^{A}>X^{B}$, or we can say $X^{A}=X^{B}+x *$. Then, we plug in the value in the equation to find $\mathrm{x}^{*}$.

We can actually solve these questions in a much easier way by drawing percentage of reduction burden curve through time. To simulate the situation, first, we gather each country's reduction burden percentage of a representative individual, $\% R B_{t_{0}, T}^{A}$. Then, we use it to plot curves as shown in the sample figures, 8 and 9 . These two figures show two different generations, the working age generation is around 25 years of age and teenagers. Then, after we plot both generation curves in our sample countries, Korea and Thailand, we observe that Thailand's curve is above Korea's. The explanation for this event is Korea is more developed and they have been industrialized for quite some time before Thailand. Consequently, a person who was born and raised in Korea would have been emitting more than a person who was born and raised in Thailand. We can also observe from the curve the emissions of the younger generations are much closer. A simple explanation for this case is a developing country is growing faster than the more developed countries (World Development Indicators, 2012).

In 1990, Thailand and Korea had the level of $\mathrm{CO}_{2}$ at 1.68 and 5.69 metric tons per capita, respectively. Therefore, if these two countries are about to follow the protocol, Thailand has to set their emission target to 1.59 tons of $\mathrm{CO}_{2}$ per capita and Korea has to set their target to 5.39 tons of $\mathrm{CO}_{2}$ per capita.

As their emission per capita is rising each year, their reduction burden is getting bigger. However, in this method, we also accumulate their level of annual $\mathrm{CO}_{2}$ emission cumulatively, which is rising as well. Our method is to calculate the percentage of the reduction to the current cumulative level of emission. For example, if we set the year to start monitoring in 1960, Korea emitted 0.501 ton CO2 per capita and Thailand emitted 0.136 ton CO2 per capita.

By 1990, the accumulating amount of emissions for Korea and Thailand are 87.49 and 22.21 respectively. Therefore, if both want to reduce the CO2 on the year 1990, as a percentage of reduction to the cumulative level of emission, for Korea to reduce 0.296 ton CO2 and Thailand to reduce 0.087 ton $\mathrm{CO} 2$, which would be $0.36 \%$ and $0.432 \%$, respectively. One can come up with any starting point and definitely make it different. For example, in 
case 1, Korea and Thailand agree to start counting the cumulative emission from 1985, as shown in figure 8, and in case 2, they agree to start counting from the year 2000, as shown in figure 9 .

In both figures, the white line represents Thailand, and the black line represent Korea. The line itself represents the percentage of the $\mathrm{CO} 2$ reduction on that year to total amount of cumulative CO2 emissions from the year of agreement. In our framework, it would be fair, if both country reduce the same percentage of what they have been emitting, or, in another way of saying, we set $\% R B_{t_{0}, T}^{K}$ orea $=\% R B_{t_{0}, T}^{T}$ hailand. Then, solve for the $\mathrm{t}^{*}$ and, in this case, $\mathrm{t}^{*}$ approximately 6 years. From figures 8, if Korea choose the year 2002 to cut their emission to the target of $5.2 \%$ below its 1990 emission level, Thailand should start to do the same thing in 2008. From figure 9, if Korea starts in 2005, Thailand should be ready to do so in 2008 to be fair to Korea.

Figure 8

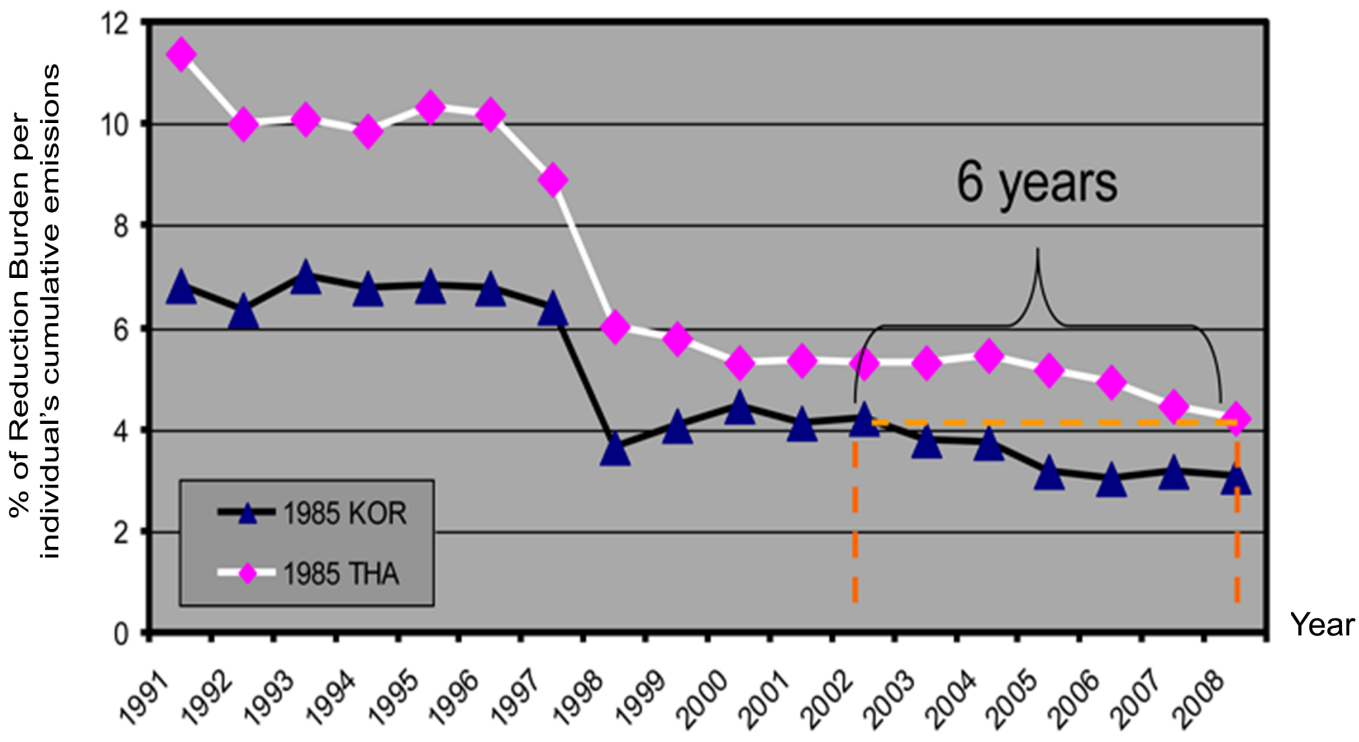

A side note here, in figure 8, we observe the sudden drop from both countries during the Asian financial crisis period, 1997-1998, due to production cut causing emission per capita to decline sharply. The graphs in the figures come from the percentage of reduction burden to the individual's cumulative emissions to that point in time. When the unexpected external shock happened to the emission per capita, it surely has some effect on both numerator and denominator of the equation(35). In the case of the numerator, the crisis lowered emission per capita to a number very close to the level of emission 
target. Therefore, the value of the numerator became much lower relative to the year before the crisis. In the case of the denominator, even though the value of emission per capita in 1998 itself is much lower than the year 1997, the denominator is still larger, because it is cumulative. Since the effect to both sides work in the same direction, the $\% R B$ dropped drastically.

After the crisis, some might question why the curve is not moving back up to the level before the crisis, the answer is also in the equation (35). Take a look at its numerator and denominator again. Even though the emissions per capita of both countries are rising each year causing a reduction burden, the numerator grows larger yearly. Since the denominator is a cumulative value of emission per capita, it always outgrows its numerator value. In another words, the numerator can decline over year if the level of emission per capita falls, but, on the other hand, the cumulative emission per capita cannot be lower regardless of any conditions.

Figure 9

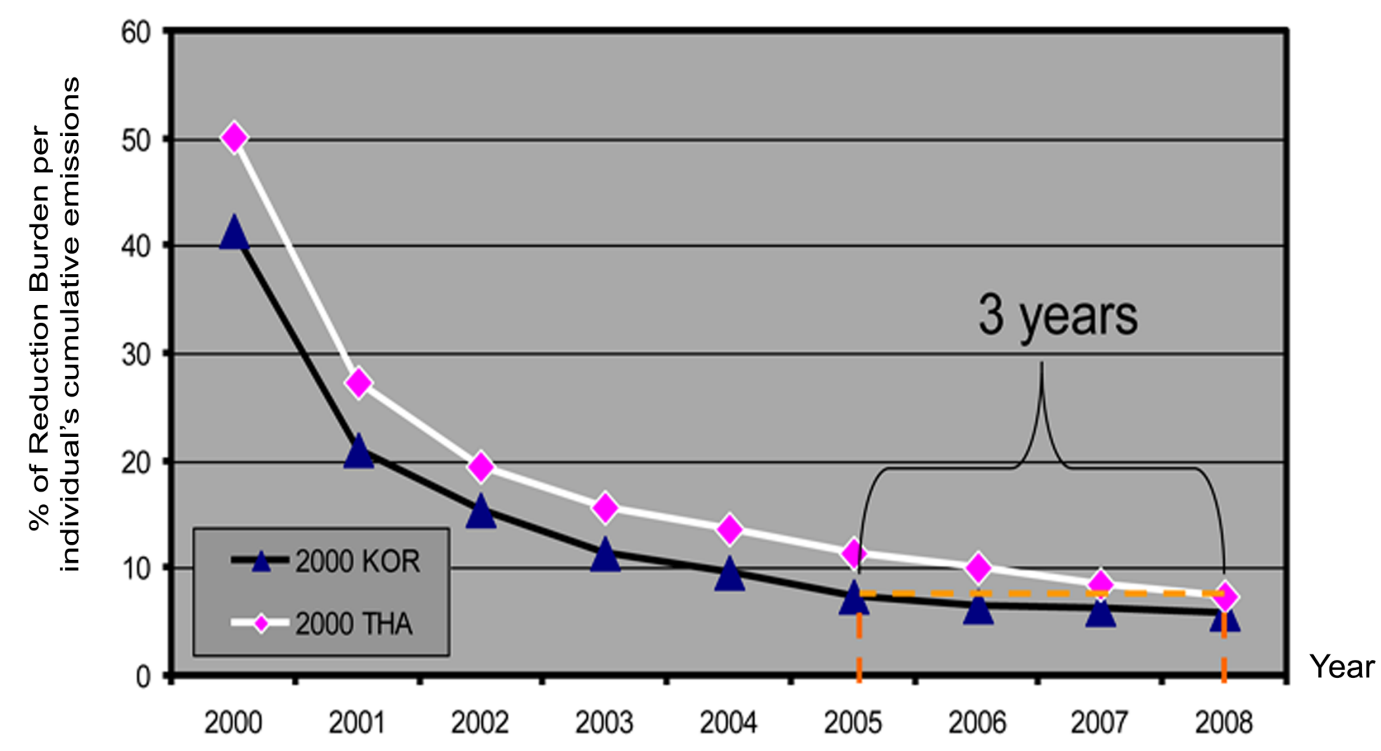

Now, we explore another application of our model, which actually allowed us to set the time of reduction of both countries simultaneously. We fixed the starting time instead of the reduction rate. If both countries agree to cut their emissions at the same time in year 2005, from the figure 8, this representative individual in Thailand faced slightly above $5 \%$ and slightly above $3 \%$ for the person in Korea. Therefore, in this comparison case, we take average of these two countries, we suggested that, for the people in this working generation, each should take $4 \%$. Then, we take this $4 \%$ to do a 
reverse calculation to find out the new national emission target, [Current $\mathrm{CO}_{2}$ emissions - (4\%(cumulative $\left.\mathrm{CO}_{2 t}\right)$ )x Population $\left._{t}\right]$. Korea would be responsible for higher reduction rate, if Thailand has to reduce their emissions at the same time, since Korea is more developed.

We designed this model to be another option to consider for an international carbon emission reduction agreement on the fairness issues. This model allowed some flexibility for government to set up some simulations. We, here, did not try to present a case that a time-based scheme is better than a differential rate-based scheme.

Table 19

Korean and Thailand Emission Elasticity of Revenue on average by Industry

\begin{tabular}{lll}
\hline SIC - Industry Name & $\begin{array}{l}\text { Korea } \\
\text { (\%change) }\end{array}$ & $\begin{array}{l}\text { Thailand } \\
\text { (\%change) }\end{array}$ \\
\hline 15 - Food and Beverages & 0.38 & 0.429 \\
17 - Textiles & 0.109 & 0.232 \\
18 - Wearing apparel & 0.329 & 0.146 \\
19 - Leather and Footwear & 0.264 & 0.239 \\
20 - Wood & 0.34 & 0.044 \\
21 - Paper & 0.147 & 0.229 \\
22 - Publishing and Printing & 0.17 & 0.363 \\
23 - Refined petroleum & 0.373 & 0.425 \\
24 - Chemicals & 0.197 & 0.351 \\
25 - Rubber and Plastics & 0.208 & 0.184 \\
26 - Other Nonmetallic mineral & 0.331 & 0.32 \\
27 - Basic metals & 0.182 & 0.546 \\
28 - Fabricated metal & 0.118 & 0.369 \\
29 - Machinery and Equipments & 0.122 & 0.191 \\
30 - Office and Computing & 0.09 & 0.028 \\
31 - Electrical machinery & 0.178 & 0.29 \\
32 - Electronic & 0.107 & 0.016 \\
33 - Medical and Precision & 0.103 & 0.394 \\
34 - Motor vehicles & 0.184 & 0.047 \\
35 - Other Transport & 0.246 & 0.015 \\
\hline
\end{tabular}

However, we can also present some advantages of our time-based scheme according to our findings earlier from the manufacturing production section. From table 19, in about every case the Korean elasticity is lower than the Thai elasticity, this suggests that poorer countries give up more output when they reduce their emissions than richer ones do, and helps justify waiting a period of time to impose restrictions on Thailand. 
For a developing country to progress to a point where the marginal disutility of emissions reductions is equal, or perhaps cite the greater flexibility of a more developed country. In this case, that a country at a later stage of development does have a qualitatively greater ability to reduce its emissions at low cost. Then, this could be a key justification of our time-based scheme. Back to our actual purpose of this model, we here present a model that could cover all the reliable international fairness criteria in order to be another new possible choice for any inter country emission reduction negotiation. We promote the idea that an individual from country A and B should have right to have equal percentage of reduction burden to their lifetime cumulative emissions, $\% R B_{t_{0}, T^{A}}^{A}=\% R B_{t_{0}, T^{B}}^{B}$. In another word, if, in reality, it is too hard to set it equal and solve for right time frame, $T^{A}-T^{B}$ and/or emission reduction rates, $X^{A}$ and $X^{B}$. We have an option to do the minimization of the gap at a given $t_{0}$ of each country and choose the best $\mathrm{T}$ and/or $\mathrm{X}$ for our model:

$$
\min _{\left\{T^{A}, T^{B}, X^{A}, X^{B}\right\}} \% R B_{t_{0}^{A}, T^{A}}^{A}-\% R B_{t_{0}^{B}, T^{B}}^{B}
$$

We can use life expectation of each country to figure out the $t_{0}$ for each country with at least one country fixed date of reduction. For example, if life expectation for Korean people on average is at 75 years and given that Korea would start to reduce their emissions in year 2012, we have $t_{0}^{K}$ orea $=$ 1937. Then, we plug in known numbers into the equation(36) and solve for unknowns.

This model is a prototype that can be modified and applied to use for a larger scale and with more than two countries with several generations at the same time which it will need to be developed in the future research. 


\section{Conclusion}

We took a new approach to estimate the social preferences related to the trade-offs between income and environmental quality. This approach was obtained by drawing on research conducted earlier by Copeland and Taylor's theoretical model of international emissions trading between developed and developing countries. Our regression result, obtained through the use of a very comprehensive firm-level South Korean and Thailand data sets, provided support for our hypothesis. We also showed different production functions and several ways to estimate technical efficiency. After, we took some technical efficiency/ inefficiency out. This hypothesis asserted that the measured gap between the marginal revenue product of electricity and its price may be related to the social preference for environmental quality. These preferences increased with income levels and total emissions levels. By the way, most of the industries appeared to show a positive relationship between per capita income and the environmental value. More to the point, we found out that an external shock would have affected the utility function of people, and the results implied that many of the industries shift to become more profit oriented. In addition, results also indicated, as a whole manufacturing segment, firms seem to react positively and quite strongly with their own emission level. It was evident they care more and are willing to pay more.

Furthermore, since this paper only touches the implications of international consequences of reductions in electricity production to reduce externalities, we propose further research to be conducted in this realm. It would be intriguing to figure out how nations might react with their neighbors in cooperation or hindering one another in their pursuits. The neighbor effect relationship could be quite interesting to investigate.

The evidence presented by these results largely support the Environmental Kuznets Curve proposition that environmental quality is a normal good. Moreover, these methods and results provide a more direct measure of the effect of income on demand for environmental quality than does the usual econometric specification found in the EKC literature. Our findings are consistent with the proposition that even if there is no government control people still value their environment inside their utility function. In some cases, the utility function is expressed naturally through industries' everyday decisions. If governments reinforced environmental values through the implementation of new laws and regulations on pollution emissions, governments could achieve emission reduction goals quickly and minimize the financial effects.

Finally, we covered the popular international argument on the fairness of 
carbon emission reduction. We presented a couple of new approaches using one model to serve all five reliable international fairness principles. If the UN was to determine time frame for emission reduction for each country, we developed the approach to show when countries should begin to cut emissions based on their representative individual's lifetime cumulative rate of emissions. But, if the UN was to force emission reduction on all countries at the same time, we have developed the other approach to find the reduction rate for each country that would be fair to other nations, which is also based on their representative individual's lifetime cumulative rate of emissions. This approach would be very helpful when we cannot apply the time approach, in the case the gap between two countries is too large to compensate with a time. This model is still a prototype which can be developed in future research to be able to apply and use with several age generations and many countries at the same time. 


\section{Bibliography}

[1] Aingner, Dennis and S.F. Chu. On Estimating the Industry Production Function. American Economic Review 58 (1968): 826-839. Print.

[2] Aingner, Dennis, C.A. Knox Lovell, and Peter Schmidt. Formulation and Estimation of Stochastic Frontier Production Function Models. Journal of Econometrics 6 (1977): 21-37. Print.

[3] Blackman, Allen. "Alternative Polltion Control Policies in Developing Countries: Informal, Informational, and Voluntary." Rev Environ Econ Policy 4.2 (2010): 234-253. Print.

[4] Bostrom, Ann, et al. "What Do People Know About Global Climate Change?" Risk Analysis 14.6 (1994). Print.

[5] Buttel, F. H. "The Environmental Movement: Consensus, Conflict, and Change." Journal of Environmental Education 7: 53-69. Print.

[6] Cho, Hong Sik. An Overview of Korean Environmental Law. Environmental Law 29, 1999.

[7] Coelli, Tim and Perelman, Sergio. "A comparison of parametric and nonparametric distance functions: With application to European railways." European Journal of Operational Research 117.2 (1999): 326-339. Print.

[8] Copeland, Brian R. and M. Scott Taylor. "North-South Trade and the Environment." The American Economic Review. Sep. 1995: 716-737.

[9] Dasgupta, S., Huq, M., Wheeler, D., Zhang, C.H. Water pollution abatement by Chinese industry: cost estimates and policy implications. World Bank, Policy Research Department Working Paper 1630 August 1996.

[10] Dornbusch, Rudiger, Fischer, Stanley and Samuelson, Paul A. Heckscher-Ohlin Trade Theory with a Continuum of Goods. The Quarterly Journal of Economics XCV 2 (1980). Print. 
[11] How much carbon dioxide is produced per kilowatt hour when generating electricity with fossil fuels Energy Information Administration. 27 Apr. 2012. ihttp://205.254.135.7/tools/faqs/faq.cfm?id $=74 \& t=11$.

[12] Greene, W. H. "A gamma-distributed stochastic frontier model." Journal of Econometrics 46 (1990): 141-163.

[13] Grossman, Gene M., and Alan B. Krueger. "Environmental Impact of a North American Free Trade Agreement". National Bureau of Economic Research Working Paper 3914, Cambridge, MA, 1991.

[14] Hettige Hemamala, Muthukumara Mani* and David Wheeler. Determinants of Pollution abatement in developing countries: Evidence from South and Southeast Asia. World Development 24, no. 12 (1996). Print.

[15] Hettige Hemamala, Muthukumara Mani* and David Wheeler. Industrial pollution in economic development: the environmental Kuznets curve revisited. Journal of Development Economics 62 (2000). Print.

[16] Hyeun, Chang, Cho, Gurcan Gulen, and Michelle Michot Foss, "Electricity and Natural Gas Sectors in Korea: Synthetically Overview and Recent Developments", KIET Industrial Economic Review 12.2 (2007).

[17] International Energy Agency, Energy Prices and Taxes. Quarterly Statistics. Fourth Quarter 2009. 19 May. 2012. ¡http://www.oecdilibrary.org/energy/energy-prices-and-taxes/volume-2009/issue4_energy_tax-v2009-4-en;.

[18] International Energy Agency. $\quad$ CO2 $\quad$ Emissions from fuel Combustion Highlights. 19 May. 2012. ¡http://www.iea.org/co2highlights/co2highlights.pdf;.

[19] Intergovernmental Panel on Climate Change. Organization. 19 May. 2012. ¡http://www.ipcc.ch/organization/organization.shtmli.

[20] Intergovernmental Panel on Climate Change. Summary for Policymakers. 19 May. 2012. ¡http://www.ipcc.ch/pdf/assessmentreport/ar4/wg3/ar4-wg3-spm.pdfi.

[21] International Strategy for Disaster Reduction. Disaster Statistics Occurrence: trends-century. 19 May. 2012. ¡http://www.geo.umass.edu/courses/geo250/isdrocc.pdf. 
[22] Korea Ministry of Environment. Environmental Laws of the Ministry of Environment 2001. UNPAN. 19 May. 2012. ¡http://unpan1.un.org/intradoc/groups/public/documents/apcity/unpan009445.pdf..

[23] Kathuria, Vinish. "Informal Regulation of Pollution in Developing Country - Empirical Evidence from Gujarat, India."

[24] Kim, Seoyong and Kim, Sungwook. " Comparative Studies of Environmental Attitude and its Determinants in Three East Asia Countries: Korea, Japan, and China." International Review of Public Administration 15.1 (2010).

[25] Lim, Young Eal, Kun Jai Lee, and Byong Whi Lee. Environmental assessment of nuclear power generation in Korea. Progress in Nuclear Energy 37, (2000): 113-118. Print.

[26] Lovell, C.A.K., S. Richardson, P. Travers and L.L. Wood. "Resources and Functioning: A New View of Inequality in Australia." Models and Measurement of Welfare and Inequality, Berlin, Springer-Verlag, W. Eichhorn (ed.), 1994.

[27] Olli E., Grandstad G., and Wollebaek D. "Correlates of Environmental Behaviors: Bringing Back Social Context." Environmental and Behavior 33(2): 181-208.

[28] Paweewun, Oranan. "Thailand To Delay Development Of Nuclear Power." The Wall Street Journal. 27 April 2011.

[29] Ray, Julie and Anita Pugliese. Fewer Americans, Europeans View Global Warming as a Threat. Gallup World. 24 April. 2012. ¡http://www.gallup.com/poll/147203/Fewer-Americans-EuropeansView-Global-Warming-Threat.aspx\#2i.

[30] Ray, Julie and Anita Pugliese. Worldwide, Blame for Climate Change Falls on Humans: Americans among least likely to attribute to human causes. Gallup World. 24 April. 2012. ¡http://www.gallup.com/poll/147242/Worldwide-Blame-ClimateChange-Falls-Humans.aspx $\# 2$ i.

[31] Ringius, Lasse and Torvanger, Asbjorn, and Underdal, Arild "Burden Sharing and Fairness Principles in International Climate Policy", International Environmental Agreements: Politics, Law and Economics 2: 122, 2002. 
[32] Robert N. Stavins, Forest L. Reinhardt, Richard H. K. Vietor. "Corporate Social Responsibility Through an Economic Lens." Review of Environmental Economics and Policy 2.2 (2008): 219-239. Print.

[33] Shin, Youngchul, Seunghun Joh, Yun-Mi Nam, ShangGyoo Shim, and Joohon Sung. Empirical study of environmental ancillary benefits due to greenhouse gas mitigation in Korea. International Journal of Sustainable Development 6, (2003): 311-327. ¡http://inderscience.metapress.com/content/8481ple9yq6awelp/fulltext.pdfi.

[34] Simar, Leopold and Wilson, Paul. "Statistical inference in nonparametric frontier models: recent developments and perspectives." In: H. Fried, C. A. K. Lovell, and S. S. Schmidt, (Eds.), The Measurement of Productive Efficiency, 2nd edition. Oxford University Press, Oxford, 2008.

[35] Tomitaa, Yasuo and Akutagawa, Yoshinori. "A Method for Measuring Environmental Value Conciosness nby Factor Analysis." International Journal of Urban Sciences, 13(2), (2009): 172-186. Print.

[36] U.S Congressional Research Service. Power Plants: Characteristics and Costs (RL34746; 13 Nov. 2008, by Stan Kaplan, pg. 3). 26 April. 2012. ¡http://www.fas.org/sgp/crs/misc/RL34746.pdfi.

[37] U.S. Department of Energy. Levelized Cost of New Generation Resources in the Annual Energy Outlook 2011. 19 May. 2012. ¡http://205.254.135.24/oiaf/aeo/pdf/2016levelized_costs_aeo2011.pdfi.

[38] U.S. Energy Information Administration. Coal, International, Data, Reserves, Korea and Thailand 27 April. 2012 ¡http://www.eia.gov/cfapps/ipdbproject/IEDIndex3.cfm?tid=1\&pid=7\&aid=6 .

[39] Vinuales, Jorge E. "Balancing Effectiveness and Fairness in the Redesign of the Climate Change Regime", Leiden Journal of International Law, 24/1, 2011,

[40] U.S. Energy Information Administration, Natural Gas, International, Data, Reserves, Korea and Thailand, last visited 4/27/2012, ¡http://www.eia.gov/cfapps/ipdbproject/IEDIndex3.cfm?tid=3\&pid=3\&aid=6 .

[41] Wheeler, D. The economics of industrial pollution control: an international perspective. World Bank Industry and Energy Department Working Paper. No. 60 (1991). 
[42] World Coal Institute. How Coal is Used, History of Coal Use. Last visited March 20, 2007. ¡http://www.worldcoal.org/pages/content/index.asp?PageID=107i.

[43] World Development Indicators, World databank. Select Database. Last modified May, 19, 2012. ¡http://databank.worldbank.org/ddp/home.do¿.

[44] Yale Center for Environmental Law \& Policy / Center for International Earth Science Information Network at Columbia University. "2005 Environmental Performance Index Report". Retrieved May 19, 2012., pp. 4-5, ¡http://sedac.ciesin.columbia.edu/es/esi/ESI2005.pdf;.

[45] Yale University. Environmental Performance Measurement Project. Last modified May 19, 2012. ¡http://www.yale.edu/esi/i.

[46] Wongkhomton, Dejsingchai, and Chantachon, Songkoon, and Wongjunta, Prayoon. "The Nuclear Power Plant: The Feasibility Studies and Effect to Socials Cultural of Power Plant Which Construction in Thailand." Research Journal of Internatonal Studes - Issue 21, October, 2011.

[47] Zheng, Qipeng P., Pardalos, Panos M. "Stochastic and Risk Management Models and Solution Algorithm for Gas Transmission Network Expansion and LNG Terminal Location Planning." Journal of Optimization Theory and Applications, Volume 147, Number 2, pp. 337-357, 2010. 